\title{
Nondestructive Evaluation of Thermal Barrier Coating Systems Using Ultrasonic Techniques
}

\author{
Binwei Zhang \\ West Virginia University
}

Follow this and additional works at: https://researchrepository.wvu.edu/etd

\section{Recommended Citation}

Zhang, Binwei, "Nondestructive Evaluation of Thermal Barrier Coating Systems Using Ultrasonic Techniques" (2010). Graduate Theses, Dissertations, and Problem Reports. 2276.

https://researchrepository.wvu.edu/etd/2276

This Thesis is protected by copyright and/or related rights. It has been brought to you by the The Research Repository @ WVU with permission from the rights-holder(s). You are free to use this Thesis in any way that is permitted by the copyright and related rights legislation that applies to your use. For other uses you must obtain permission from the rights-holder(s) directly, unless additional rights are indicated by a Creative Commons license in the record and/ or on the work itself. This Thesis has been accepted for inclusion in WVU Graduate Theses, Dissertations, and Problem Reports collection by an authorized administrator of The Research Repository @ WVU. For more information, please contact researchrepository@mail.wvu.edu. 


\title{
Nondestructive Evaluation of Thermal Barrier Coating Systems Using Ultrasonic Techniques
}

\author{
Binwei Zhang
}

Thesis submitted to the

College of Engineering and Mineral Resources

at West Virginia University in partial fulfillment of the requirements

for the degree of

\author{
Master of Science \\ in \\ Civil Engineering
}

Roger H.L. Chen, Ph.D., Chair

Department of Civil and Environmental Engineering

Hailin Li, Ph.D.

Nick Wu, Ph.D.

Department of Mechanical and Aerospace Engineering

Morgantown, West Virginia

2010

Keywords: Thermal Barrier Coating; Ultrasonic 


\section{ABSTRACT \\ Nondestructive Evaluation of Thermal Barrier Coating Systems Using Ultrasonic Techniques}

\section{Binwei Zhang}

Nondestructive evaluation (NDE) as a diagnostic tool has been extensively used to inspect the integrity of structure members. In the energy sector, the pre-mature failure of the protective Thermal Barrier Coating (TBC) covering the turbine blade can cause the structural metal base of the blade to be exposed at extremely high temperature fluids, thus reduce the service life. It is highly necessary that an NDE technique be developed for effective inspection of the thermal barrier coated turbine blade.

The ultrasonic Pulse-Echo and Pitch/Catch techniques were used to test the TBC coupons nondestructively after each thermal exposure. The Pulse-Echo traveling time and amplitude measurement, performed on isothermally oxidized René N5 coupon coated with commercially available MCrA1Y and $7 \mathrm{wt} \%$ Yittra Stabilized Zirconia (7YSZ), received an early warning of delamination at the top coat/bond coat interface. The same traveling time and amplitude evolution were also observed on another three thermal barrier coated René N5 coupons subjected to isothermal exposure under $1100^{\circ} \mathrm{C}$ using the ultrasonic Pulse-Echo technique. The interface delaminations of these coupons mentioned above were successfully predicted before visual confirmation later. In addition, the proposed technique was successfully demonstrated on an as-manufactured turbine blade coated with thermal barriers for thickness and material properties. The Young's modulus values of the 7YSZ top coat at different exposure hours were calculated using the Pulse-Echo traveling time for stressed and non-stressed coupons. Surface wave measurement setup was developed for the estimation of top coat thickness (around 300 $\mu \mathrm{m})$ and material degradation after thermal exposure. The mass density of the free standing air plasma spray (APS) and electron beam physical vapor deposition (EBPVD) YSZ top coats were measured using Archimedes' principle. Finite Element analysis (FEA) simulation of the ultrasonic wave propagation on a simplified TBC system with 
nonlinear effects was conducted. The FEA results correlate well with the experimental observation and can clearly show detection of a small embedded void simulating delamination. The FEA was also used to estimate the material properties of different components in the TBC system. Finite Element thermal analysis was also conducted on a TBC model to find out the stress distribution inside TBC after temperature changed from $1100^{\circ} \mathrm{C}$ to room temperature $\left(25^{\circ} \mathrm{C}\right)$.

Results from this study show that the ultrasonic technique developed can nondestructively detect the internal delamination and degradation of the top coat at different exposure hours. Early warning of delamination was identified before it could be visually confirmed. The ultrasonic signals were found to be very sensitive to the degradation of the 7YSZ top coat and the growth of delamination. The Young's modulus values of APS YSZ top coat TBC coupons at different exposure hours can be predicted using the measured signals. 


\title{
DEDICATED
}

\section{TO}

\author{
MY FAMILY
}




\section{Acknowledgements}

I would like to extend my gratitude to my academic advisor and chairman of my advisory committee, Dr. Roger H. L. Chen, for giving me the opportunity to conduct the research project, and for his guidance and support throughout this study. My thanks also go to Dr. Nick Wu and Dr. Hailin Li, members of my advisory committee, for their valuable suggestions and comments of this thesis.

I also wish to thank my officemates Mr. Joseph Sweet, Mr. Kyle Baranoski, for their assistance in the project. I would like to acknowledge Mr. Jared Tannenbaum for his assistance in the experiments. The research funding from NETL/USDOE under Contract DE-AC26-04NT41817.606.01.01 is acknowledged. I sincerely appreciate the project monitor, Ms. Mary Anne Alvin of NETL/USDOE for her technical comments and encouragements during this research.

Last but by no means least, my heartfelt thanks go to my parents, Ruxiang Zhang and Xiaofen Liu for their unconditioned love and consistent support. My appreciation is extended to other members of my family and my friends, who have given me support and encouragement.

This work constitute partially of the final project report submitted to NETL/DOE in September, 2009. 


\section{Table of Contents}

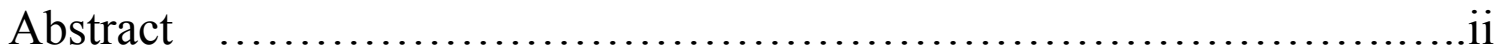

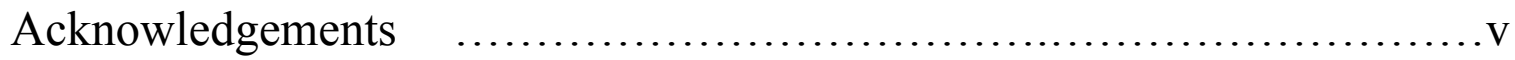

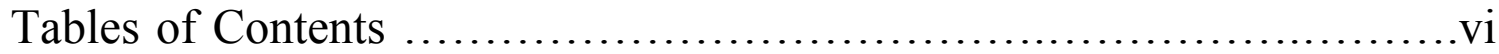

List of Tables .......................................................iii

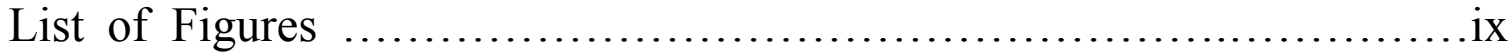

List of Pictures......................................................

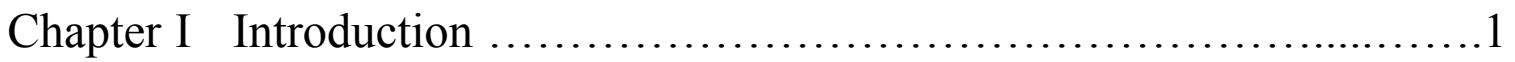

1.1 General Remarks...............................................

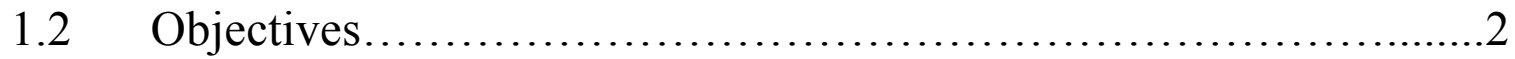

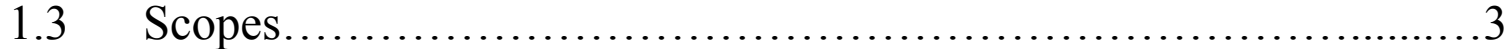

1.4 Experimental Techniques........................................

1.4 .1 Pitch/Catch ....................................................

1.4.2 Pulse-Echo..........................................................

Chapter II Literature Review $\ldots \ldots \ldots \ldots \ldots \ldots \ldots \ldots \ldots \ldots \ldots \ldots \ldots \ldots \ldots$

2.1 Gas Turbine.................................................. 9

2.2 Thermal Barrier Coatings ....................................... 10

2.3 Nondestructive Evaluation ..................................11

2.4 Finite Element Analysis ....................................12

Chapter III Ultrasonic Evaluation of Thermal Barrier Coating Coupons.....14

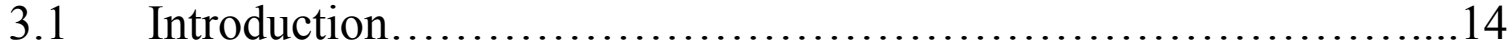

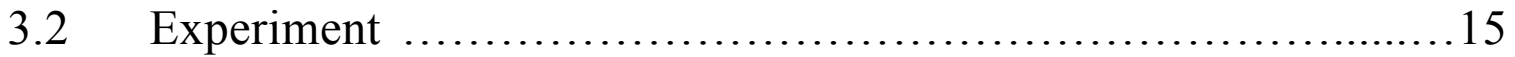

3.3 Materials and Specimens....................................... 16

3.4 Finite Element Analysis......................................... 17

3.4.1 Finite Element Analysis of Pitch/Catch .....................17

3.4.2 Finite Element Analysis of Pulse-Echo .............................19

3.4.3 Finite Element Thermal Analysis of Thermal Barrier Coating

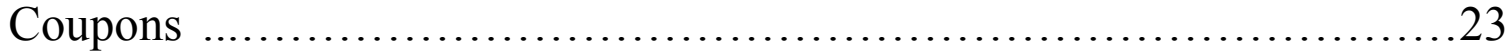

3.5 Experimental Results and Discussion .............................24

3.5.1 Pitch/Catch Experimental Results...............................24

3.5.2 Pulse-Echo Experimental Results .............................25

3.6 Failure Process Observation of Haynes 230 Coupon ................31 
3.7 Nondestructive Evaluation of Turbine Blade .......................32

3.7.1 Pulse-Echo Traveling Time Distribution ..........................32

3.7.2 Top Coat Thickness Distribution ...............................33

Chapter IV Thermal Barrier Coating Material Properties Assessment........73

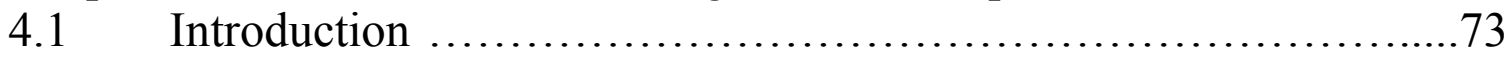

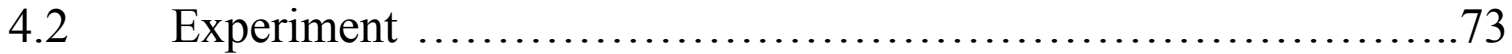

4.2.1 Top Coat Density Measurement .............................73

4.2.2 Top Coat Young's Modulus Calculation .........................75

Chapter V Conclusions and Future Work ….......................... 80

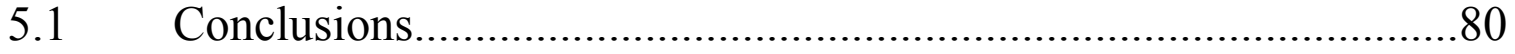

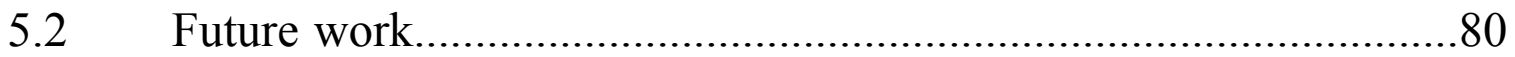

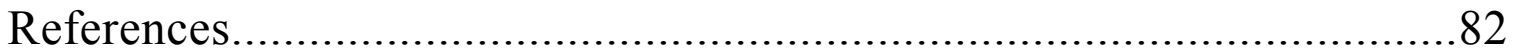

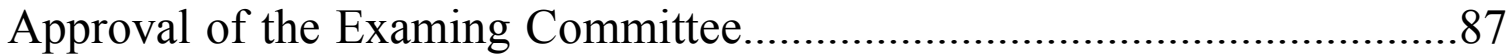




\section{List of Tables}

Table 1.1 Coupons tested by ultrasonic techniques..................................

Table 3.1 Material Properties for Finite Element analysis of Pitch/Catch............. 36

Table 3.2 Pitch/Catch waveform arrival time for isothermal coupons.................47

Table 3.3 Pitch/Catch waveform arrival time for cyclic coupons.....................47

Table 3.4 Pitch/Catch waveform arrival time for 100 -hour coupons..................48

Table 3.5 Pitch/Catch waveform arrival time for 300-hour coupons...................48

Table 3.6 Round trip traveling time for two 100 hours René N5 Coupons...............62

Table 3.7 Pulse-Echo travel time in top coat for stressed 300 hours René N5 Coupons...62

Table 3.8 Pulse-Echo travel time in top coat for unstressed 300 hours René N5 Coupons........................................................... 63

Table 3.9 Pulse-Echo travel time in top coat for 1000 hours René N5 Coupon \#28 under

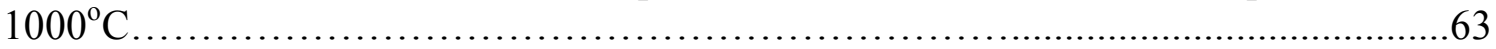

Table 3.10 Pulse-Echo travel time in top coat for 1000 hours René N5 Coupons \#29

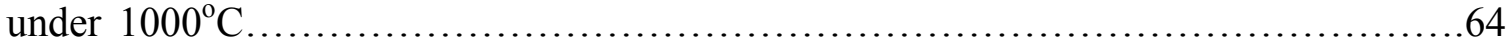

Table 3.11 Pulse-Echo travel time in top coat for 1000 hours René N5 Coupons \#13

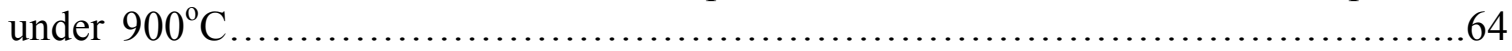

Table 3.12 Pulse-Echo travel time in top coat for 1000 hours René N5 Coupons \#20

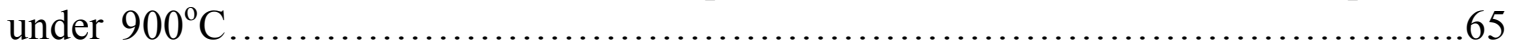

Table 3.13 Pulse-Echo travel time in top coat for 3000 hours René N5 Coupons \#18

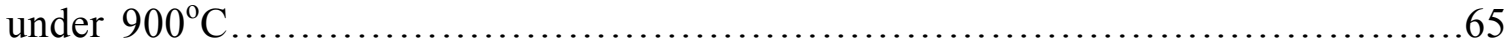

Table 3.14 Pulse-Echo traveling time in the top coat for 3000 hours René N5 Coupon \#19

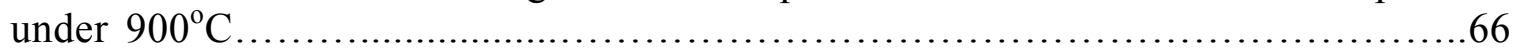

Table 4.1 Mass density of YSZ top coat from literatures........................... 78

Table 4.2 Young's moduli calculation for 300 hours René N5 coupons.................79

Table 4.3 Young's modulus of YSZ top coat from literatures........................79 


\section{List of Figures}

Figure 1.1 Schematic drawing for the Pitch/Catch technique........................6

Figure 1.2 Pitch/Catch waveform normalized at the first arrival peak.........6

Figure 1.3 Schematic drawing of Pulse-Echo technique..........................

Figure 1.4 Pulse-Echo experimental waveforms..................................

Figure 2.1 Details of conventional thermal barrier coatings applied over a turbine blade...................................................................... 13

Figure 3.1 Pulse-Echo testing location...................................... 35

Figure 3.2 Pulse-Echo signal pulsing on the top coat.............................. 35

Figure 3.3 Pulse-Echo signal pulsing on the metal side...........................

Figure 3.4 René N5/MCrAIY/APS YSZ coupon cross-section under SEM.............36

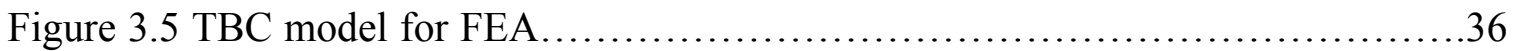

Figure 3.6 Output Pitch/Catch waveforms for TBC under different conditions................37

Figure 3.7 TBC model with voids................................................

Figure 3.8 Comparison of output waveforms at $7.4 \mathrm{~mm}$ from origin................38

Figure 3.9 Comparison of output waveforms at $3 \mathrm{~mm}$ from origin.....................

Figure 3.10 Stress wave propagating through the TGO with delamination at $1.25 \mu \mathrm{s}$,

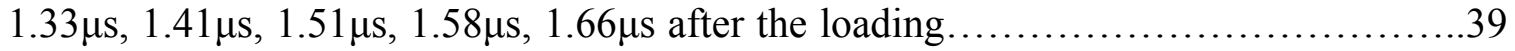

Figure 3.11 Finite Element simulation of nodal velocity on top coat surface due to uniform pressure impulse applied on top coat...............................40

Figure 3.12 Vertical velocity of node \# 1 on the surface of the substrate..............40

Figure 3.13 Pulse-Echo simulation results (WVU-N5) ..................................41

Figure 3.14 FEM model with delamination for Pulse-Echo when pulsing on the top coat

Figure 3.15 Wave propagates through the delamination at $0.1800 \mu \mathrm{s} \ldots \ldots \ldots \ldots \ldots \ldots . . .42$

Figure 3.16 The opening of delamination at time $0.2442 \mu$ s..................... 42 
Figure 3.17 Wave propagates through top coat (no delamination) at time $0.2442 \mu$ s.... 42

Figure 3.18 Top coat node \# 68822 velocity time history .42

Figure 3.19 Pulse-Echo comparisons from simulation..........................................43

Figure 3.20 TBC model with void in Wave2000................................ 43

Figure 3.21 Top coat/bond coat reflection at $5.18 \mu$ s after the initial loading.......... 44

Figure 3.22 Top coat/bond coat reflection at $5.16 \mu$ s after the initial loading............ 44

Figure 3.23 Waveforms pulsing from metal side using Wave2000..................44

Figure 3.24 Waveforms pulsing on the top coat side using Wave2000..................45

Figure 3.25 FEM model of TBC Coupon for thermal analysis.......................45

Figure 3.26 Deformed shape and Von Mises stress of TBC thermal analysis...........46

Figure 3.27 Horizontal stress (S11) of TBC thermal analysis......................46

Figure 3.28 Round trip traveling time in the first WVU isothermal René N5 coupon...49

Figure 3.29 Amplitude ratio (A2/A1) vs. exposure hour pulsing on the metal side for the first isothermal René N5 coupon .................................. 51

Figure 3.30 Amplitude ratio (A2/Delay line) vs. exposure hour pulsing on the top coat for the first isothermal René N5 coupon ....................................................51

Figure 3.31 Pulse-Echo round trip traveling time in the New René N5 Coupon \#1 ......52

Figure 3.32 Pulse-Echo round trip traveling time in the New René N5 Coupon \#2 .....53

Figure 3.33 Pulse-Echo round trip traveling time in the New René N5 Coupon \#3.....54

Figure 3.34 A2/A1 amplitude ratio of New René N5 Coupon $\# 1 \ldots . . . . . . . . . . . . . . .59$

Figure 3.35 A3/Delay line amplitude ratio of New René N5 Coupon \#1...............59

Figure 3.36 A2/A1 amplitude ratio of New René N5 Coupon $\# 2 \ldots \ldots \ldots \ldots \ldots \ldots . . . . . . .60$

Figure 3.37 A3/Delay line amplitude ratio of New René N5 Coupon \#2 ..................60

Figure 3.38 A2/A1 amplitude ratio of New René N5 Coupon \#3...................61 
Figure 3.39 A3/Delay line amplitude ratio of New René N5 Coupon \#3............61

Figure 3.40 Location of the initial crack...................................66

Figure 3.4110 minutes after initial crack...................................66

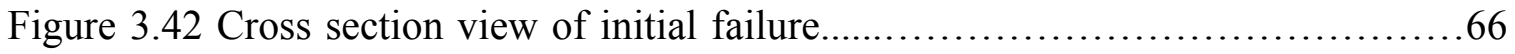

Figure 3.43 Top coat failure..............................................66

Figure 3.44 Crack propagation pattern......................................67

Figure 3.45 Pulse-Echo waveform of the model turbine blade.......................69

Figure 3.46 Pulse-Echo traveling time in the top coat of the model turbine blade on the convex side.............................................................. 69

Figure 3.47 Pulse-Echo traveling time in the substrate of the model turbine blade on the convex side.................................................................. 70

Figure 3.48 Normalized top coat thickness distribution of the model turbine blade

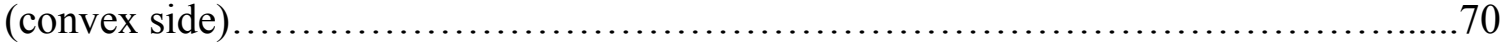

Figure 3.49 Normalized top coat thickness distribution............................71

Figure 3.50 Normalized metal plus bond coat thickness distribution of the turbine blade

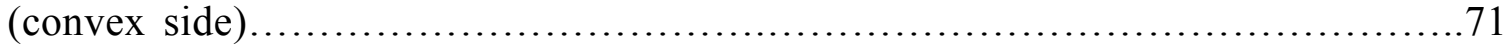

Figure 3.51 Normalized metal plus bond coat thickness distribution from Location 1 to 7 on the $1^{\text {st }}$ Row

Figure 3.52 Normalized metal plus bond coat thickness distribution from Location A to

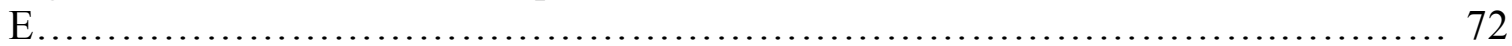




\section{List of Pictures}

Picture 3.1 Spallation at one corner of WVU isothermal René N5 coupon after 400 hours of exposure........................................................... 50

Picture 3.2 Spallation at one corner of WVU isothermal René N5 coupon after 450 hours of exposure .............................................................. 50

Picture 3.3 Spallation at one corner of WVU isothermal René N5 coupon after 500 hours of exposure. .50

Picture 3.4 Spallation at one corner of WVU isothermal René N5 coupon after 550 hours of exposure............................................................. 50

Picture 3.5 Failure Process along one edge of New René N5 coupon \#1................55

Picture 3.6 Failure Process along Edge One of New René N5 coupon \#2..............56

Picture 3.7 Failure Process along Edge Two of New René N5 coupon \#2 .............57

Picture 3.8 Failure Process along one Edge of New René N5 coupon \#3...............58

Picture 3.9 Crack pattern at about 10 minutes after the first crack initiated...............67

Picture 3.10 Crack pattern at about 42 minutes after the first crack initiated..............67

Picture 3.11 Final failure of Haynes 230 coupon (View One).......................68

Picture 3.12 Final failure of Haynes 230 coupon (View Two)......................68

Picture 3.13 Final failure of Haynes 230 coupon (cross section)....................68

Picture 4.1 EBPVD YSZ top coat........................................... 77

Picture 4.2 Free standing APS YSZ top coat.................................. 77

Picture 4.3 Scale.............................................................. 77

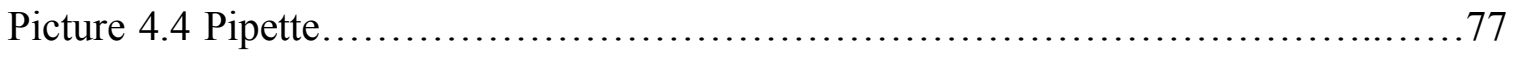

Picture 4.5 Furnace.......................................................... 78

Picture 4.6 Plastic pipe................................................... 78 


\section{CHAPTER I \\ INTRODUCTION}

\subsection{GENERAL REMARKS}

The advanced gas turbine for the next generation electric power system requires high thermal efficiency. The materials for a high performance system require new high-heat resisting alloys and thermal barrier coatings (TBC). TBCs consisting of a yttria-stabilized zirconia (YSZ) top coat and an underlying bond coat have been routinely used to coat the hot sections of systems, such as internal combustion engines and turbines, to enable them to operate at high temperatures. The YSZ TBC layer are deposited by air plasma spraying (APS), generally to thicknesses between 200 to $300 \mu \mathrm{m}$, or by electron beam physical vapor deposition (EBPVD) to thicknesses of $\sim 100$ to $125 \mu \mathrm{m}$ (Alvin 2008; Alvin et al., 2007).

Thermal barrier coatings have a complex multi-layer structure that exhibits high attenuation, high porosity, and many interfaces of different materials, and these characteristics pose challenges that would need to be overcome in order to develop a suitable nondestructive evaluation method (Ellingson et al., 2006). Coating failures, such as spallation/delamination, have a crucial influence on the function of the thermal barrier (Zhou et al., 2001). The mismatch of the mechanical and thermal properties at the interfaces or interfacial defects can cause severe stresses accumulation during service. Therefore, Nondestructive evaluation (NDE) of interface layer failures is necessary. In particular, detecting the formation of these delaminations on the interfaces would be useful for estimation of the TBC's remaining life (Cruse et al., 1998). However, the difficulty in determining the interface delamination remains to be overcome (Zhou et al., 2003; Crutzen et al., 1996). In this study, an ultrasonic technique was used to nondestructively evaluate the interface delamination. Nonlinear wave diagnostics reveal that damaged materials show a greater nonlinear response such as amplitude-dependent characteristics, and have been extensively investigated for earlier detection of interface degradation because interface failure is usually preceded by nonlinear phenomena (Chen et al., 2009).

There are a number of existing test methods used to inspect TBC systems such as Mid-infrared reflectance (MIR) imaging, X-ray diffraction, and Infrared (Eldridge et al 2005; 
Ellingson et al., 1997; Muralidhar et al., 2006). These techniques are effective in evaluating the defects and material properties within, however the techniques generally required sophisticated machinery setup, huge cost with poor flexibility to perform on-site job. The developed ultrasonic technique in this thesis could provide a relatively low cost solution to quickly inspect the TBC parts. The equipments are easy to setup, which enables on-site inspection possible. The change of the output waveforms with the service time are used to determine the interface delamination and predict the remaining life. All these features indicate the promising future of this techniques for nondestructive inspection of thermal barrier coated parts.

A total of thirty-five TBC coupons have been evaluated in this study using the developed NDE technique. Two of them were coupons with MCrA1Y and no top coat was in the system. There were another two Haynes 230 substrate with MCrA1Y bond coat and 7 wt \%YSZ (7YSZ) top coat deposited by EBPVD method. The rest of them were René N5 substrate with MCrA1Y bond coat and YSZ top coat deposited by APS method. Table 1.1 presents the tested TBC coupons and the corresponding oxidation condition. Theoretical investigations using Finite Element method are also conducted to verify the changes from the experimental results. The TBC coupons were thermally exposed with different length of dwelling time and also under different temperatures. Detailed discussions about the evolution of the ultrasonic response after each thermal exposure are presented. The material properties of the YSZ top coat are assessed and the results for the testing on a model turbine blade are discussed.

\subsection{OBJECTIVES}

This project aims at assessing the stability and life of TBC applied to a high temperature superalloy using signal crystal metal substrate for potential use in advanced oxy-fuel and hydrogen-fired gas turbine applications. The objectives of the present study are: (1)To demonstrate the proof-of-concept to detect potential interface delamination between the TBC bond coat and the underlying metal substrate in the first stage of the study, which has been accomplished and the detail are discussed by Chen et al.(2009). (2)To explore the ultrasonic diagnostic techniques for early failure detection of commercial MCrA1Y/EBPVD and MCrA1Y/APS systems as a function of extended thermal cycling 
and static oxidation exposure at $1100^{\circ} \mathrm{C}$. (3)To develop a portable device for in-situ application. Efforts will also be put to explore the Finite Element simulation of the nonlinear acoustic effects to project detection of delamination and change of material properties in TBC systems.

\subsection{SCOPES}

This thesis describes the study of NDE of thermal barrier coated coupons. The coupons tested using ultrasonic methods at various thermal exposure stages included NETL bond coat coupons, TBC coupons with top coat deposited using either EBPVD or APS methods. The Young's modulus and mass density of the YSZ ceramic top coat were evaluated at different exposure hours. This report incorporates a total of five chapters. Chapter II discusses the literature review. Chapter III addresses the ultrasonic evaluation of the TBC coupons under isothermal exposure. The Nondestructive evaluation of a model turbine was also discussed in Chapter III. The material properties assessment is described in Chapter IV and the conclusions and future work are stated in Chapter V.

\subsection{EXPERIMENTAL TECHNIQUES}

\subsubsection{PITCH/CATCH}

A Two-sensor setup, namely Pitch/Catch was utilized in the experiment. For Pitch/Catch, one ultrasonic transducer was used as the transmitter and the other one served as the receiver so that Surface Acoustic Wave (SAW) was detected after an impulse propagating along the coupon surface for a fixed distance (Crutzen et al., 1997). The

nonlinear behavior of the receiving signal can indicate the defects under the surface. The schematic drawing for the Pitch/Catch setup is shown in Figure 1.1. Figure 1.2 shows the received Pitch/Catch experimental waveform that was normalized at the first arrival peak.

\subsubsection{PULSE-ECHO}

The ultrasonic Pulse-Echo technique has been extensively used in nondestructive evaluation and material characterization (Achenbach, 2000). Ultrasonic Pulse-Echo technique uses a short impulse of ultrasound generated by a transducer connected to a pulsing device, often in direct contact with the specimen. The pulse propagates through the material of interest, reflects from the interface of two materials with different physical 
properties, and returns an echo to the same transducer. A measurement of the round-trip traveling time and travel distance yields the wave speed from which an elastic constant could be determined (Willemetz et al., 1989). In this study, Pulse-Echo determines the location of delamination by measuring the time required for a short ultrasonic impulse traveling through the coupon. The impulse reflects back at the interfaces between different materials, such as the top coat/bond coat interface, bond coat/substrate interface and substrate/air interface.

The Pulse-Echo experimental technique was adopted to test the TBC coupons along the thickness direction. The impulse is generated through a Pulser-Receiver unit (DPR300, JSR ultrasonics), and sent to the testing material using a $20-\mathrm{MHz}$ transducer (Olympus NDT). The same transducer was utilized to pick up the reflection. The high frequency characteristics of the transducer make it possible to measure thin materials or find small flaws while using the direct contact method. The transducer also has a delay-line tip to introduce a time delay between the generation of the ultrasonic wave and the arrival of any reflected waves. This allows the transducer to complete its "sending" function before it starts its "listening" function such that the near surface resolution is improved. The reflected signal was shown on a digital oscilloscope and multiple reflections can be identified due to the wave traveling back and forth inside the TBC coupons (Chen et al., 2009). Because of the attenuation property of the materials, the wave amplitude dwindled when traveling inside the media. Stress wave traveling time measured between the two reflections indicates how long the longitudinal wave needs to travel inside one particular medium. The measured traveling time resolution was obtained as two nanosecond(ns). Figure 1.3 shows the schematic drawing of the Pulse-Echo technique and Figure 1.4 shows the experimental Pulse-Echo waveforms on a TBC coupon with top coat, bond coat and substrate. Figure 1.4(a) shows the waveform when pulsing on the top coat; Figure 1.4(b) shows the waveform when pulsing on the substrate metal surface. 
Table 1.1 Coupons tested by ultrasonic techniques

\begin{tabular}{|c|c|c|}
\hline No. & Coupon name & Oxidation condition \\
\hline 1 & NETL-N5A1 & $1100^{\circ} \mathrm{C}$, Cyclic \\
\hline 2 & NETL-H230A1 & $1100^{\circ} \mathrm{C}$, Cyclic \\
\hline 3 & WVU René N5 & $1100^{\circ} \mathrm{C}$, Isothermal, failed at 550 hours \\
\hline 4 & WVU Haynes 230 & $\begin{array}{l}1100^{\circ} \mathrm{C} \text {, Isothermal, } \\
\text { failed at } 60 \text { hours }\end{array}$ \\
\hline 5 & PITT René N5 & $1100^{\circ} \mathrm{C}$, Cyclic \\
\hline 6 & PITT Haynes 230 & $\begin{array}{l}1100^{\circ} \mathrm{C}, \text { Cyclic } \\
\text { failed at } 60 \text { cycles }\end{array}$ \\
\hline $7-12$ & $\begin{array}{l}\text { PITT René N5 } \\
\# 11 \\
\# 12 \\
\# 5 \\
\# 4 \\
\# 24 \\
\# 3\end{array}$ & $\begin{array}{l}100-\mathrm{hr}, 900^{\circ} \mathrm{C} \text {, Isothermal, unstressed } \\
100-\mathrm{hr}, 900^{\circ} \mathrm{C} \text {, Isothermal, stressed } \\
100-\mathrm{hr}, 1000^{\circ} \mathrm{C} \text {, Isothermal, unstressed } \\
100-\mathrm{hr}, 1000^{\circ} \mathrm{C} \text {, Isothermal, stressed } \\
100-\mathrm{hr}, 1100^{\circ} \mathrm{C} \text {, Isothermal, unstressed } \\
100-\mathrm{hr}, 1100^{\circ} \mathrm{C} \text {, Isothermal, stressed }\end{array}$ \\
\hline $13-18$ & $\begin{array}{l}\text { PITT René N5 } \\
\# 14 \\
\# 9 \\
\# 6 \\
\# 10 \\
\# 7 \\
\# 16\end{array}$ & $\begin{array}{l}300-\mathrm{hr}, 900^{\circ} \mathrm{C} \text {, Isothermal, unstressed } \\
300-\mathrm{hr}, 900^{\circ} \mathrm{C} \text {, Isothermal, stressed } \\
300-\mathrm{hr}, 1000^{\circ} \mathrm{C} \text {, Isothermal, unstressed } \\
300-\mathrm{hr}, 1000^{\circ} \mathrm{C} \text {, Isothermal, stressed } \\
300-\mathrm{hr}, 1100^{\circ} \mathrm{C} \text {, Isothermal, unstressed } \\
300-\mathrm{hr}, 1100^{\circ} \mathrm{C} \text {, Isothermal, stressed }\end{array}$ \\
\hline $19-20$ & $\begin{array}{c}\text { PITT René N5 } \\
\# 28 \\
\# 29\end{array}$ & $\begin{array}{l}1000-\mathrm{hr}, 1000^{\circ} \mathrm{C} \text {, Isothermal, stressed } \\
1000-\mathrm{hr}, 1000^{\circ} \mathrm{C} \text {, Isothermal, unstressed }\end{array}$ \\
\hline $21-22$ & $\begin{array}{l}\text { PITT René N5 } \\
\# 13 \\
\# 20\end{array}$ & $\begin{array}{l}1000-\mathrm{hr}, 900^{\circ} \mathrm{C} \text {, Isothermal, stressed } \\
1000-\mathrm{hr}, 900^{\circ} \mathrm{C} \text {, Isothermal, unstressed }\end{array}$ \\
\hline $23-24$ & $\begin{array}{c}\text { PITT René N5 } \\
\# 18 \\
\# 19 \\
\end{array}$ & $\begin{array}{l}3000-\mathrm{hr}, 900^{\circ} \mathrm{C} \text {, Isothermal, stressed } \\
3000-\mathrm{hr}, 900^{\circ} \mathrm{C} \text {, Isothermal, unstressed }\end{array}$ \\
\hline $25-30$ & $\begin{array}{l}\text { PITT René N5 } \\
\text { \#8 } \\
\# 21 \\
\# 23 \\
\# 25 \\
\# 26 \\
\# 27 \\
\end{array}$ & A-manufactured \\
\hline $31-34$ & $\begin{array}{c}\text { WVU René N5 } \\
\text { \#1 } \\
\# 2 \\
\# 3 \\
\end{array}$ & $1100^{\circ} \mathrm{C}$, Isothermal \\
\hline 35 & PITT René N5 & As-manufactured, cross-sectioned for SEM \\
\hline
\end{tabular}




\section{Pitch and Catch}

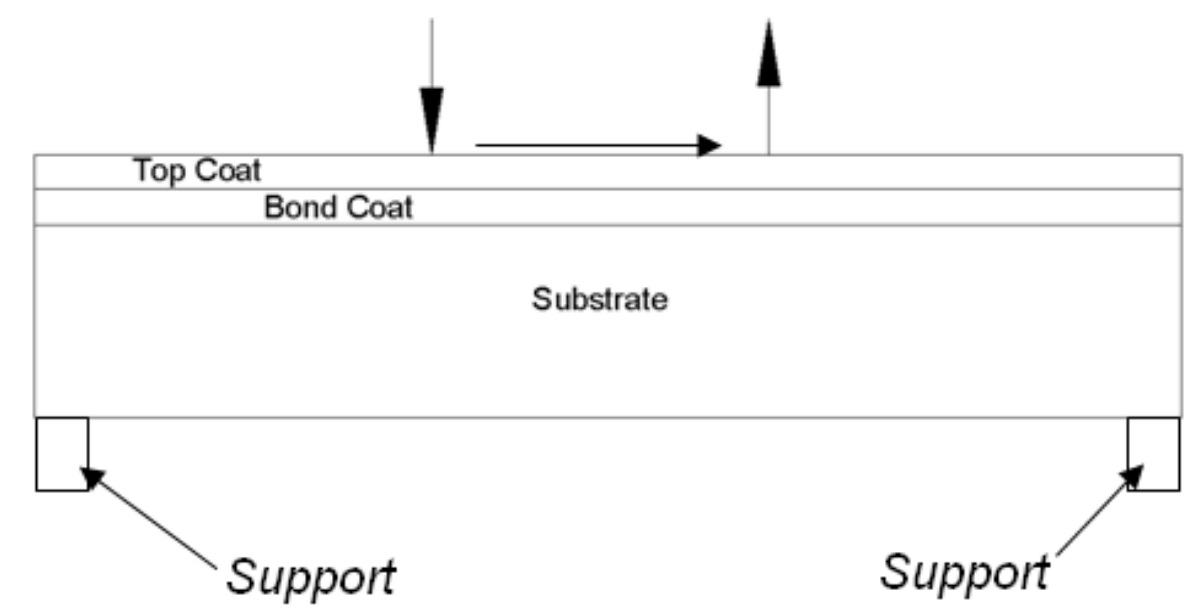

Figure 1.1 Schematic drawing for the Pitch/Catch technique

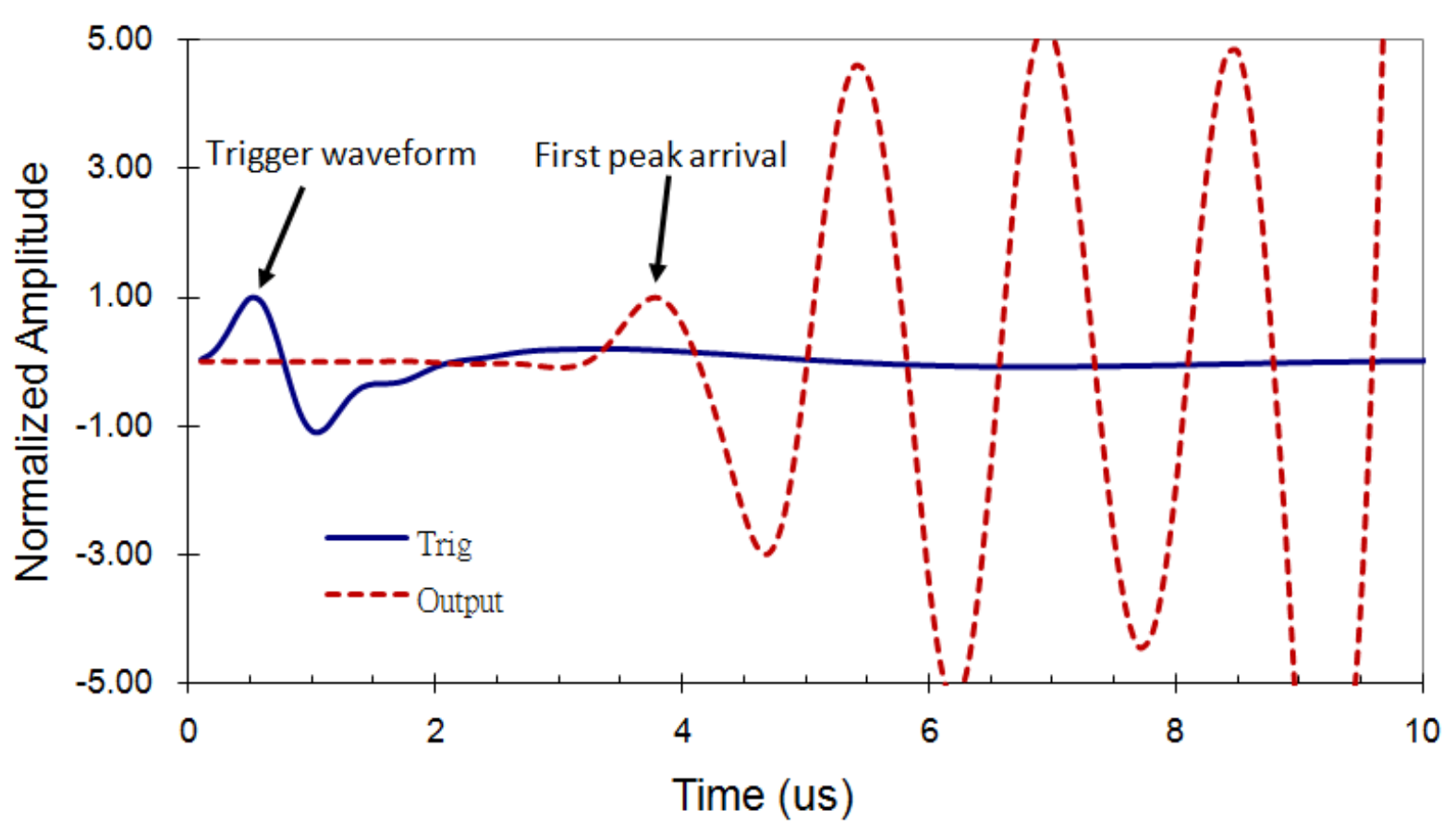

Figure 1.2 Pitch/Catch waveform normalized at the first arrival peak 


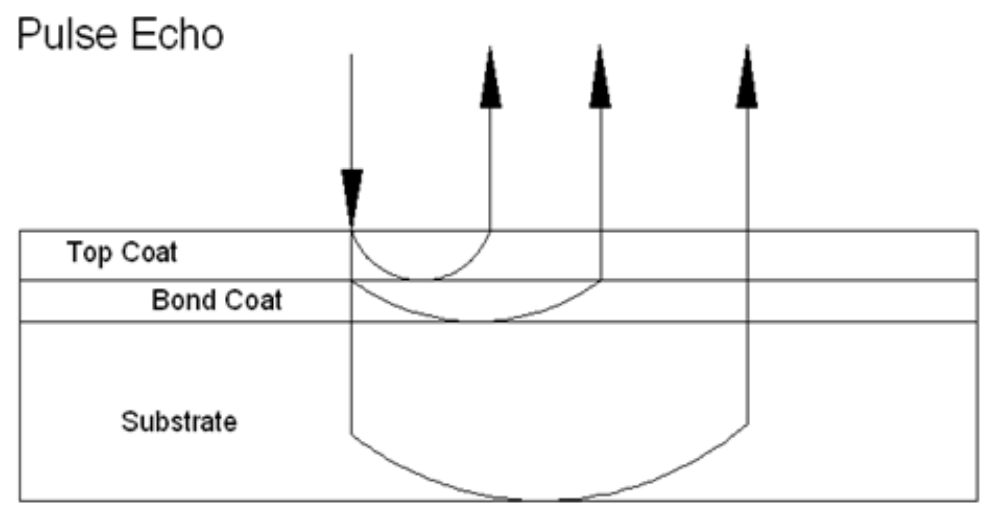

Figure 1.3 Schematic drawing of Pulse-Echo technique

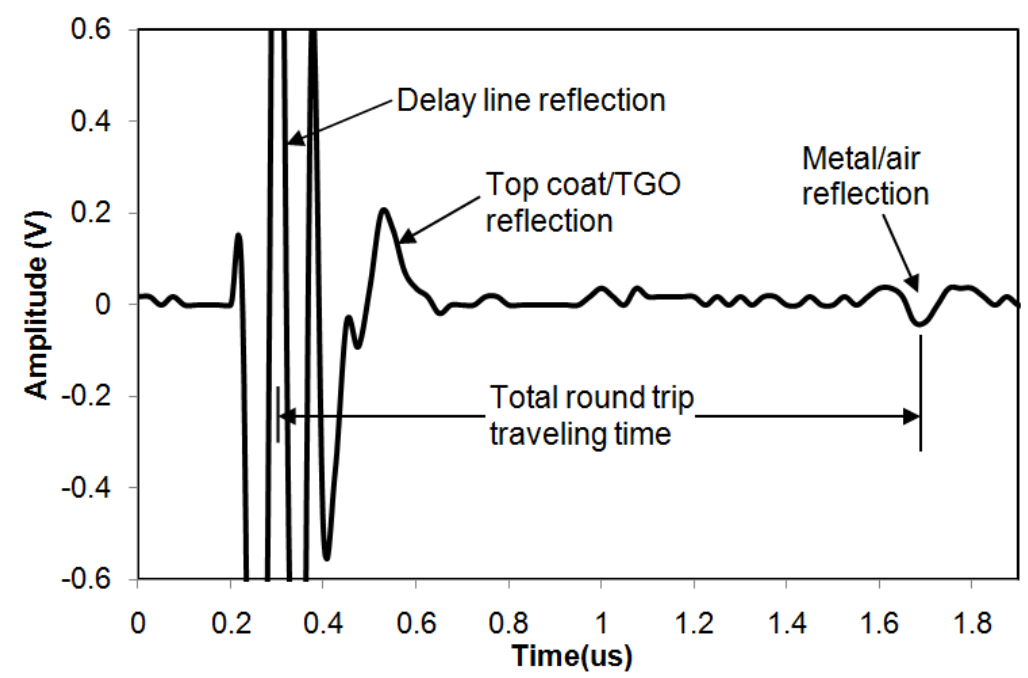

(a) Pulse-Echo waveform from pulsing on the top coat

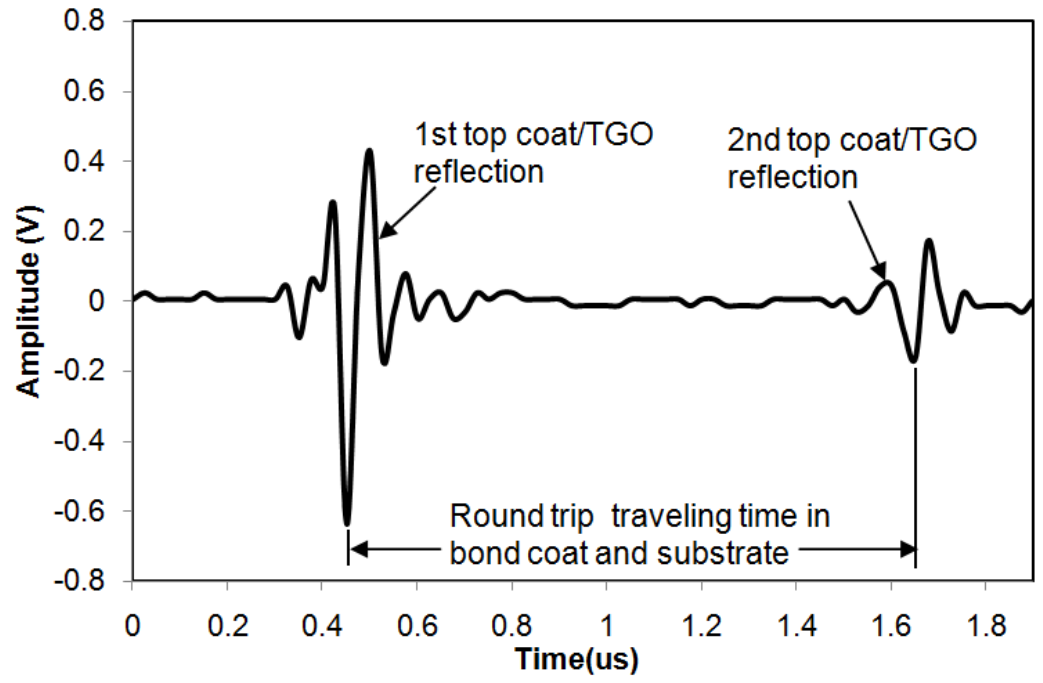

(b) Pulse-Echo waveform from pulsing on the metal surface

Figure 1.4 Pulse-Echo experimental waveforms 


\section{CHAPTER II \\ LITERATURE REVIEW}

There are a great number of industrial operations under very aggressive environments featured by high temperature, high pressure, large stresses on the working components and the presence of oxidizing and corroding environment. The examples of the processes with the above characteristics can be found in machines including aircraft gas turbine engines, steam turbines, industrial gas turbines, coal conversion, petroleum refining, and nuclear power generation so on and so forth (Bose, 2007). The gas temperature in modern gas turbine engines could go beyond $1650^{\circ} \mathrm{C}$ in the combustor section. The temperature of the cooled components would also reach as high as $1200^{\circ} \mathrm{C}$ (Grünling and Mannsmann 1993). These industrial processes require machine components made of materials constructed with superior high temperature capability under loading in order to meet performance and durability requirement. However, if the superalloys are exposed to such an aggressive environment of modern gas turbine engines, they will generally deteriorate very quickly. To protect the metal substrate of the turbine blades from high temperature and oxidation, $\mathrm{TBC}$ is developed.

Thermal barrier coating is applied to the hot components of gas turbines to allow higher turbine entry temperatures which increase the thermal efficiency of the gas turbine. Lower underlying metal temperatures can be achieved using a internal cooling system. A typical TBC system is composed of a heat-resistant ceramic top coat and a metallic bond coat (Koolloos, 2001). Zirconia $\left(\mathrm{ZrO}_{2}\right)$ has one of the lowest thermal conductivities and high melting point, and has been widely used as the top coat material in a TBC system. Yttria is usually used to prevent the transformation to deleterious phase by stabilizing the high temperature phase and eliminating the volume change (Schlichting et al., 2001). The optimum yttria stabilizer content is $7 \mathrm{wt} \%$, which was achieved by trial and error in decades of TBC research. Significantly lower yttria contents do not stop the transformation, while higher levels stabilize a phase which does not have the adequate strength and toughness. Accordingly, $7 \mathrm{wt} \%$ yttria-stabilized zirconia has become the industry standard for the top coat of a typical TBC system (Bose, 2007). The bond coat, an intermediate metallic layer deposited between the ceramic top coat and metal substrate, is usually referred to MCrA1Y, 
where "M" denotes some composition of $\mathrm{Ni}$ and/or Co. To have certain surface roughness, the metallic bond coat is applied to the superalloy substrate to enhance the bonding of the ceramic top coat to the substrate (Demasi-Marcin et al., 1994).

Over the past two decades, substantial advances have been made regarding the application of thermal barrier coatings to protect nickel-based superalloys substrate against the deleterious effects of high temperature turbine service environments. The application of TBC leads to a substantial improvement in service durability of hot-sections of turbine components, as well as dramatic improvement in the thermal efficiency of gas turbine combustion produced with high pressure and high temperature. More recent years have witnessed an ever increasingly significant function for the TBC in industrial gas turbine applications (Trubelja et al., 1997). As a result, the development of NDE methodology capable of providing detailed information about TBC failure becomes of vital importance (Desai, 1998).

\subsection{GAS TURBINE}

A conventional, gas turbine engine is composed of a compressor, used to pressurize the air, a combustion chamber where the injected fuel is mixed with the pressurized air in a high temperature environment, and a turbine propelled by the gas stream from the combustion section to power the compressor, as well as drive machineries such as an electric generator (Epstein et al., 1997).

In 1905, the first gas turbine and compressor unit built by Brown Boveri was installed in the Marcus Hook Refinery of the Sun Oil Company near Philadelphia, PA., providing 5300 kilowatts. Another early gas turbine industrial installation, commissioned in 1949, was a central power plant in the U.S. at the Huey Station of the Oklahoma Gas \& Electric Co., Oklahoma City (Giampaolo, 2009). The advancement of the current gas turbine has given rise to more efficient and more powerful industrial engines. Over the past fifty years, a great leap forward has been made in increasing the maximum gas temperature produced in the gas turbine engine (Marijnissen et al., 1999). This increase in temperature has in turn promoted efficiency, but brought up other problems such as the constraints in material itself. To protect the superalloys of the turbine, the addition of TBC has released 
the restrain to some extent and provided an additional increase in the capability of the superalloys to sustain repeated and prolonged exposures to high temperature corrosive operating environments (Wright et al.,1994; DeMasi-Marcin et al.,1990; Nicholls et al., 2002).

\subsection{THERMAL BARRIER COATINGS}

TBCs are thin ceramic layers with low thermal conductivity and high melting point $\left(2690^{\circ} \mathrm{C}\right)$ deposited onto the hot-section components of turbine engine, to protect them from erosion, wear and high temperature deterioration (Rogé et al., 2003). Thermal barrier coatings constructed out of fully or partially stabilized zirconia offer a unique capability in gas turbines to increase the gas inlet temperature significantly while keeping the temperature of the material of the structural components in a machine within conventional limits. The heat insulation of combustor parts and transition components as well as of some stationary parts is state of the art, the design of which requires safe life within defined time intervals. These depend on the overhaul and repair intervals of the engines. For large land based industrial or utility gas turbines, for example, coating life between 25000 and 30000 hours is a minimum requirement. Premature failure of a coating by e.g. local spallation causes local overheating of the component with the consequence of its total destruction or even more severe secondary damages (Grünling and Mannsmann 1993). Figure 2.1 shows the typical TBC applied on a turbine blade which is used in aircraft engine/gas turbine.

A TBC system typically consists of three layers: (1) a metal bond coat deposited on the superalloy substrate; (2) a thermally grown oxide (TGO) - primarily $\alpha$-alumina - that forms during high temperature exposure; and (3) a ceramic top coat (Shi et al., 2006). The bond coat is created by the vacuum or low pressure plasma-sprayed MCrAlY and a top coat of yttria and partially stabilized zirconia is produced by the APS or EBPVD. The characteristic features of the ceramic coating microstructure are summarized to have 10 to $15 \%$ porosity, rough surface and interface between the ceramic and bond coat, and transverse microcracks (Bose, 2007).

These coatings, nevertheless, have relatively short lifetime, which is the result of the difference in thermal properties between the coating and the underlying metal. Thermal 
residual stresses occur in $\mathrm{TBC} /$ metallic substrate during cooling from the temperature of processing. The residual stresses in TBC systems play an important role in the behavior, performance and lifetime time of the coated parts (Portinha et al., 2002). These residual stresses could initiate micro-cracks which deeply affect the integrity of the TBC and cause damage accumulation between the interfaces and leads to the final failure (Swadźba et al., 2007). The overall stresses are responsible for the growth of delamination or fracture of the material at the interface between the thermal growth oxide (TGO) and the ceramic top coat layer (Kuroda et al., 1991; Teixeira et al., 1999). In view of this, to develop a nondestructive way for evaluation of the remaining service life of the thermal barrier coated working piece is highly necessary and beneficial.

\subsection{NONDESTRUCTIVE EVALUATION}

The lifetime and performance of TBC depend primarily on the micro-structural features of the layers, such as pore morphology and concentration and the distribution and number of micro-cracks. The lifetime of such coatings rely on a number of service related parameters, such as temperature, degree of erosion and the surface exposure environment (Crutzen et al., 1997). Therefore, NDE of interface layer failures is necessary to avoid catastrophic consequences. Particularly, detection the formation of these debondings at the interfaces would be useful for estimation of the TBC's remaining life (Cruse et al., 1998). However, the complex nature of TBC system has attenuation, porosity, microcracks and is composed of different materials, and these characteristics create difficulties that would need to be overcome to develop a suitable NDE method (Ellingson, et al., 1997). An effective NDE method can be used to monitor the TBC system performance and provide a continuous remaining lifetime prediction.

A thermal sensing NDE method was reported to have the capability to assess the reliability of new coating processes, identify components with defect, monitor degradation rates during engine service, and provide data for reaching decisions on replace/repair of components (Sun, 2008). Nondestructive techniques capable of performing control and inservice inspection are being developed in various areas of applied physics and generally tackle the measurement of the coating thickness or the detection and measuring the size of bonding defects, which were discussed in the introduction. In the ultrasonic field, some 
techniques have been developed for thickness and elastic constants measurement, as well as for bonding defect detection and sizing.

\subsection{FINITE ELEMENT ANALYSIS}

Finite Element analysis is a powerful tool in the field of engineering (Heckman,1998). In Finite Element analysis, the structure to be analyzed is discretized into small elements, each having a stiffness matrix associated with other elements. When problem-specific parameters such as dimensional coordinates, the material properties such as elastic modulus, Poisson's ratio and mass density are input to these equations, the local stiffness, as represented by one element, is uniquely calculated. This basic concept can be used to solve many problems related to a variety of applied loading conditions, including externally applied static forces, pressures and temperatures (Newell et al., 2002).

Numerous cases of Finite Element analysis have been carried out to simulate the mechanical and thermal behaviors of TBC systems. Others intended to predict the service life of TBC. Govindarajan et al. (2007) developed half symmetry TBC model using plane strain formulations to carry out transient thermal and structural Finite Element analysis, in an effort to estimate the lifespan of TBC. Ghosn and Raj (2002) determined through thickness temperature variations on a TBC model as a function of coating thickness for metallic coatings. Busso et al. (2007) developed a mechanism-based life prediction methodology for thermal barrier coating systems, which revealed the magnitudes of the local TBC stresses known to lead to the failure of this type of coating. Chen et al. (2004) established an axi-symmetric model to study the high temperature properties of columnar structure TBC system by simulating a high temperature impression test. However, the simulation of wave propagation on TBC model is limited. In this study, the Finite Element analysis of the stress wave propagation in TBC is highly suggested and was conducted. 


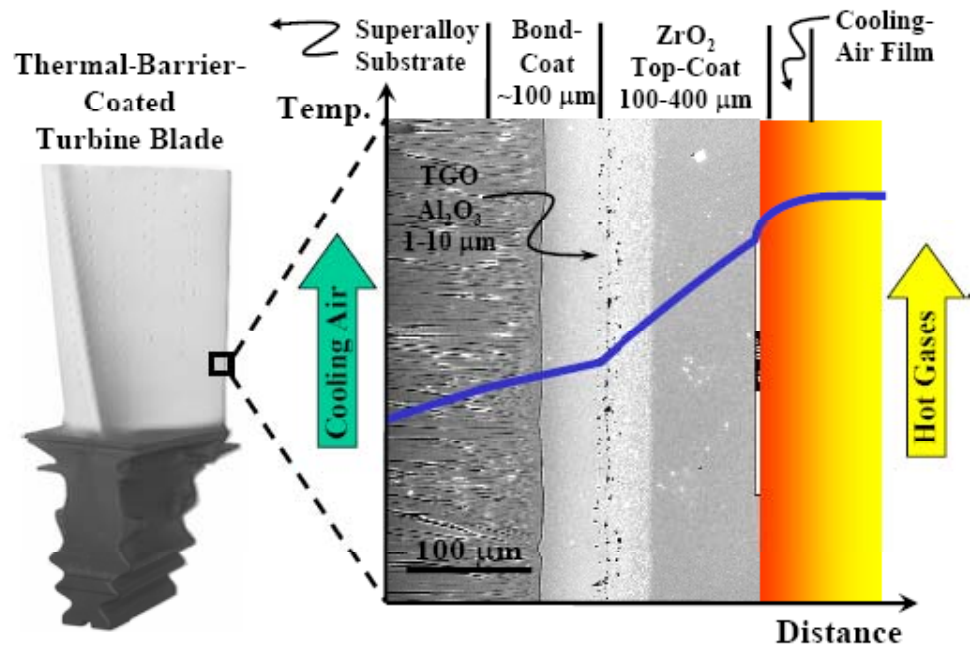

Figure 2.1: Details of conventional thermal barrier coatings applied over a turbine blade (Padture et al., 2002) 


\section{CHAPTER III}

\section{ULTRASONIC EVALUATION OF THERMAL BARRIER COATING COUPONS}

\subsection{INTRODUCTION}

This chapter presents the exploration of the use of the ultrasonic diagnostic techniques for the detection of void/delamination on commercial MCrA1Y/EBPVD and MCrA1Y/APS TBC systems as a function of thermal cycling or static exposure at $1100^{\circ} \mathrm{C}$. In collaboration with the University of Pittsburgh (U PITT), a total of thirty five TBC coupons were tested under various thermal conditions. Thirty two of them were composed of a $\sim 3 \mathrm{~mm}$ René N5 superalloy substrate, $\sim 200 \mu \mathrm{m}$ MCrA1Y bond coat and $\sim 300 \mu \mathrm{m}$ 7YSZ top coat deposited using APS method. These coupons are denoted as René N5 coupons. The rest two were Haynes 230 superalloy substrates with MCrA1Y bond coat and 7YSZ top coat deposited using EBPVD method. These two coupons are denoted as Haynes 230 coupons. Four René N5 coupons were subjected to isothermal exposure under $1100^{\circ} \mathrm{C}$ at West Virginia University (WVU), with a dwell time of 25 to 40 hours for each exposure. One René N5 coupon was cross-sectioned without thermal exposure for Scanning Electron Microscope (SEM) inspection at U PITT. Another René N5 coupon was subjected to cyclic thermal oxidation under $1100^{\circ} \mathrm{C}$ at U PITT. The remaining twenty-six René N5 coupons were isothermally exposed at various temperatures for different length of dwell time from 100 hours to 3000 hours with either stressed or non stressed condition at U PITT. Eighteen of those coupons were tested before and after isothermal exposure, and eight coupons were tested as-manufactured.

The ultrasonic Pitch/Catch and Pulse-Echo techniques were utilized to test the TBC coupons. The Pitch/Catch surface wave traveling time was measured before and after the cyclic or isothermal oxidation for those coupons. A trend of surface wave speed increase was identified for the 300-hour isothermal coupons. However the test results for other coupons did not show notable change. The reason will be addressed in Section 3.4.1 in detail. The results from the Pulse-Echo traveling time and amplitude measurement sent an early warning of delamination for the René N5 coupons isothermally oxidized at WVU. The receiving waveforms indicate the delamination at the top coat/TGO interface prior to its 
visual confirmation at later exposure hours. Finite Element analysis was continued to include the ceramic top coat as well as the TGO layer in the model besides bond coat and substrate. The Pulse-Echo and the Pitch/Catch wave propagation on a TBC system were simulated using ABAQUS 5.1 package, considering the change of material properties of the top coat, the occurrence of TGO layer and the different lengths of delaminations between the top coat and the TGO. The FEA results were also compared with the experimental results to estimate the material properties of the ceramic top coat, bond coat and substrate.

\subsection{EXPERIMENT}

In addition to the Pitch/Catch measurement, those coupons were also tested using Pulse-Echo. A total of five locations were tested using Pulse-Echo technique on each coupon at different thermal stages. Figure 3.1 shows the test location on the top coat of the coupons. The test was performed on the top coat surface as well as the metal substrate surface. By testing on the top coat surface, the time to travel through the entire coupon can be acquired. Figure 3.2 shows the experimental signal for comparison when pulsing on the top coat. In Figure 3.2, the total traveling time in the coupon could be measured from the delay line reflection to the metal/air reflection. By testing on the substrate surface, the time to travel from the substrate to the bond TGO/top coat interface can also be obtained. The TGO is included in the bond coat due to its small thickness (up to $10 \mu \mathrm{m}$ ). Figure 3.3 shows the experimental signal when pulsing on the metal side. In Figure 3.3, the traveling time in the substrate and bond coat was measured from the $1^{\text {st }}$ bond coat(TGO)/top coat reflection to the $2^{\text {nd }}$ bond coat (TGO)/top coat reflection. The traveling time for both cases was recorded, and the time to travel through the top coat only could be obtained by subtracting the time through the metal from the time for the entire coupon. The traveling time in the top coat can also be acquired by measuring the time from the impulse reflecting at the delay line tip to the bond coat(TGO)/top coat reflection. The change of the measured traveling time at different exposure stages at the same location infers the change of the longitudinal wave speed inside the coupon. Since the wave speed is closely related to the material properties such as Young's Modulus, Poisson's ratio and mass density. The change of the traveling time could indicate the degradation of the TBC system due to thermal exposure. 
In addition, the amplitude of the Pulse-Echo signal (A1, A2, A3) from Figure 3.2 and Figure 3.3 was also used to indicate the deterioration process of a TBC system subjected to thermal oxidation. The change of amplitude of the signal is closely related to the change of the acoustic impedance $\rho \cdot \mathrm{C}(\rho=$ mass density and $\mathrm{C}=$ longitudinal wave speed), which are determined by the material properties. The change of acoustic impedances will cause more energy to reflect back at the interface between two materials and less energy propagating through, such that the reflection from intermediate interface such as top coat/bond coat interface will become stronger and the reflections from outside interface such as metal/air interface will become weaker when pulsing on the top coat.

This two parameters (Traveling time, Amplitude) from the Pulse-Echo experiments were used to record the degradation of the TBC coupon subjected to thermal testing. An early warning signal can be identified from Pulse-Echo results to indicate the occurrence of the delamination/spallation between the YSZ top coat and the bond coat along the TGO layer. This method was also used to provide quantitative estimation of the material properties of the TBC system.

\subsection{MATERIALS AND SPECIMENS}

The test specimens are $\sim 3 \mathrm{~mm}$ René N5 coupons with $\sim 200 \mu \mathrm{m}$ commercially applied MCrA1Y bond coat (M stands for Co, Ni) and a 300 $\mu \mathrm{m}$ 7YSZ top coat system applied using APS method and Haynes 230 coupons with MCrA1Y bond coat and EBPVD YSZ top coat. Zirconia exhibits a high melting point of $2690{ }^{\circ} \mathrm{C}$. With the purpose to provide corrosion resistance, an aluminum-rich metallic coating termed as bond coat is applied to the superalloy prior to the deposition of the YSZ top coat. During high temperature exposure the bond coat oxidizes and produces a protective TGO (Renusch and

Schütze, 2007). The cross-section of a René N5 coupon under Scanning Electron Microscope (SEM) is shown in Figure 3.4. In Figure 3.4, the top layer is the YSZ top coat (about $300 \mu \mathrm{m}$ ), the intermediate layer is the MCrA1Y bond coat (about $200 \mu \mathrm{m}$ ) and the bottom layer shown partly is the metal substrate. The APS YSZ top coat is characterized with rough surface, high porosity and laminated structure with transverse crack as shown in Figure 3.4. However, its high melting point and low thermal conductivity make it a good 
thermal insulator and greatly reduces the operation temperature for the metal substrate underneath.

The typical failure modes of plasma-sprayed TBC observed during both engine service and laboratory testing are fracture and delamination of the porous YSZ top coat near to and parallel to the irregular bond coat interface (Haynes et al., 1999). The TBC system has residual stress because of high temperature deposition and thermal expansion mismatch in the system (Waki et al., 2008). The build-up of the residual stress contributes to the growth of interface spallation and delamination and leads to the final failure of a TBC system. A total of four coupons were subjected to isothermal exposure under $1100^{\circ} \mathrm{C}$ at WVU, with a dwell time of 25 or 40 hours during each thermal cycle. The experimental results will be discussed later in this chapter.

\subsection{FINITE ELEMENT ANALYSIS}

\subsubsection{FINITE ELEMENT ANALYSIS OF PITCH/CATCH}

FEA simulation of the wave propagation on a simplified TBC system with nonlinear effect was conducted. The FEA results can clearly show presence of a small embedded delamination (Surface seperation) between the ceramic top coat and the TGO layer in the model. An axisymmetric dynamic analysis using ABAQUS Explicit was carried out. The change of material properties of the top coat, and embedment of delaminations were considered during the analysis. A simplified TBC model was established incorporating a $300 \mu \mathrm{m}$ top coat, $10 \mu \mathrm{m}$ TGO layer, $200 \mu \mathrm{m}$ bond coat and $3 \mathrm{~mm}$ substrate. The TBC model has 729210 quadrilateral elements and 741278 nodes. The material properties were assumed and shown in Table 3.1. Figure 3.5 shows the meshed TBC model. A $0.25 \mu$ s duration negative Hanning function impulse with unit amplitude located at the origin was used as the input excitation for the analysis of Pitch/Catch simulation.

Several cases were simulated for wave propagation on a TBC model to see the effect of the material properties: Case 1, The TBC model does not include a TGO layer, labeled as 250ns-no-tgo-pnc; Case 2, the TGO layer was added to the model, labeled as 250ns-tgo-pnc. Case 3, the material properties for the top coat were changed, labeled as 250ns-lower material. The rest of the input file remained the same, including the size of the model, material properties for other components (bond coat, substrate) in the model, and impulse 
loading condition. Figure 3.6 compares the output waveforms at $7.4 \mathrm{~mm}$ away from the loading point. In Figure 3.6, the output waveform with lower Young's modulus of the top coat, bond coat as well as TGO (Black waveform) is delayed in the arrival and shows greater oscillation, when compared to the one with relatively higher Young's modulus (Blue waveform). The waveform in red shows the response without the TGO layer. The output waveform is sensitive in terms of the arrival and the amplitude when the TGO appeared.

To find the effect of the delamination, another two models were constructed to include the voids with different lengths. The delaminations were introduced between the top coat and the TGO layer, where they would normally occur in a TBC system subjected to thermal testing. Separation was predetermined at the interface of the delamination. There are 2 cases of voids with different lengths, denoted as Void1s and Void2s. The length of Void1s is $874 \mu \mathrm{m}$ with a starting point located at $1.372 \mathrm{~mm}$ from origin; The Void2s has a shorter length of $403 \mu \mathrm{m}$, with a starting point located at $1.843 \mathrm{~mm}$ from origin. The output waveforms at were calculated at two locations for each void case. The first location of detection is $7.4 \mathrm{~mm}$ away from the origin and the other location is $3 \mathrm{~mm}$ away from the origin. Figure 3.7 shows the TBC model including the position of the delaminations and location of detection.

The results of the delamination cases were compared with the delamination-free one. Figure 3.8 shows the comparison of the three waveforms detected at $7.4 \mathrm{~mm}$ away from the origin. In Figure 3.8, the red waveform represents the Voidls case having a long delamination; the green waveform is the output of Void2s case with a short delamination and the red waveform is the result of the solid case (no delamination). From the comparison, it is noticeable that the delamination will reduce the peak amplitude and distort the waveform. The larger the delamination size is, the smaller the amplitude of the output waveform will be with more distortion on the waveform. Figure 3.9 compares the waveform of the three cases at the location of $3 \mathrm{~mm}$ away from the origin, where is closer to the location of the two voids. In Figure 3.9, the effect of the voids caused a even stronger nonlinear effect and greater disturbance to the output waveforms when the detection point is closer to the loading position, especially in the Void1s case which has a longer delamination. The images of the stress wave propagating through the TGO with the longer delamination 
were captured at different times and shown in Figure 3.10. Figure 3.10 incorporated a series images captured at a sequence of the wave propagation from the left to the right in each figure at the time of $1.25 \mu \mathrm{s}, 1.33 \mu \mathrm{s}, 1.41 \mu \mathrm{s}, 1.51 \mu \mathrm{s}, 1.58 \mu \mathrm{s}, 1.66 \mu \mathrm{s}$ after the initial loading at the origin. From these figures, the delamiation is open up when the wave is passing this area and it closed when the wave has propagated beyond this region.

Nonlinear effect due to delamination between TGO and top coat was simulated successfully using a rough contact surface with separation capability. FEA results show the possibility of detecting TGO using the surface acoustic wave with Pitch/Catch. FEA can clearly show detection of a small embedded delamination. In the next section, the PulseEcho simulation along the thickness direction was. A comparison between experimental measurement and FEA can be used to estimate the material properties of the coatings and the substrate.

\subsubsection{FINITE ELEMENT ANALYSIS OF PULSE-ECHO}

(a) Finite Element Analysis of Pulse-Echo on solid TBC Model

Pulse-Echo FEA model was constructed based on the dimensions and the material properties of René N5 coupon with MCrA1Y bond coat and APS 7YSZ top coat. In FEA, it is assumed a $3 \mathrm{~mm}$ substrate with a Young's Modulus, mass density and Poisson's ratio of $\mathrm{E}=213 \mathrm{GPa}, \rho=8630 \mathrm{~kg} / \mathrm{m}^{3}$ and $v=0.25$, a $200 \mu \mathrm{m}$ bond coat $\left(\mathrm{E}=211 \mathrm{GPa}, \rho=7176 \mathrm{~kg} / \mathrm{m}^{3}\right.$ and $v=0.3)$ and a $350 \mu \mathrm{m}$ top coat $\left(E=30 \mathrm{GPa}, \rho=5100 \mathrm{~kg} / \mathrm{m}^{3}\right.$ and $\left.v=0.2\right)$. No TGO layer was included in this analysis. The shape of the impulse with duration of $144 \mathrm{~ns}$ was composed on the basis of transducer response to excitation in the Pulse-Echo experiments. Because of the size of the contacting tip of the transducer being relatively large compared to the area of the coupon. The dynamic loading imposed on the top coat surface of the coupon is considered a pressure covering a certain area on the surface of the specimen instead of a point load. In view of this, the ultrasonic impulse was modeled as a pressure covering the entire the top coat surface of the model simulating plane waves. The results are shown in Figure 3.11. In Figure 3.11, immediately after the arrival of the wavefront, a reflection from the top coat/bond coat interface was observed. Three other reflections from the top coat/bond coat interface were also obtained after the initial one. The reflections in this Finite Element analysis are similar to the experimental results when pulsing on the ceramic 
side of a TBC coupon. Compared with the experimental results, the results of stress wave traveling time from this FEA provide us with an estimation of the material properties and the thickness of the TBC coupons.

In another case, the position of the loading was modified to simulate the Pulse-Echo experiment when impulse was loaded on the metal side. The load was imposed onto the metal substrate surface of the model. The material properties were assumed as: top coat $\left(E=30 \mathrm{GPa}, \rho=5100 \mathrm{~kg} / \mathrm{m}^{3}\right.$ and $\left.v=0.2\right)$, René N5 substrate metal $\left(E=213 \mathrm{GPa}, \rho=8630 \mathrm{~kg} / \mathrm{m}^{3}\right.$ and $v=0.25)$, and bond coat $\left(E=211 \mathrm{GPa}, \rho=7176 \mathrm{~kg} / \mathrm{m}^{3}\right.$ and $\left.v=0.3\right)$. The thickness of the top coat was $300 \mu \mathrm{m}$ for this model, smaller than the previous case, the bond coat thickness is $200 \mu \mathrm{m}$, and the substrate thickness is $3 \mathrm{~mm}$. Figure 3.12 shows the surface vertical velocity-time history of the node \#1 located on the surface of the substrate. This result shows a good resemblance of the experimental Pulse-Echo waveform. The waveform at the beginning is the starting point of the loading from the metal side. After that, the first reflection comes from the top coat/bond coat interface and the second reflection is from the top coat/air interface; third reflection (inverse sign) is the first top coat/air reflection bounce back from the top coat/bond coat interface. This wave bounced back reaching at the top coat/air surface, and then reflected back from the top coat/air surface to reach the substrate surface. Round trip total time in ceramic thickness is the time difference between the second and the third reflection in Figure 3.12. It is about $0.2 \mu$ s round trip, so one-way trip in the top coat will be about $0.1 \mu \mathrm{s}$. Round trip time going through the total thickness is the time difference between the first waveform and the second reflection and the value is about $1.4 \mu \mathrm{s}$ in this FEA simulation.

A third case was accomplished to estimate the material properties. A TBC model was constructed to have a $350 \mu \mathrm{m}$ top coat, $220 \mu \mathrm{m}$ bond coat and a $3 \mathrm{~mm}$ substrate. By comparing the simulation and the experimental results, an estimation of the material properties was made for the René N5 coupon isothermally exposed after 85 hours at WVU. The top coat mass density and Young's modulus were assumed to be $5100 \mathrm{~kg} / \mathrm{m}^{3}$ and 39 $\mathrm{GPa}$ and the Poisson's ratio was 0.2 . The bond coat has a mass density of $7176 \mathrm{~kg} / \mathrm{m}^{3}$ and Young's modulus of $200 \mathrm{GPa}$. The density for the substrate was $8630 \mathrm{~kg} / \mathrm{m}^{3}$ and the Young's modulus was $205 \mathrm{GPa}$. The Poisson's ratios for the bond coat and the substrate 
were assumed to be 0.3 and 0.25, respectively. As shown in Figure 3.13, the total time traveled through the entire thickness obtained from the simulation was $1.4895 \mu$ s (Peak A to Peak C) and the top coat traveling time was $0.2450 \mu$ s (Peak A to Peak B). The simulation results were compared with the experimental results. In the experimental results, the total traveling time for 85-hour René N5 coupon was $1.4974 \mu$ s and the travel time in the substrate and the bond coat is $1.2572 \mu \mathrm{s}$, so the top coat round trip traveling time is 0.2402 $\mu \mathrm{s}$, compared to $0.245 \mu \mathrm{s}$ from FEA. The round-trip time in the top coat and the entire coupon were in good agreement with the simulation result. Hence, the material properties of the top coat of this 85-hour René N5 coupon can be estimated using this model, where the top coat thickness was $350 \mu \mathrm{m}$ with $\mathrm{E}=39 \mathrm{GPa}, \rho=5100 \mathrm{~kg} / \mathrm{m}^{3}$ and $v=0.20$.

\section{(b) Finite Element Analysis of Pulse-Echo on TBC Model with Delamination}

The delamination was considered for the Pulse-Echo analysis and the result was compared with that from the delamination-free case. A length of $2.5 \mathrm{~mm}$ (radius) from the origin on the top coat was assigned to simulate the size of the impulse loading used in experiments. The coupon is a René N5 substrate (bottom layer in Figure 3.14) with a bond coat of $200 \mu \mathrm{m}$ (intermediate layer in Figure 3.14), and the top coat is $350 \mu \mathrm{m}$ (top layer in Figure 3.14). A $600-\mu \mathrm{m}$-long delamination at the top coat and the bond coat interface was embedded at $400 \mu \mathrm{m}$ away from the axi-symmetric axis as illustrated with a red line in Figure 3.14 .

Case 1 is no-delamination and case 2 has an embedded $600 \mu \mathrm{m}$ delamination (allow separation) as shown in Figure 3.14. The top coat properties are assumed as E = $30 \mathrm{GPa}, \rho$ $=5100 \mathrm{~kg} / \mathrm{m}^{3}$, and $\mathrm{v}=0.2$. The René N5 substrate metal is $\mathrm{E}=211 \mathrm{GPa}, \rho=8630 \mathrm{~kg} / \mathrm{m}^{3}$, and $v=0.25$ The bond coat possesses material properties of $E=210 \mathrm{GPa}, \rho=7176 \mathrm{~kg} / \mathrm{m}^{3}$, and $v=0.3$. Both cases have the same material properties for its components of the model. Two figures (Figure 3.15 and 3.16) show the behavior of the delamination when the energy is propagating through it. Figure 3.15 shows the energy passing through the delamination at the time of $0.1800 \mu \mathrm{s}$ and Figure 3.16 shows the energy reflected back between the top coat/bond coat interface and the opening of the delamination at the time of $0.2442 \mu \mathrm{s}$. The two figures show that the delamination is closed when it is subjected to a compressive wave and it will open when subjected to a tensile wave from the reflection. Figure 3.17 shows the 
wave propagates through the top coat where there is no delamination at the same time as in Figure 3.13. The deformed shape in Figure 3.15, 3.16 and 3.17 were amplified by $8 \times 10^{9}$ times.

To compare the influence of the delamination, a node on the top coat surface in the two cases was selected to see its velocity as a function of time. Figure 3.18 shows the comparison of the two cases. In Figure 3.18, the node labeled as 68822 was selected (592 $\mu \mathrm{m}$ away from the origin) in the case with delamination and the same node was selected for the case without delamination. The delay line reflection in Figure 3.18 shows the shape of the impulse wave with duration of $0.144 \mu \mathrm{s}$. In Figure 3.18, the peak of the top coat/bond coat reflection from the case with delamination reserved sign when compared with that from the case without delamination, which was also observed in the experimental results when delamination grew up. The waveform with embedded delamination has bigger oscillations in terms of amplitude than the case without delamination. This is due to the fact that more energy was reflected back and forth inside the top coat because of delamination preventing the energy propagating to the bond coat. While there is no delamination, the energy propagates to the bond coat and the substrate. So there is less energy reflecting inside the top coat.

(c) Simulation of Pulse-Echo using Wave 2000 software

Computer simulations of the Pulse-Echo ultrasonic wave propagation on a René N5 with a $350 \mu \mathrm{m}$ top coat, $200 \mu \mathrm{m}$ and a $3 \mathrm{~mm}$ substrate using Wave2000 computational ultrasonics software were also accomplished to see how the change of material properties in the top coat and substrate will affect the Pulse-Echo results. In Case 1, the mass density and Young's modulus were assumed to be $5100 \mathrm{~kg} / \mathrm{m}^{3}$ and $30 \mathrm{GPa}$. In Case 2, the two parameters were assumed to be $5300 \mathrm{~kg} / \mathrm{m}^{3}$ and $25 \mathrm{GPa}$. The Poisson's ratio in both cases was 0.2 for the top coat. The bond coat properties were the same in the two cases, with a mass density of $7176 \mathrm{~kg} / \mathrm{m}^{3}$ and Young's modulus of $200 \mathrm{GPa}$. The density for the substrate was the same, being $8630 \mathrm{~kg} / \mathrm{m} 3$, but the Young's modulus was different; it was $205 \mathrm{GPa}$ for Case 1 and $211 \mathrm{GPa}$ for Case 2. The Poisson's ratio for the bond coat and the substrate was assumed 0.3 and 0.25 respectively, and maintained the same value in both cases. A delay-line was also incorporated in the model to trigger the top coat surface 
reflection. Figure 3.19 compares the results from the two cases. As shown in Figure 3.19, the first peak of the two cases coincides with each other very well, which shows the reflection of the topcoat surface with the same delay-line properties. The waveform (red) in Case 2 with the lower Young's modulus and higher mass density displays a delay in the arrival of the second peak, which is the reflection from the top coat/bond coat interface.

The influence of the void to the amplitude of the receiving signals was also studied using Wave2000. A 100- $\mu$ m-thick and 2-mm-long void was composed between the top coat and the bond coat layer in the model. Figure 3.20 shows the model with embedded void. In Figure 3.20, the bottom layer represents the substrate; the third layer is the bond coat and the second layer is the top coat; the small embedded layer is the void. The top layer simulates the delay line tip on the transducer. The material properties for the model were assumed to be top coat $\left(E=39 \mathrm{GPa}, \rho=5100 \mathrm{~kg} / \mathrm{m}^{3}, v=0.2\right)$, bond coat $\left(E=211 \mathrm{GPa}, \rho=7176 \mathrm{~kg} / \mathrm{m}^{3}, v\right.$ $=0.3)$, substrate $\left(E=213 \mathrm{GPa}, \rho=8630 \mathrm{~kg} / \mathrm{m}^{3}, v=0.25\right)$, and void $(E=0.211 \mathrm{GPa}, \rho=7176$ $\left.\mathrm{kg} / \mathrm{m}^{3}, \mathrm{v}=0.49\right)$. The result of the simulation was compared to the one without void. The reflections from the top coat/bond coat interface of the two cases were compared. Figure 3.21 shows the reflection from top coat/bond coat interface of the case without void. Figure 3.22 shows the reflection in the void case. The reflection in the void case shows longer tail and more oscillations, while the reflection from the case with no void is quite clear. The waveforms of the two cases were also compared. Figure 3.23 shows the displacement time history of Pulse-Echo when pulsing from the metal side and Figure 3.24 shows the waveform when pulsing on the top coat side. As has been observed in the Pulse-Echo experiment, the void caused the amplitude of the 2 nd top coat/bond coat reflection and the 1 st top coat bond coat reflection to become stronger, while the metal/air reflection became smaller.

\subsubsection{FINITE ELEMENT THERMAL ANALYSIS OF THERMAL BARRIER COATING} COUPONS

A Finite Element thermal analysis was conducted to find out the behavior of the three components of a TBC system due to temperature change. The analysis was conducted to identify the internal stress distribution due to the temperature change. The coupon is a René N5 substrate (bottom layer in Figure 3.14) with a bond coat of $200 \mu \mathrm{m}$ (intermediate layer in Figure 3.25), and the top coat is $350 \mu \mathrm{m}$ (top layer in Figure 3.25). A temperature 
change on the $\mathrm{TBC}$ model from $1100^{\circ} \mathrm{C}$ to room temperature, $25^{\circ} \mathrm{C}$ was composed on the basis of the cooling process of the TBC coupon during the oxidation experiments. For simplicity, three steps for calculation were described for the three layers of the TBC model. The material properties were defined for top coat ( $\left.E=30 \mathrm{GPa}, \rho=5355 \mathrm{~kg} / \mathrm{m}^{3}, v=0.2\right)$, bond coat $\left(E=210 \mathrm{GPa}, \rho=7176 \mathrm{~kg} / \mathrm{m}^{3}, v=0.3\right)$, and substrate $\left(E=213 \mathrm{GPa}, \rho=8630 \mathrm{~kg} / \mathrm{m}^{3}\right.$, $v=0.25$ ). The thermal properties were defined for top coat (thermal conductivity: $0.8 \mathrm{~W} / \mathrm{mK}$ at $1000{ }^{\circ} \mathrm{C}$, thermal expansion coefficient: $9.86 \times 10^{-6} /{ }^{\circ} \mathrm{C}$ ), bond coat (thermal conductivity: $25 \mathrm{~W} / \mathrm{mK}$ at $1000{ }^{\circ} \mathrm{C}$, thermal expansion coefficient: $13.3 \times 10^{-6} /{ }^{\circ} \mathrm{C}$ ), and substrate (thermal conductivity: $73.9 \mathrm{~W} / \mathrm{mK}$ at $1000{ }^{\circ} \mathrm{C}$, thermal expansion coefficient: $12.2 \times 10^{-6} /{ }^{\circ} \mathrm{C}$ ).

The results of the thermal analysis of a TBC system are shown in Figure 3.26 and Figure 3.27. Figure 3.26 shows the deformed shape and the Von Mises stress distribution at the edge of the TBC model (12.5mm away from the center), which is circled in the right corner of Figure 3.25. In Figure 3.26, the deformed shape of the top coat shows that it tries to lift, but is restrained by the bond coat after the temperature declined from $1100^{\circ} \mathrm{C}$ to $25^{\circ} \mathrm{C}$. There is a stress concentration at the edge of the top coat/bond coat interface, which confirms and explains why the spallations always first appeared at the edge of the TBC coupon. Figure 3.27 shows the distribution of the horizontal stress within the TBC model. It can be observed that due to the difference in the thermal expansion coefficient between the top coat and bond coat, the top coat is under compression (blue part) and the bond coat is under tension after the coupon has cooled down. The residual stress is the key factor that leads to the failure of the TBC coupon. This is consistent with the data reported by Rabiel et al.(2000).

\subsection{EXPERIMENTAL RESULTS AND DISCUSSION}

\subsubsection{PITCH/CATCH EXPERIMENTAL RESULTS}

The experimental Pitch/Catch was performed on TBC coupons after thermal exposure. Those coupons include one set of René N5 and Haynes 230 coupons for isothermal exposure at WVU and another set of René N5 and Haynes 230 for cyclic exposure at U PITT. Six René N5 coupons were oxidized at various temperatures and stress condition for 100-hour and another six were oxidized for 300-hour with stress and unstressed conditions at U PITT. 
The experimental data from the testing of the coupons are show in Table 3.2 to Table 3.5. Table 3.2 shows the Pitch/Catch data from isothermal René N5 coupon and Haynes H230 coupon at different hours. Table 3.3 shows the Pitch/Catch data from cyclic René N5 coupon and Haynes H230 coupon at different cycles. Table 3.4 shows the Pitch/Catch result for the six 100-hour René N5 coupons at as-manufactured and 100-hour state. Table 3.5 shows the Pitch/Catch results for the six 300-hour René N5 coupons at as-manufactured and 300-hour state. The Pitch/Catch techniques for both isothermally exposed and cyclic exposed Haynes 230 coupons were stopped after 60-hour and 60-cycle testing due to the premature failure of the top coat for these two coupons.

It is noticed that the experimental Pitch/Catch results could not strike a direction comparison with those from the Finite Element analysis for the TBC coupons. There are three main reasons: First of all, the Finite Element analysis is in an ideal situation, considering the coatings of the coupon as isotropic and homogeneous materials, but the actual top coat and bond coat of the coupon might have porosity, micro-cracks and other

anomalies formed during manufacturing; Secondly, the loading and detection in the Finite Element analysis are all at one point on the top coat surface of the model. But in the experiments, the influence due to the size of the transducers used for transmitting and receiving is not negligible. The transducers used in the experiments have a contacting diameter of $5 \mathrm{~mm}$ and transmitter and receiver are $3 \mathrm{~mm}$ apart from the two inner edges due to the small size of the coupons (a square plate with an edge length of $25 \mathrm{~mm}$ ). Furthermore, the rough surface of the ceramic top coat can lead to a partial sensor-coupon contact, which will also bring error to the detection. Further modifications are needed for the Pitch/Catch method to enable a direct comparison with the FEA simulation.

\subsubsection{PULSE-ECHO EXPERIMENTAL RESULTS}

\section{(a) Pulse-Echo Tests of the first WVU Isothermal René N5 Coupon}

The Pulse-Echo results of the WVU isothermal René N5 coupon are shown in the following figures. Figure 3.28 (a) shows the traveling time evolution in the top coat from 60 hours to final failure after 550 hours of isothermal exposure. The total traveling time of this WVU N5 coupon shown in Figure 3.28(b) continued to decrease all the way to 210 hours of exposure since the Pulse-Echo testing started after 60 hours of exposure, while the traveling 
time in the substrate and the bond coat remains almost the same, as shown in Figure 3.28(c). However, a different trend started to show after 260 hours of exposure. The total time measured on the top coat started to increase compared with those from the previous results. In this figure, the metal/air reflection was lost in four out of five positions gradually due to the occurrence of delamination. The metal/air reflection in Location Two and Three was lost at 400 hours; then, Location One and Four lost their metal/air reflection after 450 hours. Those locations are in the spallation zones which were growing since 350 hours and were visually identified after 400 hours.

The images were recorded at different thermal exposure hours for this coupon to identify the growth of spallation. Picture 3.1 to Picture 3.4 show the growth of spallation at one corner of this René N5 coupon at different thermal stages. The Pulse-Echo reflection from the metal/air interface has been lost at four out of five locations tested after 550 hours. When pulsing from the top coat, the pulsing energy can hardly be transmitted through the delaminated gap between the top coat and bond coat, due to spallations of the top coat at those regions. The Pulse-Echo traveling time result in those remaining location that have the metal/air reflections increased after 550 hours, showing the delamination under this part of the top coat is growing.

In addition, there is also a reduction of the amplitude for the metal/air reflection when pulsing on the top coat side. On the contrary, the amplitude for the bond coat/top coat reflection increased when pulsing on the metal side of the coupon. This phenomenon reveals that there is a growing difference in the characteristic acoustic impedance $\rho \cdot C$ ( $\rho=$ density and $C=$ longitudinal wave speed) between the top coat and the bond coat, due to the reduction of longitudinal wave speed in the top coat, which was inferred to be due to the reduction of the Young's modulus of the top coat. This will lead to the fact that when pulsing on the top coat, the amount of energy reflected back from metal/air interface became smaller, and when pulsing on the metal side, a large portion of the transmitting energy was reflected back from the top coat/bond coat interface which was also observed experimentally. As shown in Figure 3.29 , the ratio between the $1^{\text {st }}(\mathrm{A} 1)$ and $2^{\text {nd }}(\mathrm{A} 2)$ reflection from top coat/bond coat reflection became larger with the increase of exposure hours. This indicates deterioration or delamination appearing at the top coat or the top 
coat/bond coat interface causing an increase in the difference of the acoustic impedance between the bond coat and the top coat, such that less energy could be transmitted through this interface. Meanwhile the amplitude ratio shown in Figure 3.30, which is the ratio between the metal/air reflection and the delay line reflection, became smaller with the increase of exposure hours. It seems that the attenuation becomes larger after each exposure, causing more and more energy loss.

These results also reveal a possibility that voids, micro-crack or delaminations started to show up and the TGO layer was enhanced and grew thicker at the top coat/bond coat interface. This induced the energy dissipation during the propagation when pulsing on the top coat such that the amount of energy reflected back to the top coat from the metal/air interface became smaller as what was observed from the smaller amplitude air/metal reflection. When pulsing on the metal side, the large difference in characteristic acoustic impedance between the void and the bond coat also caused the large reflection of the energy from this interface, leading to the increase of reflection amplitude from bond coat/top coat interface back to the metal surface. The ultrasonic signals indicate that a significant change of material properties is going on in the top coat before the time of failure. This provides a sign that this coupon is approaching its final failure stage. At 350 hours, prediction was made that the coupon was approaching its final failure stage. After 400 hours, a visual spallation was identified on one corner of this isothermal René N5 coupon. Another similar but smaller spallation was also seen on another corner.

\section{(b) Pulse-Echo Tests of Three 2009 Isothermal René N5 Coupons}

Another three René N5 coupons from the second production lot were isothermally exposed under $1100^{\circ} \mathrm{C}$ at WVU. The Pulse-Echo round trip traveling time for these three René N5 Coupons are shown in Figure 3.31 for Coupon \#1, Figure 3.32 for Coupon \#2 and Figure 3.33 for Coupon \#3. The round trip traveling time in the top coat of Coupon \#1, Coupon \#2 and Coupon \#3 are shown in Figure 3.31(a), Figure 3.32(a) and Figure 3.33(a). As shown in Figure 3.31(b), Figure 3.32(b), and Figure 3.33(b), after the first 40 hours of exposure at $1100^{\circ} \mathrm{C}$, the Pulse-Echo total time dropped for all the coupons, meaning the wave speed in the top coat increased compared to the data at as-manufactured state. This is a known result of the sintering effect of the top coat, which causes an increase of the top 
coat Young's modulus, thus leading to the increase of the longitudinal wave speed. The traveling time inside the bond coat and metal did not experience any changes over 200 hours of exposure, as shown in Figure 3.31(c), Figure 3.32(c), and Figure 3.33(c). The round trip traveling time in the top coat dropped after 40 hours, started to increase after 80 hours of exposure, and not much change was registered from 80 hours to 200 hours. The Pulse-Echo results for these René N5 coupons after 200 hours started to show changes. The total traveling time along the thickness of the coupons increased compared to those of the previous isothermal exposure hours. While, the traveling time in the bond coat and substrate had very little variation. As a result, the traveling times in the top coat of these three coupons started to increase. The increase of the traveling time indicates the top coat continued to deteriorate with the thermal exposure. The increase of the traveling time in the top coat with thermal exposure corresponds to a decrease in the wave speed. As a result, the top coat Young's modulus is decreasing, assuming the top coat mass density only has very small change. After 400 hours, the Pulse-Echo results for these three New René N5 coupons show prolonged traveling time. At some location, the metal/air reflection has disappeared, attributed to the internal delamination. A strong warning signal was identified through the Pulse-Echo results after 400 hours exposure for these three coupons and at this point there was no visible crack on the surface of the coupons. All three René N5 coupons failed after this failure prediction. The failure of Coupon \#2 took place after 440 hours of exposure and another two coupons, Coupon \#1 and Coupon \#3 failed after 480 hours of exposure.

The images of these three coupons were tracked and the growth of spallations over the failure process was recorded. The growth of spallation along the edges could be identified in the photos of those coupons. Pictures 3.5 shows the growth of the spallation along one edge of the René N5 coupon \#1 at different thermal stages. As shown in those pictures, a spallation of the top coat at the right corner of this edge was observed after 480 hours. Extending towards the left edge, the length of the spallation grew gradually with the release of the residual stresses at the top coat/bond coat interface. The residual stresses were introduced because of the mismatch of the thermal expansion coefficients between the top coat/bond coat and top coat/TGO. Another four pictures in Picture 3.6 present the growth of the spallation at one edge (Edge one) of Coupon \#2 and Picture 3.7 shows growth of 
spallation along another edge of Coupon \#2 This coupon showed the first spallation at one corner after 440 hour of exposure. Pictures 3.6(a) and (b) show this particular edge at 400 and 440 hours, respectively. Picture 3.6(c) was taken two days after 440 hours, in which the entire edge popped up from the bond coat. Another three pictures from Picture 3.7 (a), (b) and (c) show the growth of the spallation along another edge of this coupon (Edge two) at different stages. Observations made one week after the 440 hours showed no change of length of spallation at Edge One and Edge Two.

The failure process of the New René N5 coupon \#3 is similar to that of Coupon \#1. The first spallation occurred after 480 hours of exposure. The propagation of the spallation lasted for a few days. The following pictures recorded the image of one edge of this coupon at various stages. Pictures 3.8 (a) and (b) show this edge at 440 hours and 480 hours. Pictures 3.8 (c) and (d) show the growth of the spallation in one week's time after the appearance of the first spallation, after accumulating 480 hours of exposure.

The amplitudes of the reflections in Pulse-Echo waveforms for the three isothermal René N5 coupons were also analyzed and compared with each other at various thermal exposure stages. Coupons \#1 and \#3 failed after 480 hours, and Coupon \#2 failed after 440 hours, and similar trends were observed for all three coupons. The amplitude of the top coat/bond coat reflection has a tendency to grow larger after thermal exposure when pulsing on the metal side, while the amplitude of the metal/air reflection was apt to becoming smaller with thermal exposure when pulsing on the top coat side. Figure 3.34 shows the change of the amplitude ratio between $2^{\text {nd }}$ top coat/bond coat reflection (A2) and the $1^{\text {st }}$ top coat/bond coat reflection (A1) for Coupon \#1. Figure 3.35 shows the change of the amplitude ratio between the metal/air reflections (A3) and the delay line reflection for Coupon \#1. From Figure 3.34, the amplitude ratio increased with exposure time, which means more energy was reflected back at the top coat/bond coat when impulse energy was imposed on the metal surface. In Figure 3.35, the amplitude ratio decayed, indicating that less energy was reflected at metal/air interface due to the increase of attenuation inside the TBC layers when impulse was imposed on the top coat surface. The evolution of the amplitudes of those reflections indicates the degradation of the top coat. Same observations of the amplitude change were also observed for Coupon \#2 and Coupon \#3, indicating the 
degradation of the top coat with thermal exposure. Figure 3.36 and Figure 3.37 show the A2/A1 ratio and A3/Delay line ratio for Coupon \#2, respectively. Likewise, Figure 3.38 and Figure 3.39 show the A2/A1 ratio and A3/Delay line ratio for Coupon \#3.

In summary, effectiveness of the Pulse-Echo techniques to identify interface delamination and degradation of TBC system were investigated as a function of exposure time. An early warning signal could be obtained for the occurrence of delamination and spallation before visual confirmation. In Pulse-Echo results, the measured traveling time in the ceramic top coat serves as an indicator of the state of the top coat after each thermal exposure. Amplitudes of the Pulse-Echo waveforms were also used to confirm the traveling time observation to determine the delamination. The top coat thickness could be calculated using the assumed material properties and the Pulse-Echo traveling time.

(c) Pulse-Echo Tests of the Isothermal René N5 Coupons processed by U PITT

The Pulse-Echo traveling times of the René N5 Coupons with long thermal exposure hours from U PITT were obtained. Six René N5 coupons were subjected to isothermal exposure under different temperatures for 100 hours with different stressed condition at $U$ PITT. The Pulse-Echo traveling time measurement was finished for two coupons (\#3, \#24) exposed after 100 -hour exposure under $1100^{\circ} \mathrm{C}$ and shown in Table 3.6. Another six René N5 coupons were subjected to 300 hours isothermal exposure under different temperatures and stress condition. The results for these coupons are shown in Table 3.7 for stressed coupons and Table 3.8 for unstressed coupons. Two coupons (\#28, stressed; \#29 unstressed) were isothermally exposed under $1000^{\circ} \mathrm{C}$ for 1,000 hours. Table 3.9 shows the traveling time in top coat for the René N5 Coupon\#28 (stressed) and Table 3.10 shows the traveling time in the top coat for the Coupon\#29 (unstressed). Coupon \#13 (stressed) and Coupon \#20 (unstressed) were exposed under $900^{\circ} \mathrm{C}$ for 1,000 hours. Table 3.11 and Table 3.12 show the experimental results for these two coupons. Coupon \#18 (stressed) and Coupon \#19 (unstressed) were exposed under $900^{\circ} \mathrm{C}$ for 3,000 hours. These two coupons were intact after exposure. Their Pulse-Echo data are shown in Table 3.13 and Table 3.14, respectively. The traveling time in the top coat for these coupons increased after thermal exposure, indicating the deterioration of the top coat. The difference in the traveling times shown between the five measuring points can indicate that within a coupon the coating materials 
may not be homogeneous and the thickness at these five locations are not identical. Furthermore, results also show that these coupons (as-manufactured) are not identical with each other; There presents differences in the coating thickness and coating material properties. Many of these U PITT coupons are still under further thermal exposure testing at U PITT. Our NDE inspections will follow afterwards. In the mean time, the Pulse-Echo traveling time have been used to calculate the values of the Young's modulus of the top coat of these TBC coupons and the results will be described in Chapter V.

\subsection{FAILURE PROCESS OBSERVATION OF HAYNES 230 COUPON}

The failure process of the Haynes 230 coupon was observed after it was subjected to 60 hours of isothermal exposure under $1100^{\circ} \mathrm{C}$. A small crack was first identified where the receiving sensor was located during the Pitch/Catch experiments. The crack started to propagate with the appearance of a ridge along the crack within several minutes. A schematic drawing of the initial crack is shown in Figure 3.40. Two circles in Figure.3.40 represent the positions of the two sensors. The initial crack appeared under one of the sensors for Pitch/Catch experiment, and it began to propagate on the top coat surface of the coupon in a direction parallel to the right edge of the coupon shown in Figure 3.41. Two horizontal cracks appeared and propagated toward the right edge as shown in Figure 3.41. These cracks happened on the coupon without outside interference in a time period of 10 minutes. The arrows in Figure 3.41 show the directions of crack propagation and the sequence of propagation was numbered. The failure process includes not only the crack propagation but also the split of the top coat along the two sides of the ridge. Figure.3.42 shows the cross sectional view of the top coat ridge formed at the very beginning stage of the whole failure process. The top coat was delaminated and raised to form a ridge. At a certain point, the top coat splitted apart all of a sudden due to the compressive stress on each side of the ridge as shown in Figure 3.43.

At about ten minutes after the initial crack, a sudden eruption of the top coat took place and several pieces of the coating burst and scattered in the vicinity of the coupon. Picture 3.9 shows the crack pattern after the first eruption of the top coat. In Picture 3.9, two pieces of the top coat laid outside the coupon surface due to the eruption. After this first eruption, during the next thirty minutes or so, cracks continue to grow toward the left edge 
of the coupon in a similar manner as was described previously. It took about 42 minutes from the occurrence of the first crack to the final failure. Figure 3.44 shows the numbered direction of the crack propagation over the entire surface. Picture 3.10 to 3.13 shows the pictures of the failed Haynes 230 from different angles.

The failure process reveals the fact that the top coat was under compression from the residual stress due to the mismatch of the thermal properties between the top coat and the bond coat of the coupon. The whole failure process evidently shows the release of the residual stress from the crack growth on the top coat and split of the top coat. The compressive residual stress seems to be of great magnitude, because the whole process finished in a very short period of time and the failure behaved in a fierce way.

\subsection{NONDESTRUCTIVE EVALUATION OF TURBINE BLADE}

\subsubsection{PULSE-ECHO TRAVELING TIME DISTRIBUTION}

A new model turbine blade was inspected using the Pulse-Echo setup to find its ultrasonic response. Figure 3.45 shows the Pulse-Echo waveform captured when pulsing and receiving on the top coat surface of the blade. In Figure 3.45, the reflection from the top coat/bond coat interface can be differentiated from the delay line reflection. Changes of the top coat material properties can be detected by pinpointing the arrival time of the peak of the delay line reflection to the time of the peak of the top coat/bond coat reflection. In addition, the amplitude of this reflection can also be used to identify the material property changes of the top coat and top coat/bond coat interface or any possible occurrence of delamination. The round-trip traveling time in the top coat and in the entire thickness of the blade was measured in the waveform shown in Figure 3.45. The round-trip traveling time in top coat was $180 \mathrm{~ns}$ and the total round-trip traveling time through top coat, bond coat and the substrate metal was $1.186 \mu \mathrm{s}$.

A 3D image of the top coat thickness distribution and metal substrate thickness in terms of Pulse-Echo traveling time was obtained for the model turbine blade at the convex side. Figure 3.46 shows the Pulse-Echo traveling time, in nanoseconds, at different locations on the convex side of the turbine blade. The differences of the traveling times at those locations indicate the top coat might not have the same thickness uniformly sprayed 
onto the substrate of the turbine blade. In Figure 3.46, each column represents the location of the Pulse-Echo inspection point and the height of the column means the traveling time in the top coat at this location. The diameter of the sensor is about $5 \mathrm{~mm}$. The distance between the edges of the two neighboring sensors in the same row is around $15 \mathrm{~mm}$. Between each row, the spacing is also around $15 \mathrm{~mm}$.

The thickness distribution of the substrate metal in terms of traveling time was also obtained for this model turbine blade. Figure 3.47 shows the Pulse-Echo traveling time in the substrate of the blade. The height of each column represents the Pulse-Echo traveling time in the metal substrate. The distance between the edges of the two testing location in the first row (Red) is $15 \mathrm{~mm}$. The distance between the green row and the red row is $22 \mathrm{~mm}$, measuring from the side of the column. From this figure, the Pulse-Echo traveling times at different locations indicate that the metal thickness is not uniform.

\subsubsection{TOP COAT THICKNESS DISTRIBUTION}

Based on the Pulse-Echo data collected for the model turbine blade, the top coat thickness could be calculated using the assumed material properties of the top coat such as Young's Modulus, mass density and Poisson's ratio. In this way, the top coat thickness distribution for the convex side of the turbine blade could be acquired. The material properties of the model Turbine blade were not provided to us. Therefore, we assumed the top coat for the model turbine blade as an APS YSZ top coat, with a mass density $\rho=5300$ $\mathrm{kg} / \mathrm{m}^{3}$, Young's modulus $\mathrm{E}=35 \mathrm{GPa}$, and Poisson's Ratio $\mathrm{v}=0.2$. The longitudinal wave speed was calculated to be $2708 \mathrm{~m} / \mathrm{s}$, based on the above material property assumed. One location (Location 1 on the $1^{\text {st }}$ Row) was selected as an example from the measured roundtrip traveling time of $160 \mathrm{~ns}$, the thickness of the top coat at this location was calculated to be $217 \mu \mathrm{m}$. Using this method, a normalized top coat thickness in other locations could be obtained.

Figure 3.48 shows the normalized top coat thickness distribution with respect to the reference point (Location 1 on the $1^{\text {st }}$ Row) on the turbine blade. A trend could be identified along the width direction from the thin part of the blade to thick part; the calculated top coat thickness becomes thicker, which is indicated in Figure 3.48 (from $1^{\text {st }}$ Row to $3^{\text {rd }}$ Row). A 
3-D graph was generated using the normalized thickness data to show the top coat thickness distribution of that portion of the turbine blade as shown in Figure 3.49. The distance between each data point was measured from the center of sensor location to the other. The zero location point coincides with the center of Location $1,3^{\text {rd }}$ Row where the top coat thickness is calculated to be 1.075 with respect to the reference point (Location $1,1^{\text {st }}$ Row) in Figure 3.49.

The metal plus bond coat thickness can also be calculated using the same way. The material properties of the bond coat are assumed to be very close to those of the metal. The metal substrate was assumed to be René N5 superalloy, with a mass density $\rho=8630 \mathrm{~kg} / \mathrm{m}^{3}$, Young's modulus $\mathrm{E}=213 \mathrm{GPa}$, and Poisson's Ratio $v=0.25$. The longitudinal wave speed was calculated to be $5442 \mathrm{~m} / \mathrm{s}$. In the calculation of the thickness, for simplicity, we assume the same material properties for bond coat as the metal substrate. The normalized thickness distribution with respect to the thickness of the point (Location $1,1^{\text {st }}$ Row) and its corresponding locations are shown in Figure 3.50. It seems that the thickness becomes smaller along the longitudinal direction (Y-axis) of the turbine blade (from Location 1 to 7 and from A to E). A change of normalized metal plus bond coat thickness along the longitudinal direction of the turbine blade was plotted for test location from 1 to 7 , and from A to E. Figure 3.51 shows the thickness change from Location 1 to 7; Figure 3.52 shows the thickness change from Location A to E. 


\section{Specimen(coating side)}

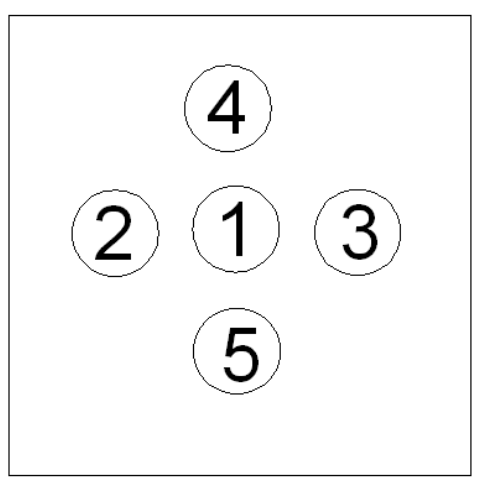

Figure 3.1 Pulse-Echo testing location

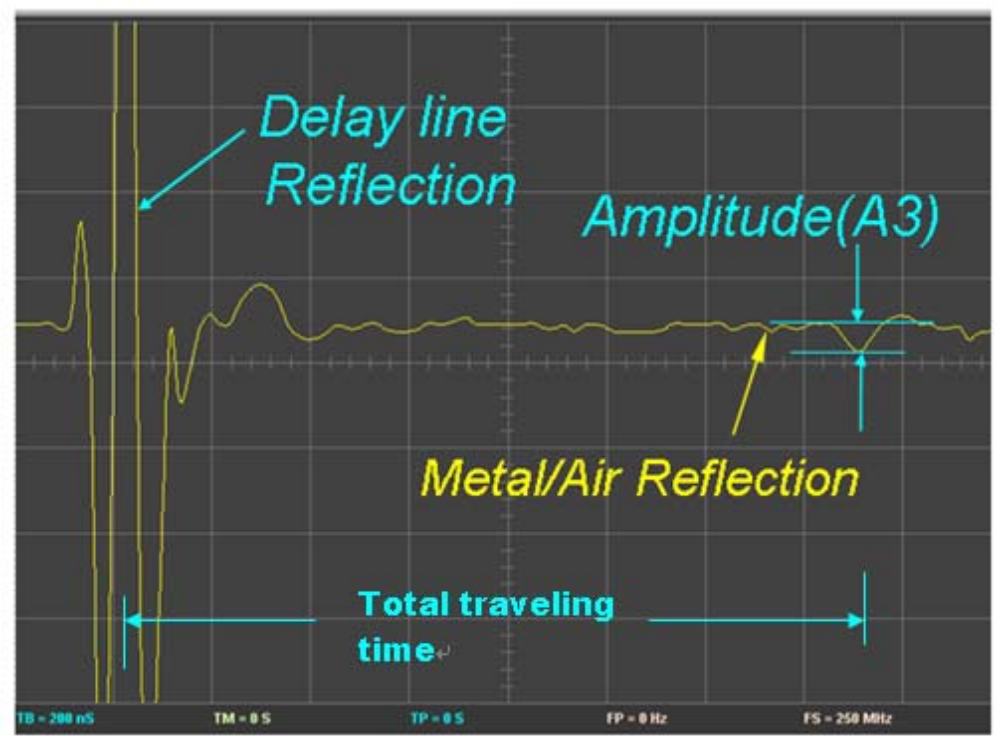

Figure 3.2 Pulse-Echo signal pulsing on the top coat

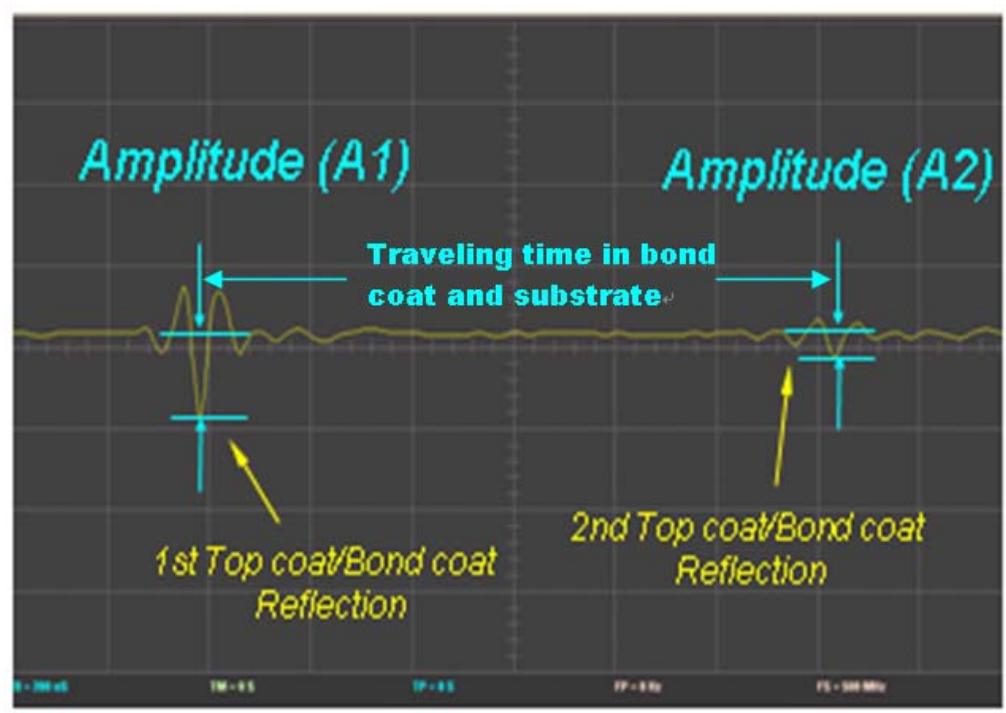

Figure 3.3 Pulse-Echo signal pulsing on the metal side 


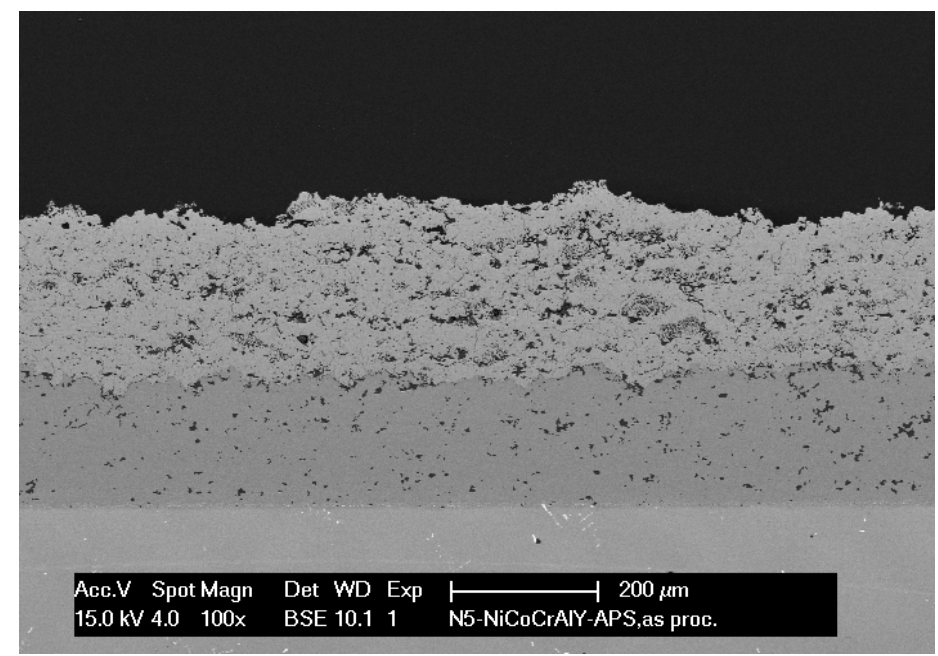

Figure 3.4 René N5/MCrA1Y/APS YSZ coupon cross-section under SEM

(Alvin et al., 2007)

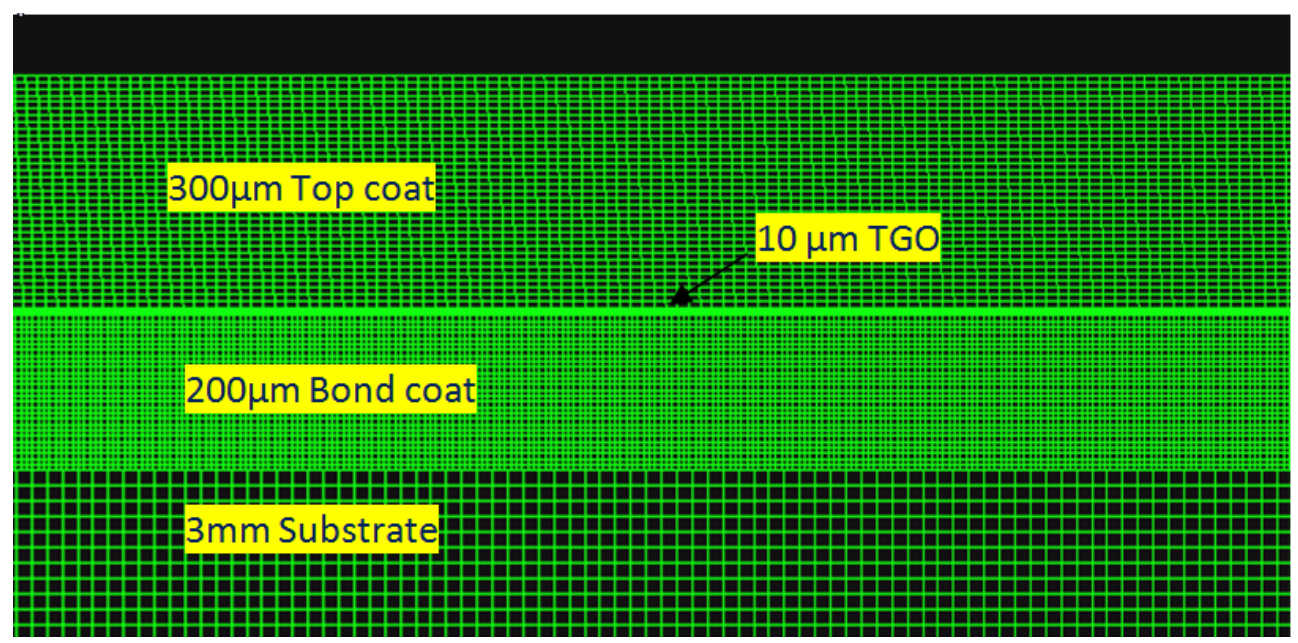

Figure 3.5 TBC model for FEA

Table 3.1 Material properties for Finite Element analysis of Pitch/Catch

\begin{tabular}{|c|c|c|c|c|c|}
\hline Part & \multicolumn{3}{|c|}{$\begin{array}{c}\text { Young' s Modulus } \\
(\mathrm{GPa})\end{array}$} & $\begin{array}{c}\text { Mass Density } \\
\left(\mathrm{kg} / \mathrm{m}^{3}\right)\end{array}$ & Poison Ratio \\
\hline Substrate & 211 & 211 & 211 & 8970 & 0.25 \\
\hline Bond Coat & 200 & 200 & 150 & 7176 & 0.3 \\
\hline TGO & -- & 400 & 300 & 3970 & 0.23 \\
\hline Top Coat & 50 & 50 & 20 & 5100 & 0.2 \\
\hline
\end{tabular}




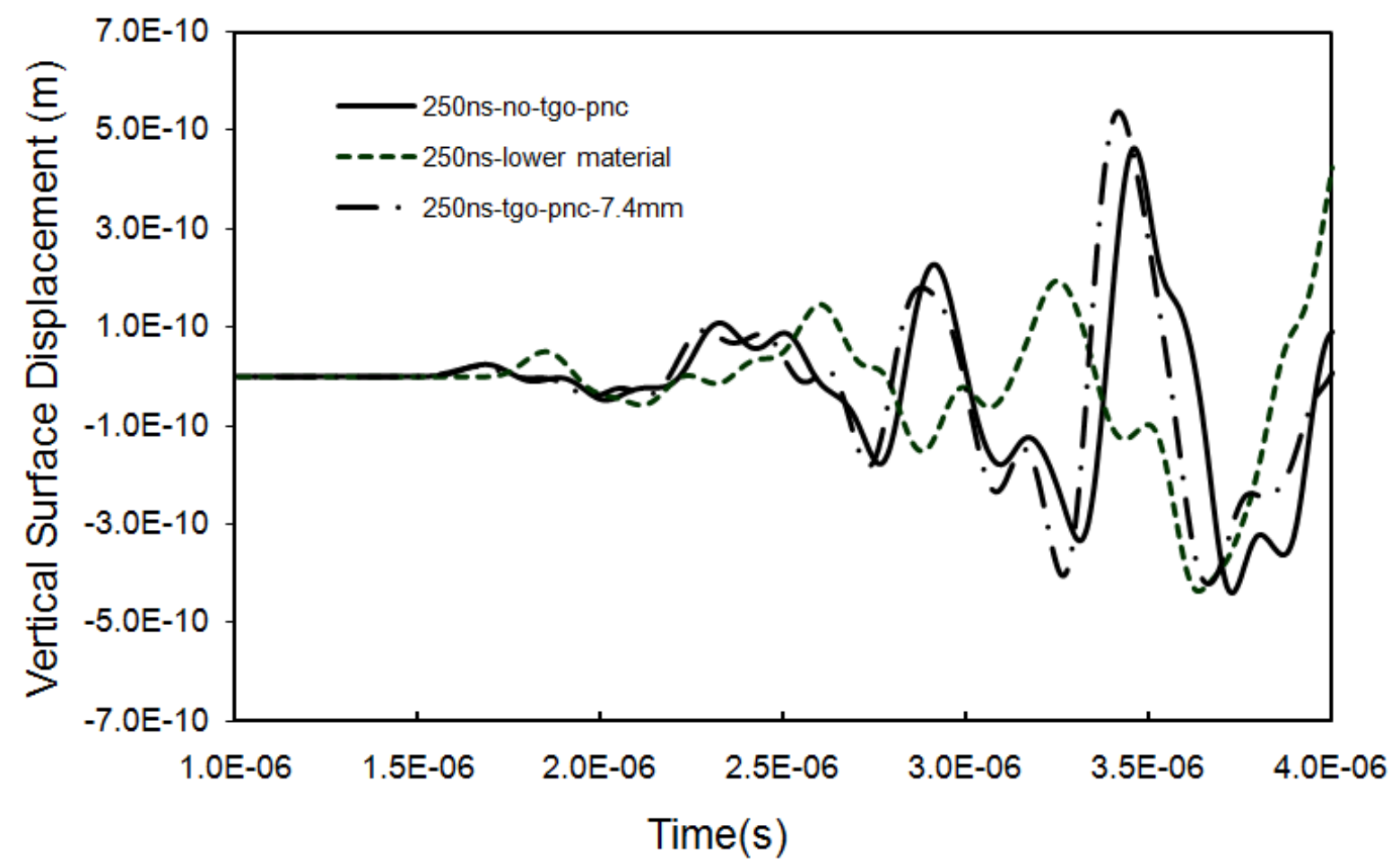

Figure 3.6 Output Pitch/Catch waveforms for TBC under different conditions

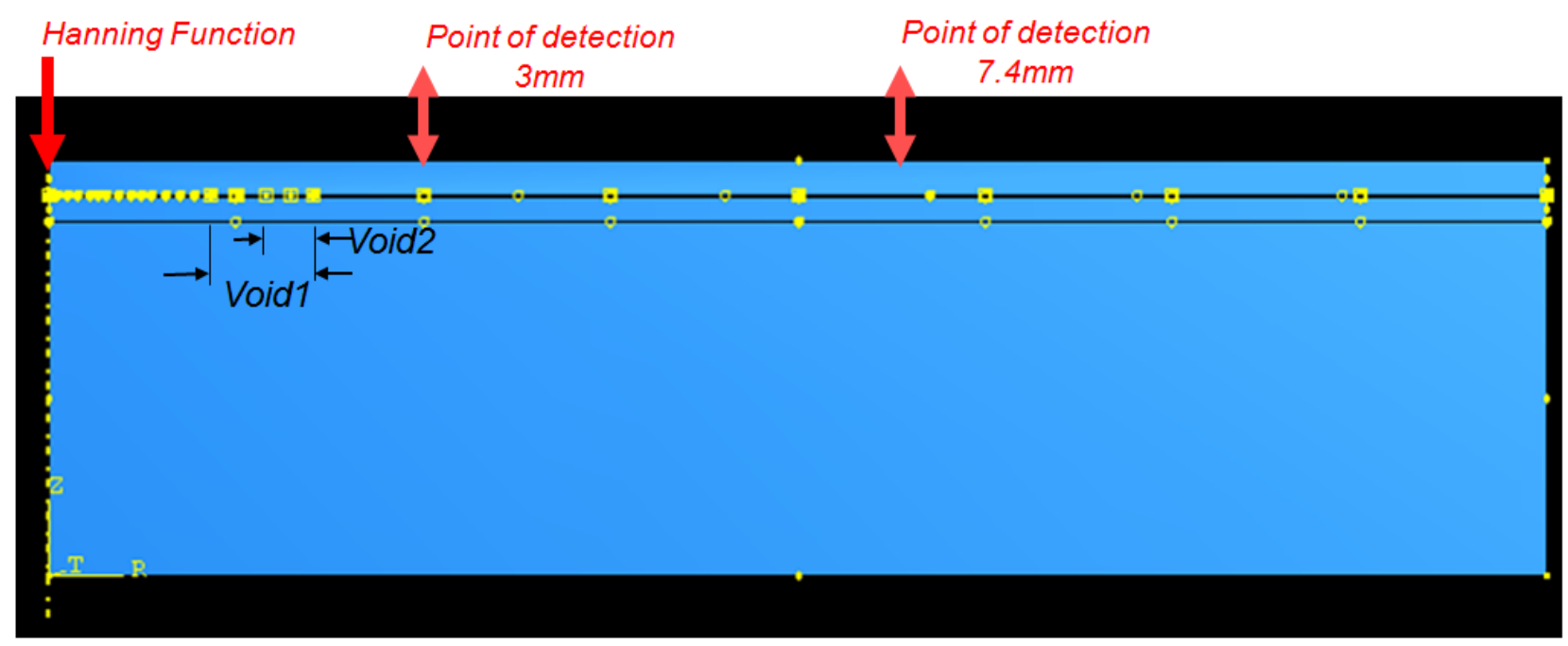

Figure 3.7 TBC model with voids 


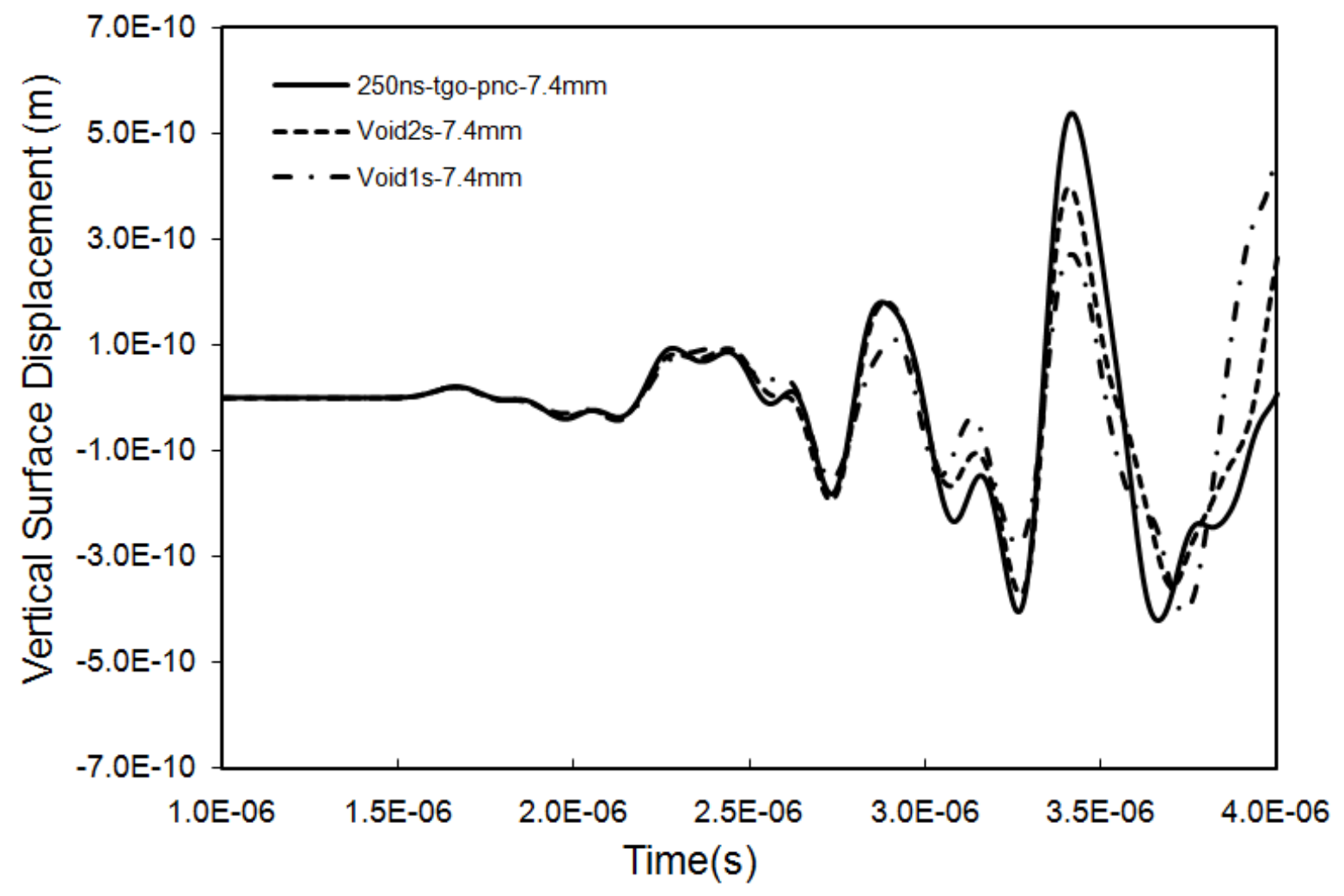

Figure 3.8 Comparison of output waveforms at $7.4 \mathrm{~mm}$ from origin

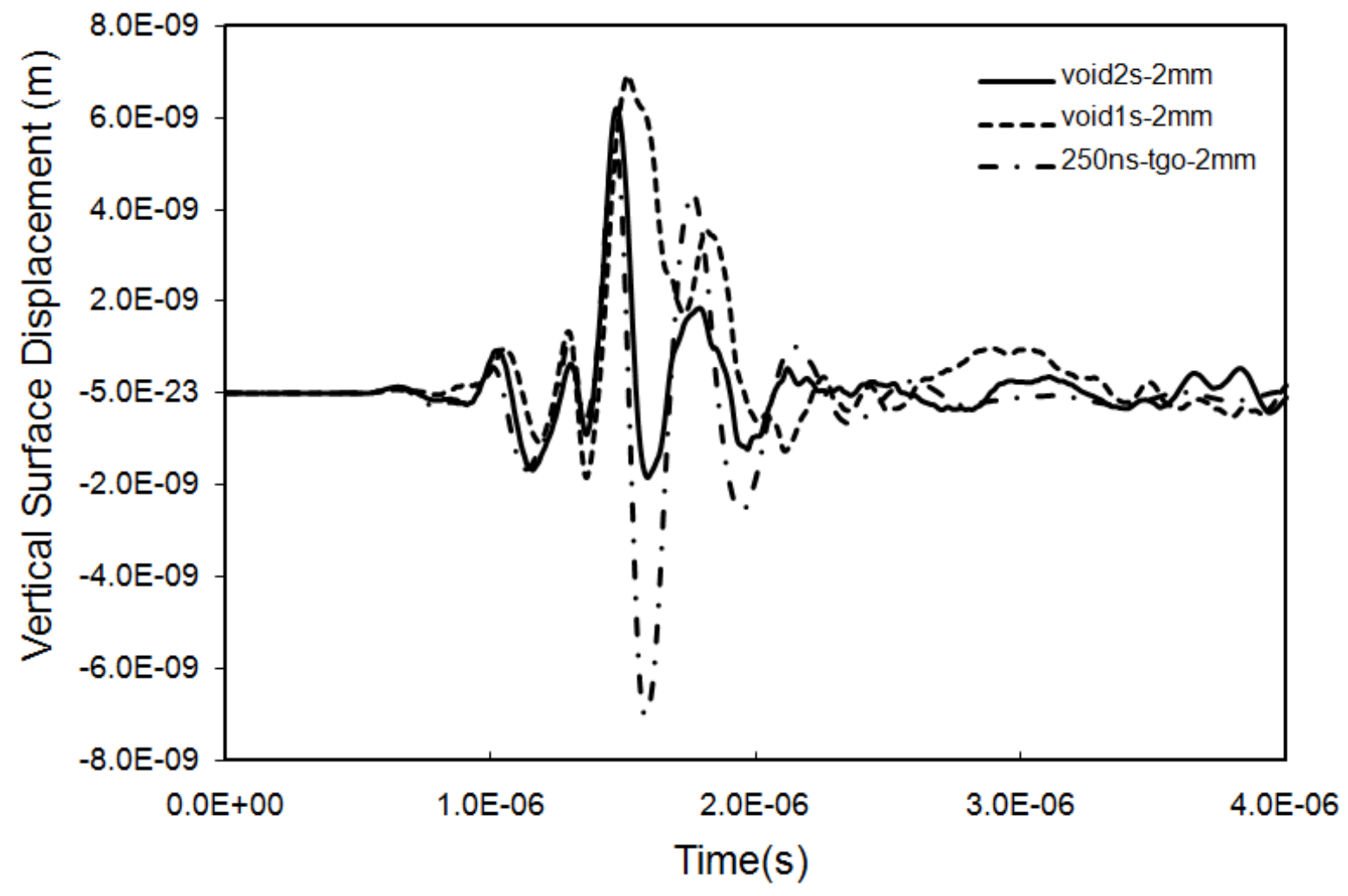

Figure 3.9 Comparison of output waveforms at $3 \mathrm{~mm}$ from origin 


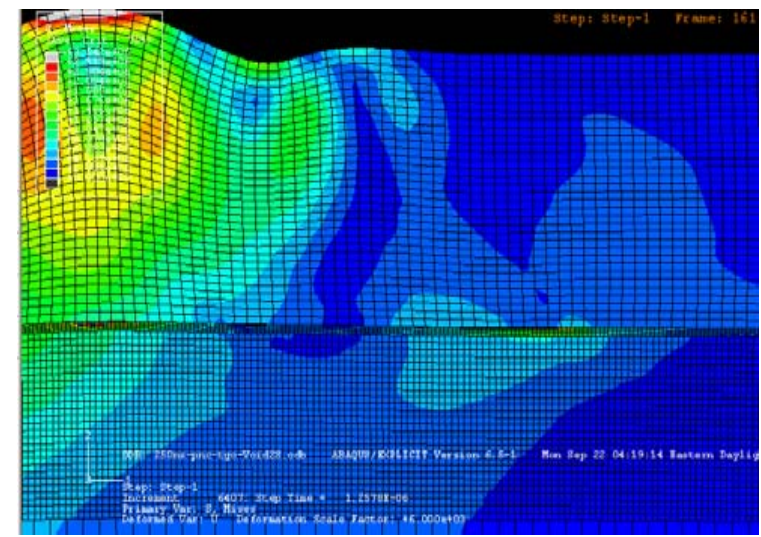

$1.25 \mu \mathrm{s}$

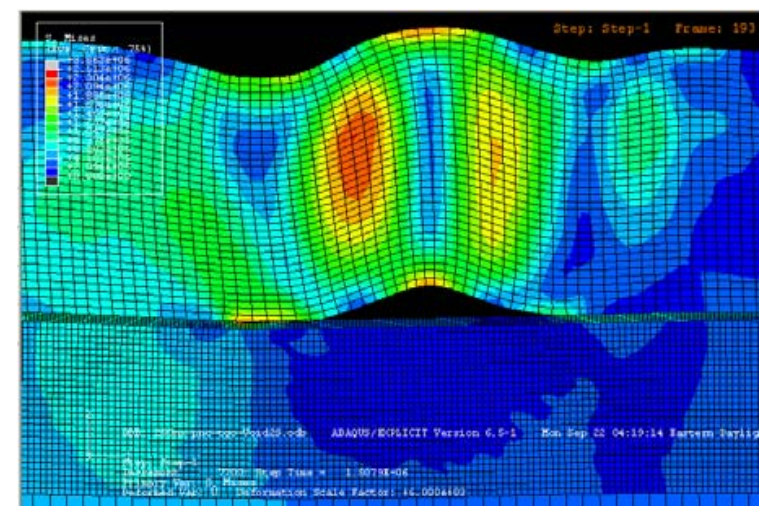

$1.51 \mu \mathrm{s}$

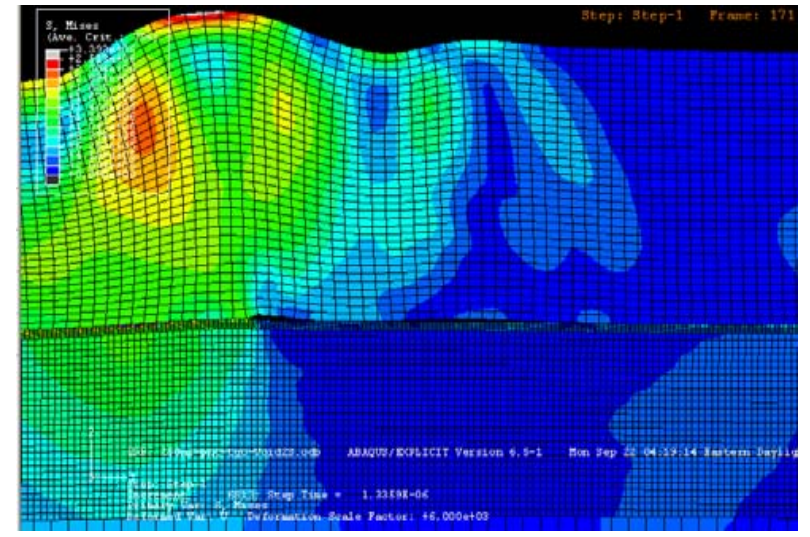

$1.33 \mu \mathrm{s}$

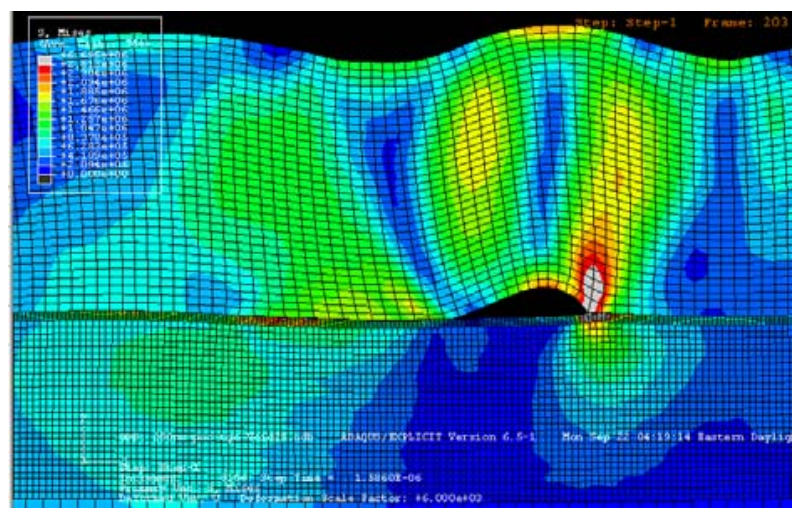

$1.58 \mu \mathrm{s}$

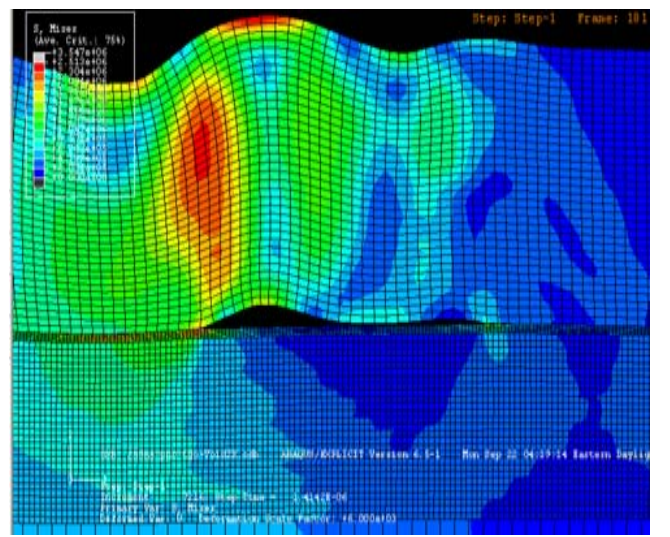

$1.41 \mu \mathrm{s}$

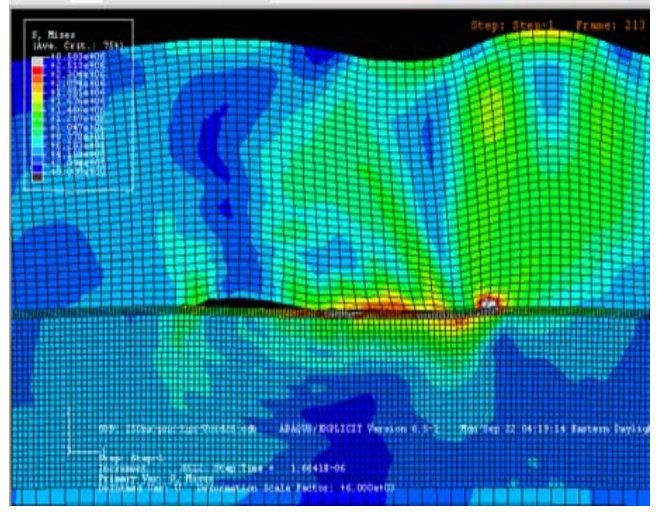

$1.66 \mu \mathrm{s}$

Figure 3.10 Stress wave propagating through the TGO with delamination at $1.25 \mu \mathrm{s}, 1.33 \mu \mathrm{s}, 1.41 \mu \mathrm{s}, 1.51 \mu \mathrm{s}, 1.58 \mu \mathrm{s}, 1.66 \mu \mathrm{s}$ after the loading 


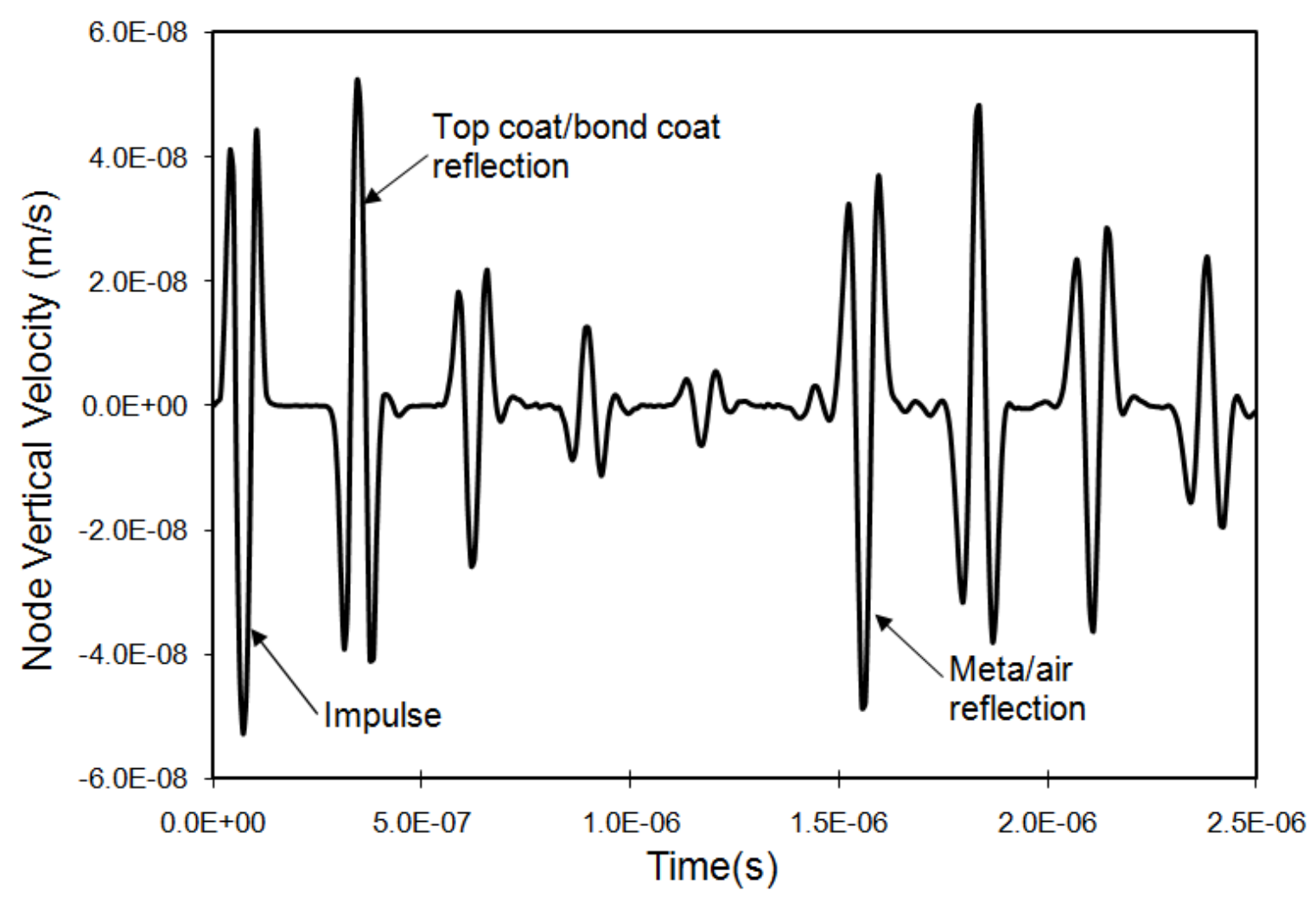

Figure 3.11 Finite Element simulation of nodal velocity on top coat surface due to uniform pressure impulse applied on top coat

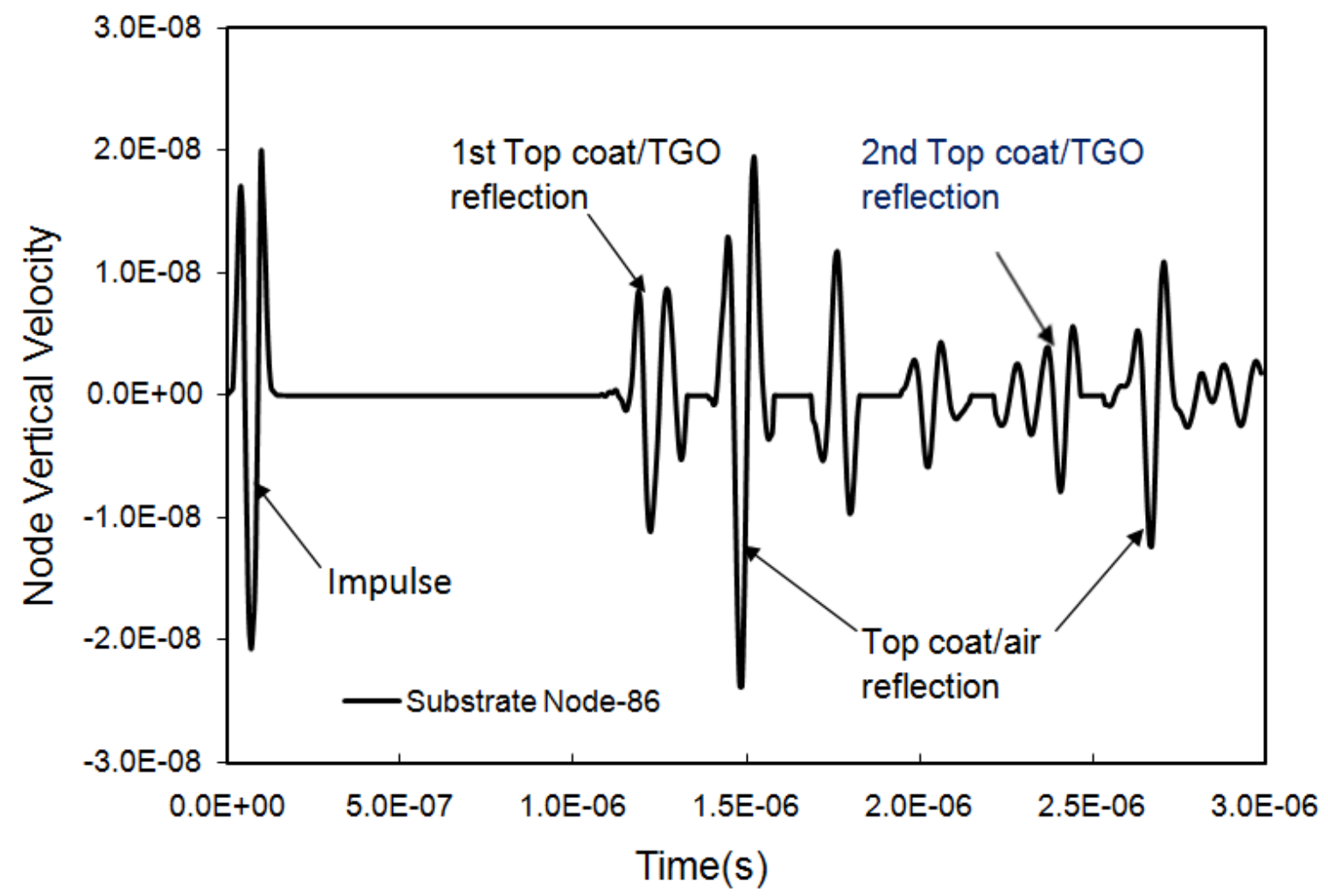

Figure 3.12 Vertical velocity of node \# 1 on the surface of the substrate 


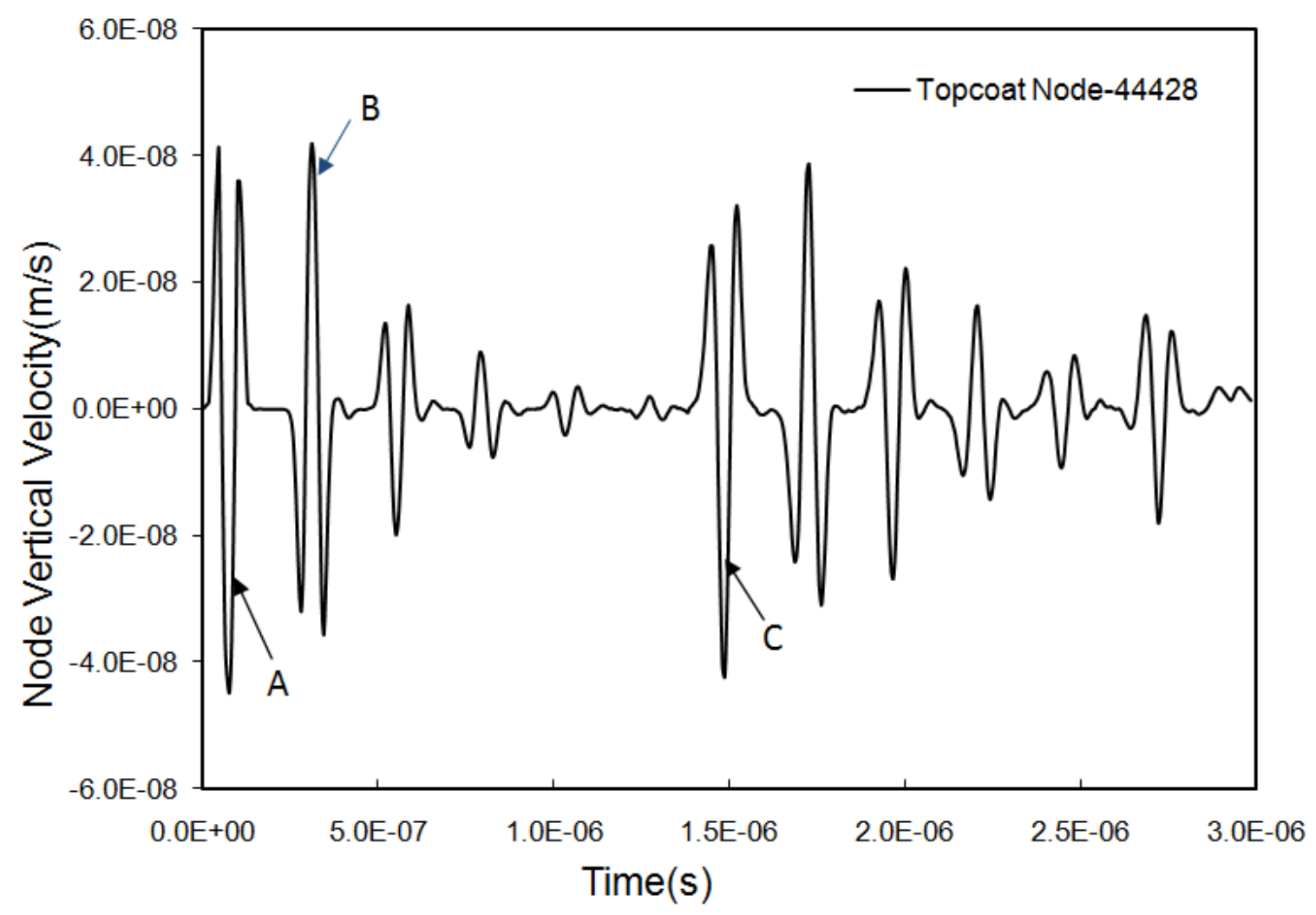

Figure 3.13 Pulse-Echo simulation results (WVU-N5)

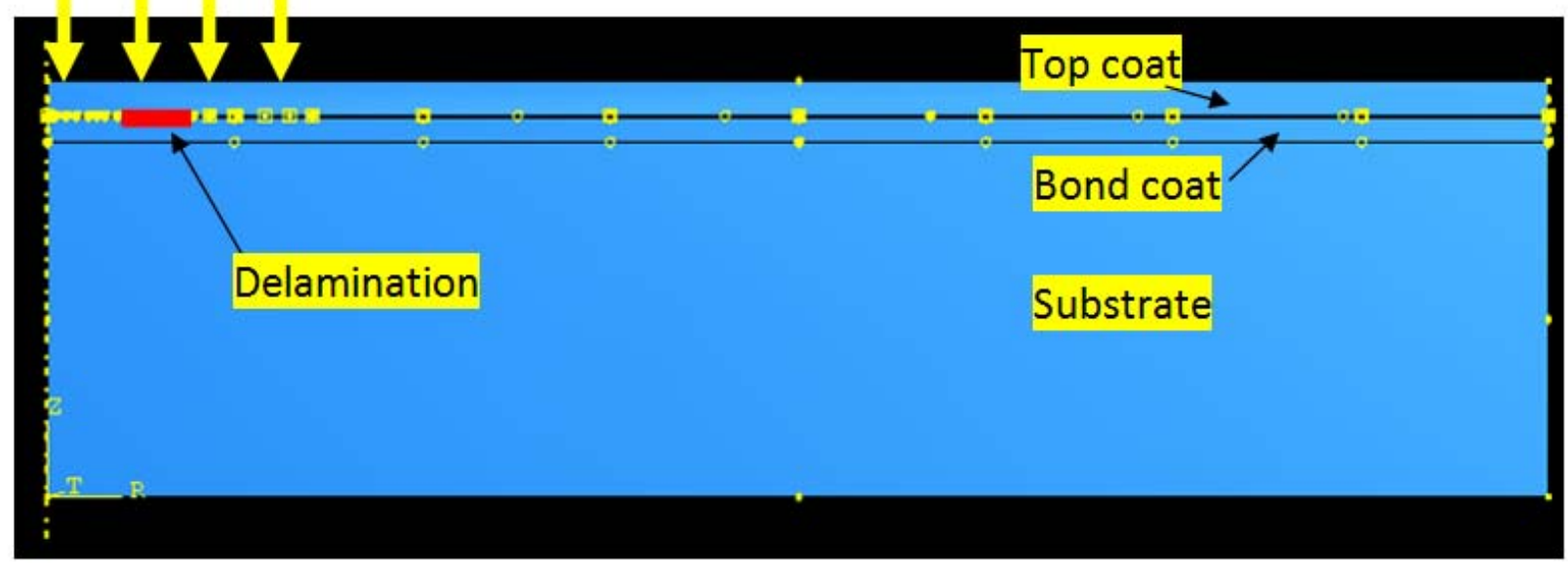

Figure 3.14 FEM model with delamination for Pulse-Echo when pulsing on the top coat 


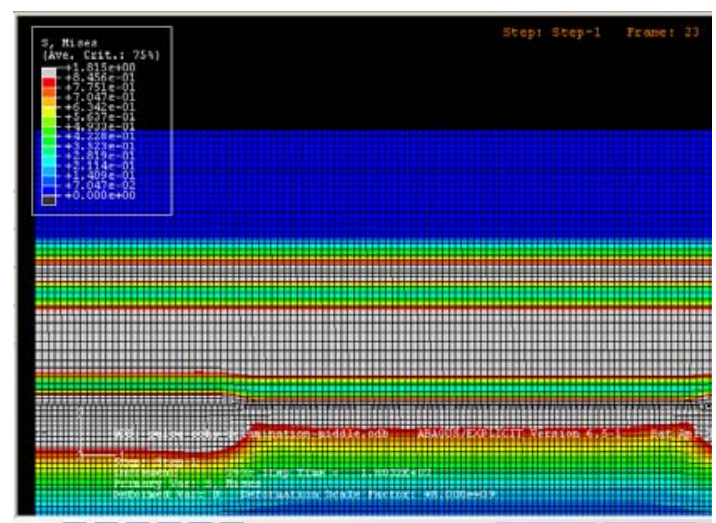

Figure 3.15 Wave propagates through the delamination at $0.1800 \mu \mathrm{s}$

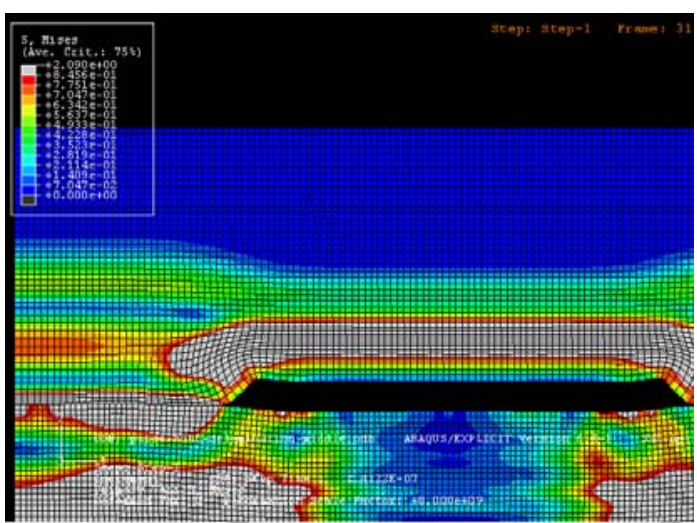

Figure 3.16 The opening of delamination at time $0.2442 \mu \mathrm{s}$

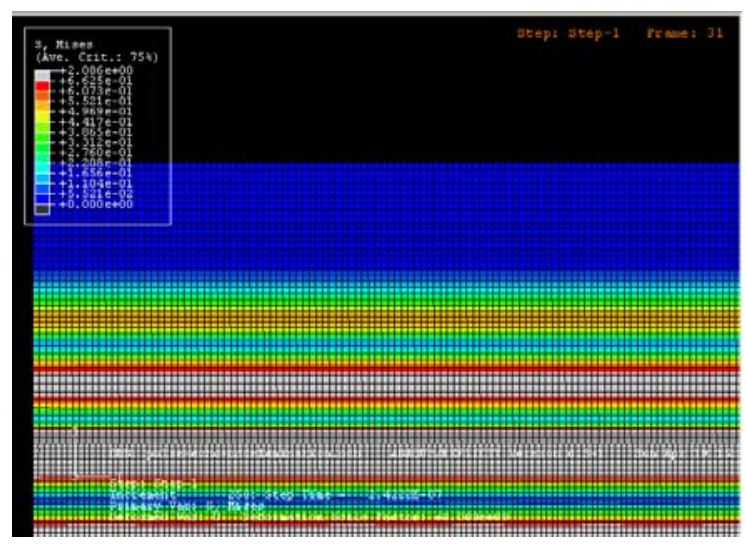

Figure 3.17 Wave propagates through top coat (no delamination) at time $0.2442 \mu \mathrm{s}$

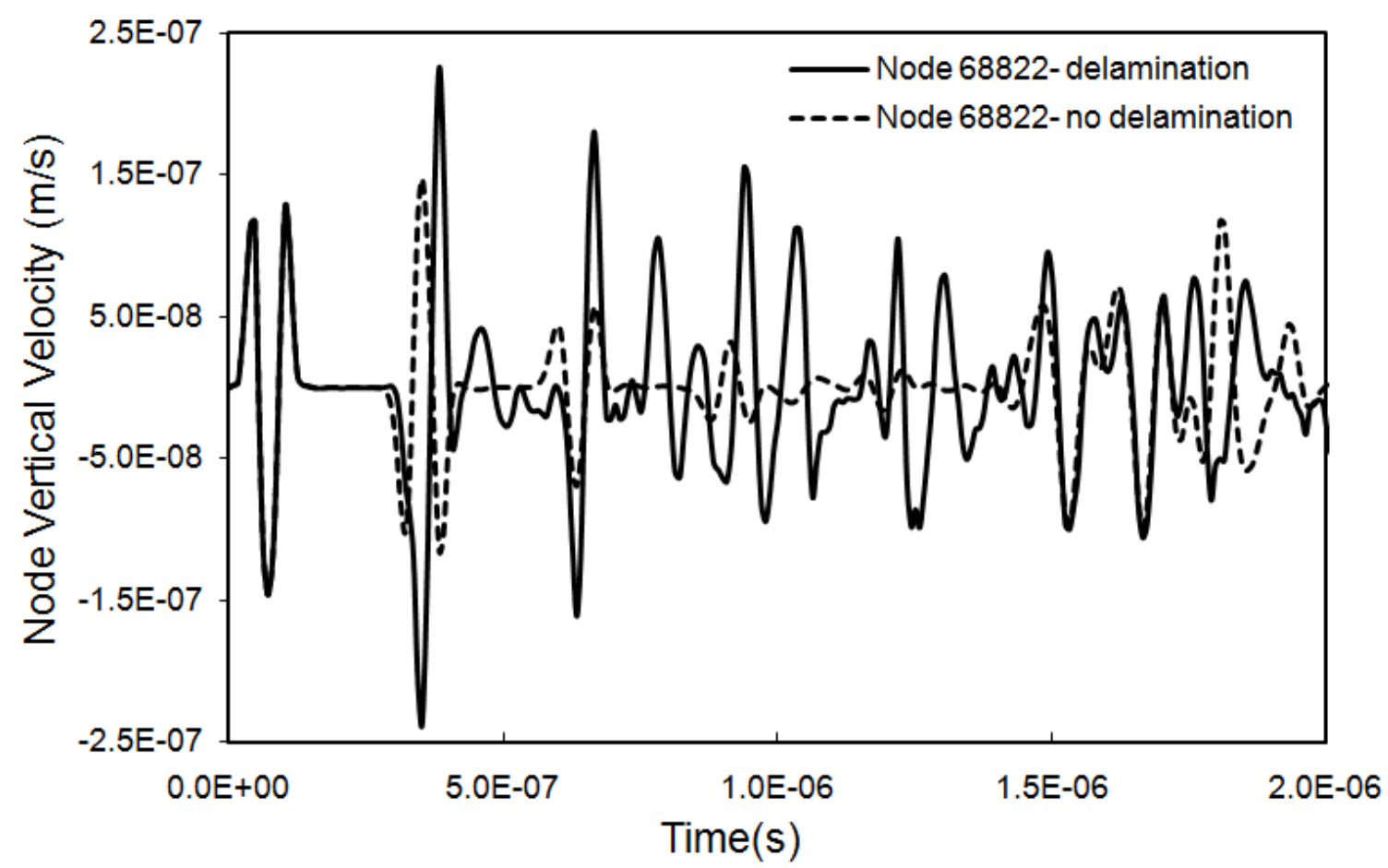

Figure 3.18 Top coat node \# 68822 velocity time history 


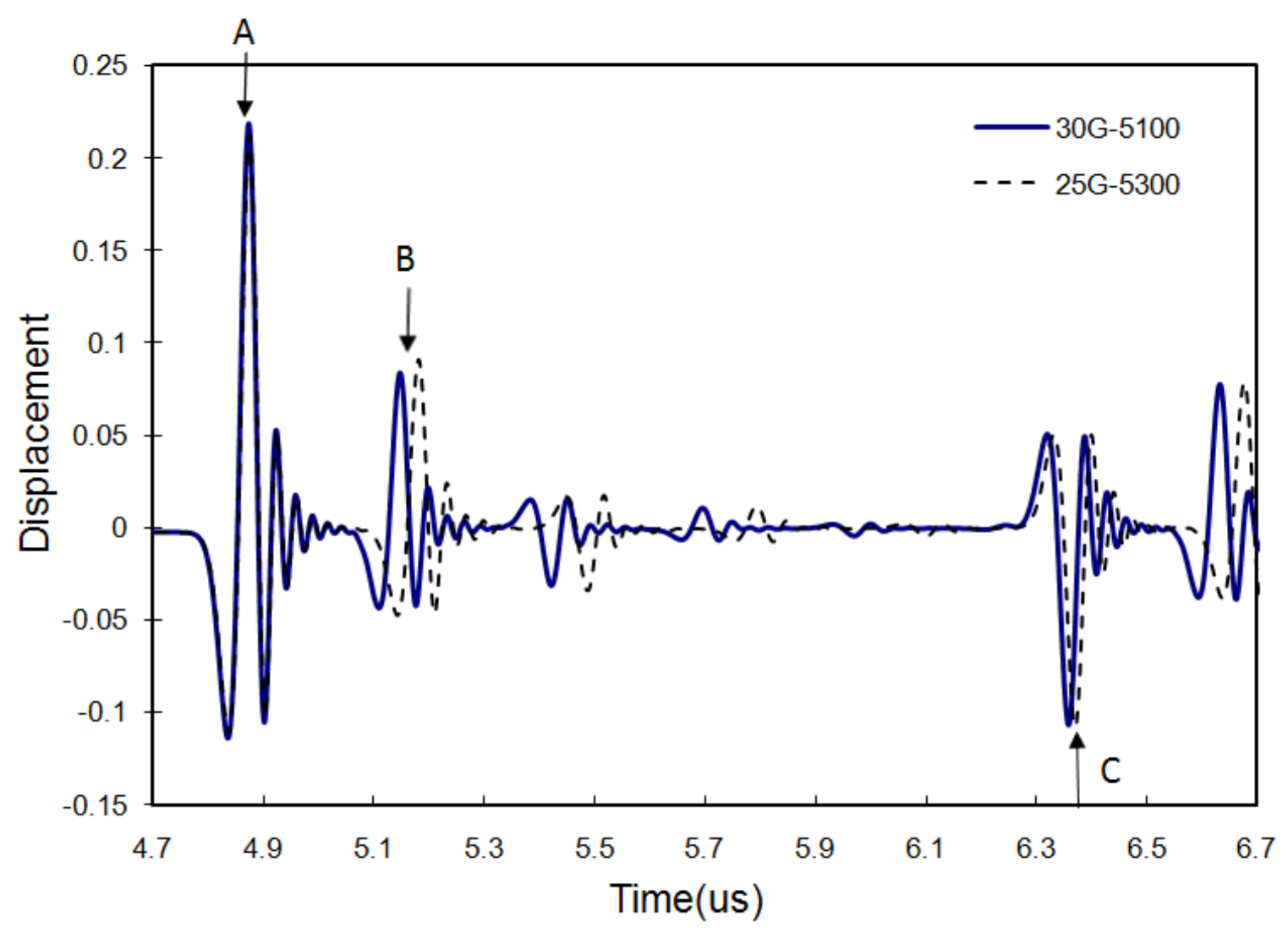

Figure 3.19 Pulse-Echo comparisons from simulation

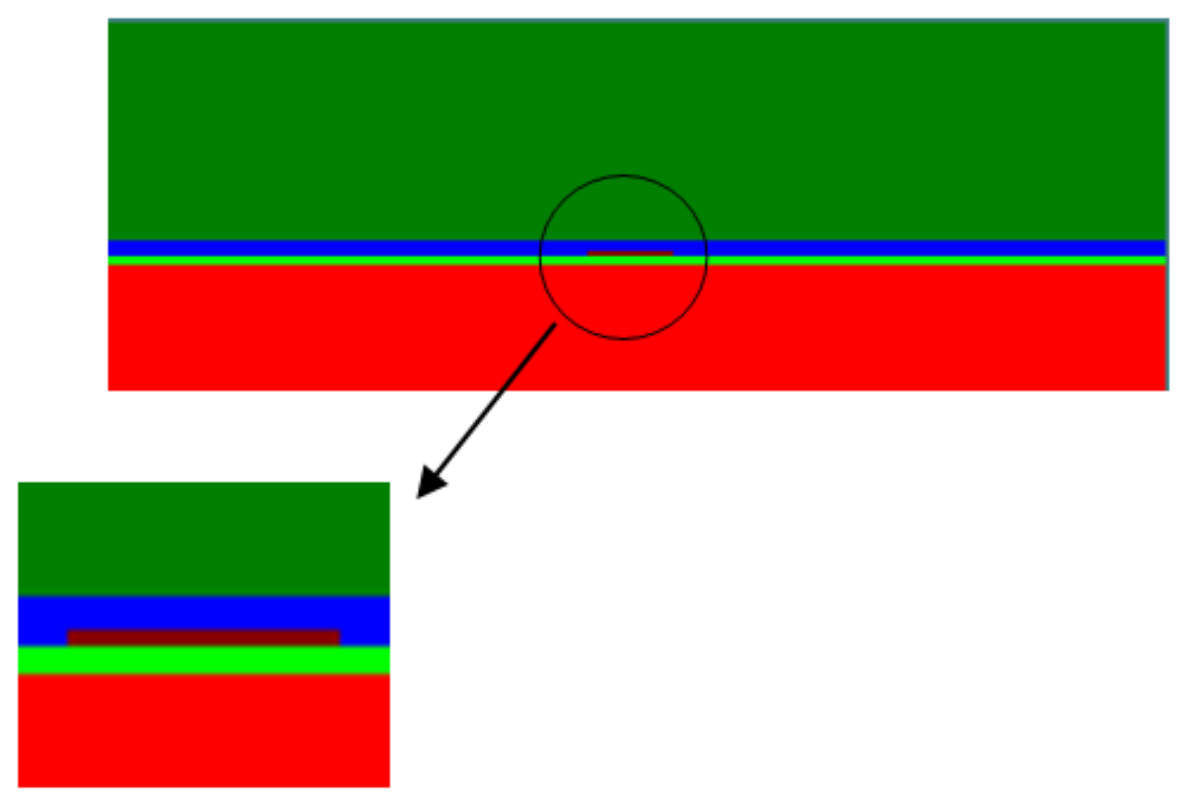

Figure 3.20 TBC model with void in Wave2000 


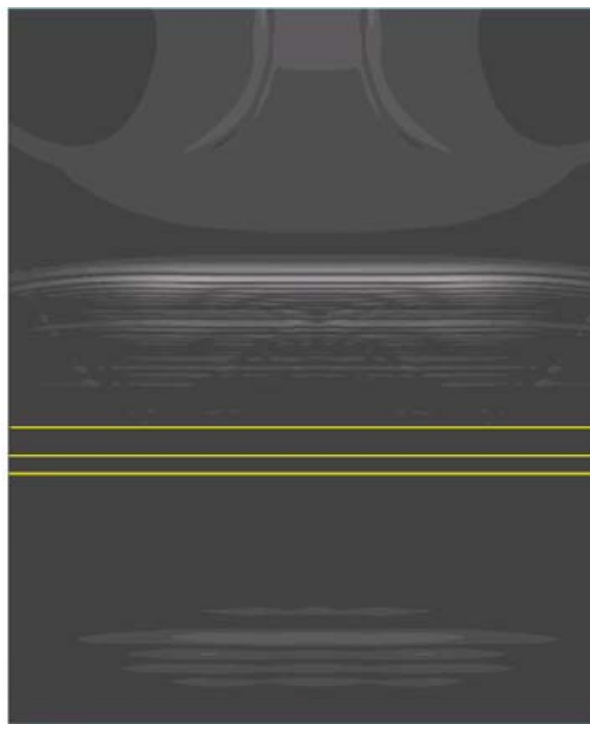

Figure 3.21 Top coat/bond coat reflection at $5.18 \mu$ s after the initial loading

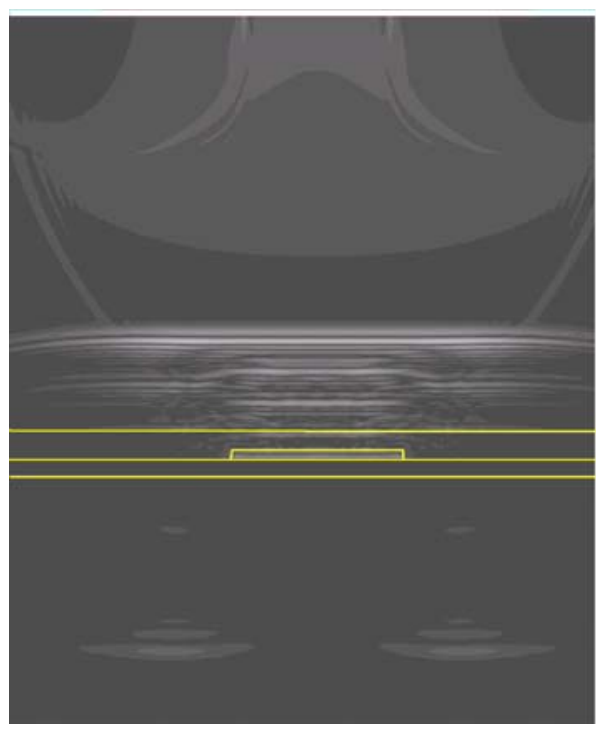

Figure 3.22 Top coat/bond coat reflection at $5.16 \mu$ s after the initial loading

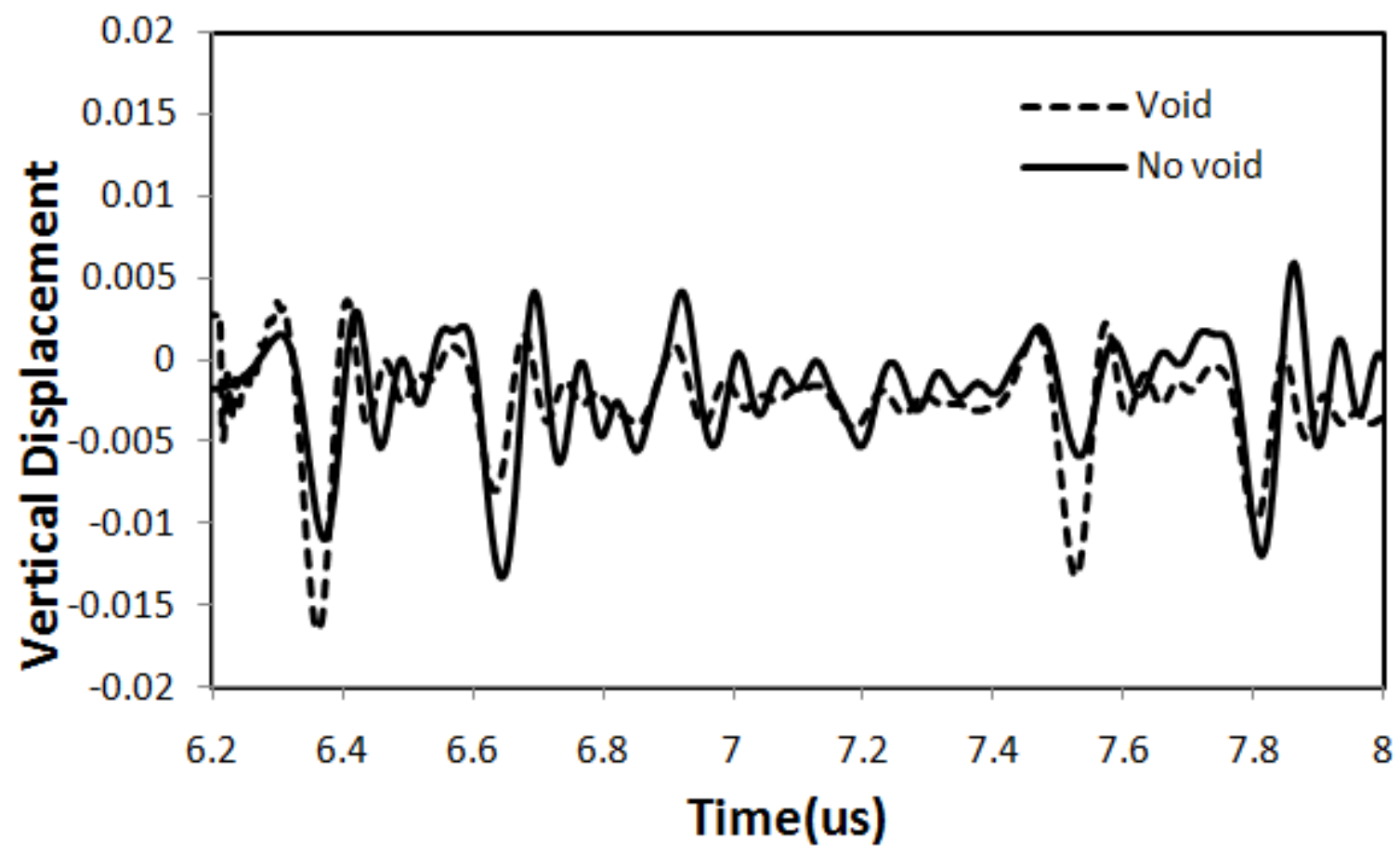

Figure 3.23 Waveforms pulsing from metal side using Wave2000 


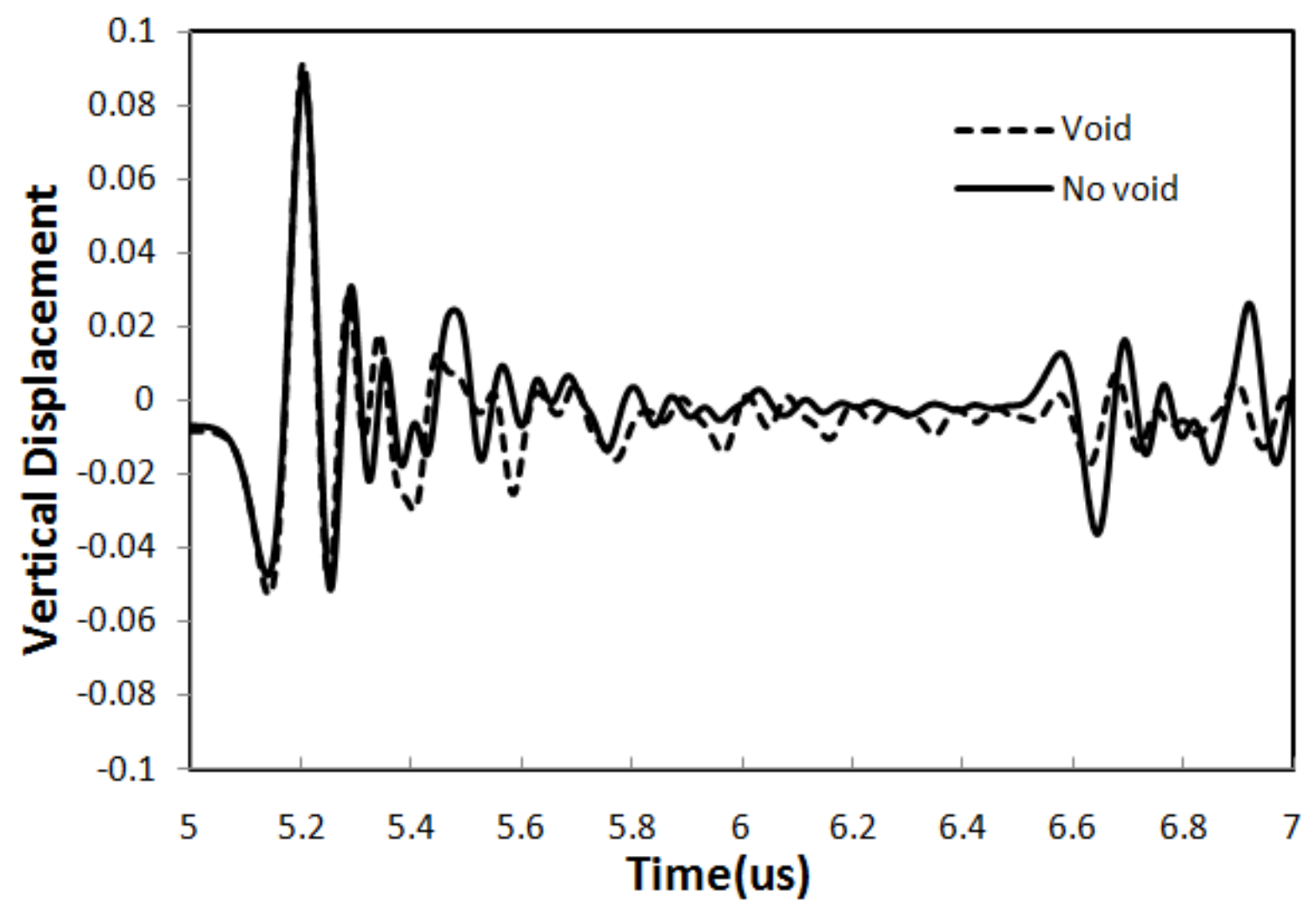

Figure 3.24 Waveforms pulsing from top coat side using Wave2000

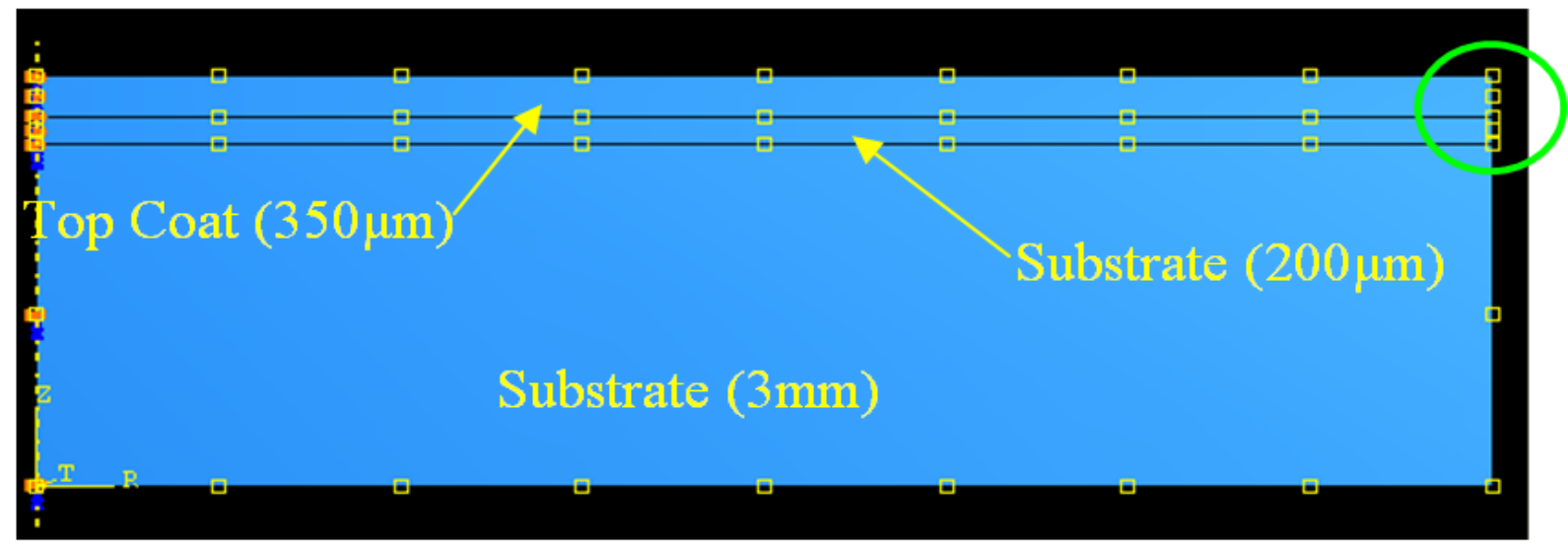

Figure 3.25 FEM model of TBC Coupon for thermal analysis 


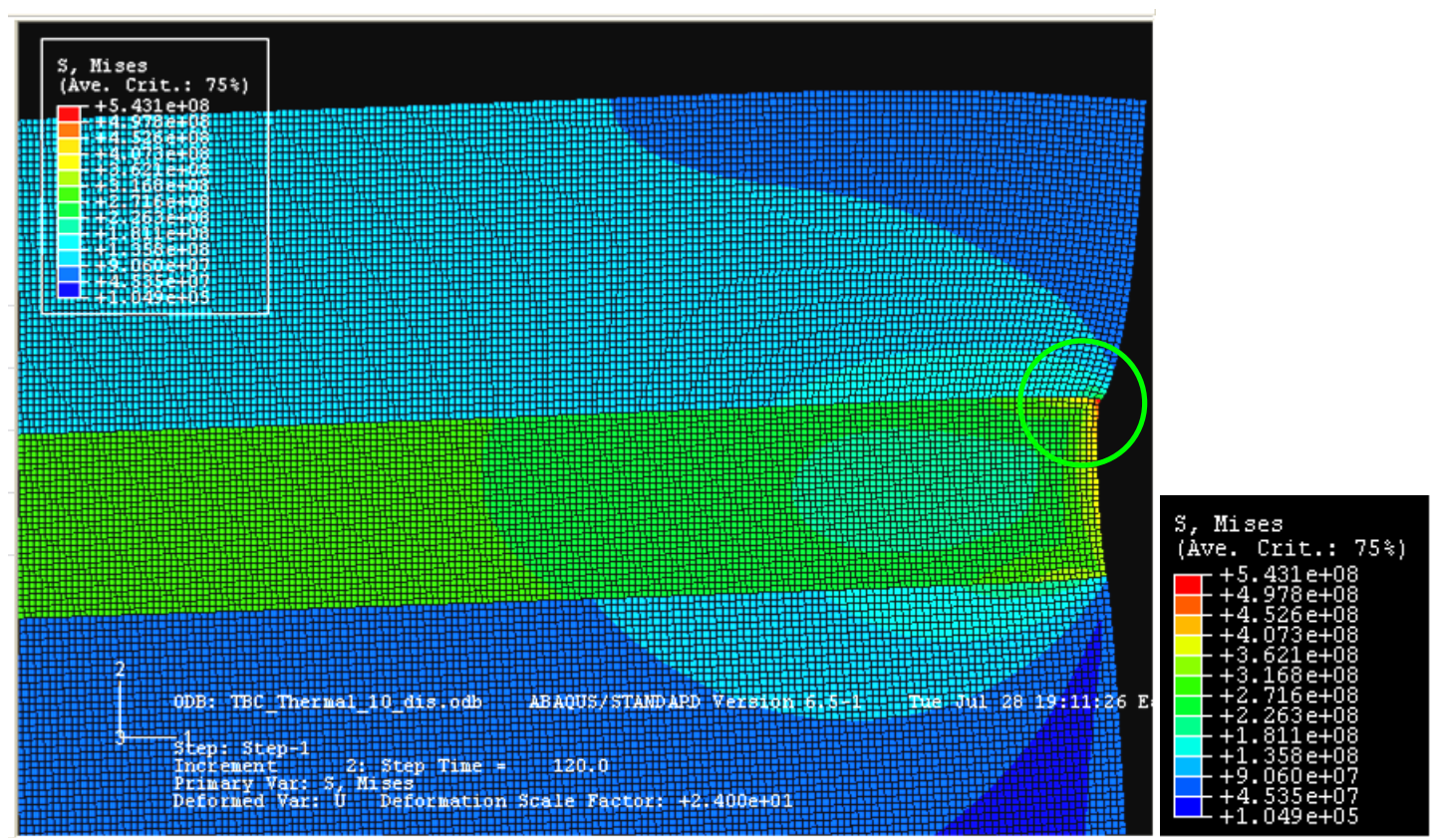

Figure 3.26 Deformed shape and Von Mises stress of TBC thermal analysis

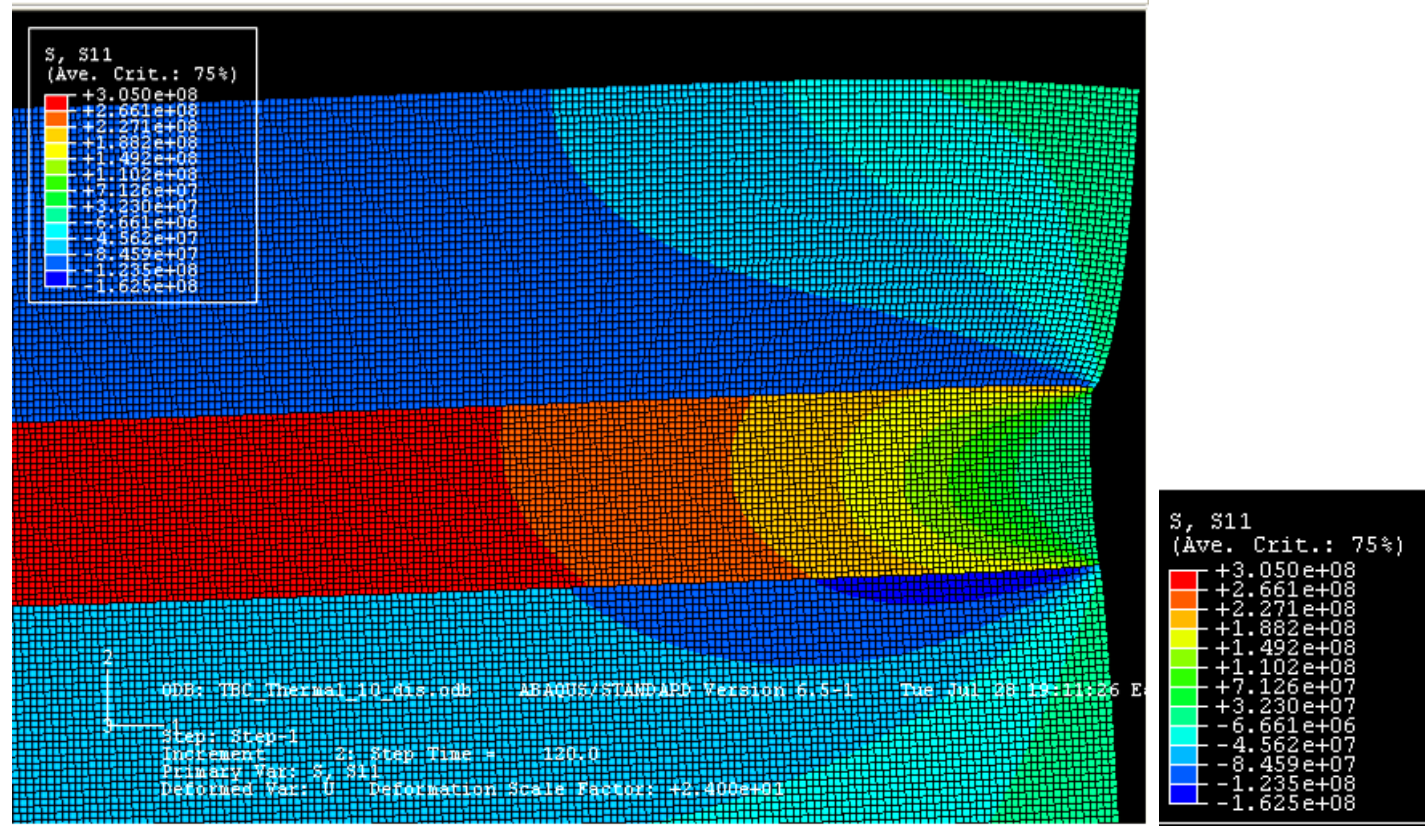

Figure 3.27 Horizontal stress (S11) of TBC thermal analysis 
Table 3.2 Pitch/Catch waveform arrival time for isothermal coupons

\begin{tabular}{|c|c|c|}
\hline \multicolumn{3}{|c|}{$\begin{array}{l}\text { ACOUSTO-ULTRASONIC ASSESSMENT } \\
\text { PITCH/CATCH ARRIVAL TIME ( } \mu \mathrm{s}) \\
\text { ISOTHERMAL COUPON } \\
-1100^{\circ} \mathrm{C} \text { ISOTHERMAL OXIDATION - }\end{array}$} \\
\hline $\begin{array}{c}\text { Exposure Time, } \\
\text { Hrs }\end{array}$ & $\begin{array}{c}\text { René } \\
\text { N5/MCrAIY/APS }\end{array}$ & $\begin{array}{c}\text { Haynes } \\
\text { 230/MCrAIY/EBPVD }\end{array}$ \\
\hline As-Manufactured & $4.46 \pm 0.05$ & $4.10 \pm 0.00$ \\
\hline 10 & $4.46 \pm 0.05$ & $4.10 \pm 0.00$ \\
\hline 20 & $4.54 \pm 0.05$ & $4.12 \pm 0.04$ \\
\hline 30 & $4.48 \pm 0.04$ & $4.14 \pm 0.05$ \\
\hline 40 & $4.42 \pm 0.16$ & $4.00 \pm 0.10$ \\
\hline 50 & $4.44 \pm 0.11$ & $4.04 \pm 0.05$ \\
\hline 60(Gel) & $3.84 \pm 0.05$ & $3.94 \pm 0.05$ \\
\hline 85 & $3.80 \pm 0.07$ & N/A \\
\hline 110 & $3.86 \pm 0.05$ & N/A \\
\hline 135 & $3.90 \pm 0.00$ & N/A \\
\hline 160 & $3.84 \pm 0.05$ & N/A \\
\hline 185 & $3.82 \pm 0.04$ & N/A \\
\hline 210 & $3.86 \pm 0.05$ & N/A \\
\hline 235 & $3.90 \pm 0.00$ & $\mathrm{~N} / \mathrm{A}$ \\
\hline
\end{tabular}

Table 3.3 Pitch/Catch waveform arrival time for cyclic coupons

\begin{tabular}{|c|c|c|}
\hline \multicolumn{3}{|c|}{$\begin{array}{c}\text { ACOUSTO-ULTRASONIC ASSESSMENT } \\
\text { PITCH/CATCH ARRIVAL TIME ( } \mu \mathrm{s}) \\
\text { CYCLIC COUPON }\end{array}$} \\
\hline $\begin{array}{c}\text { Exposure Time, } \\
\text { Hrs }\end{array}$ & $\begin{array}{c}\text { René } \\
\text { N5/MCrAIY/APS }\end{array}$ & $\begin{array}{c}\text { Haynes } \\
\text { 230/MCrAIY/EBPVD }\end{array}$ \\
\hline As-Manufactured & $3.62 \pm 0.04$ & $4.20 \pm 0.00$ \\
\hline 20 & $3.62 \pm 0.04$ & $4.24 \pm 0.05$ \\
\hline 40 & $3.58 \pm 0.04$ & $4.28 \pm 0.04$ \\
\hline 60 & $4.86 \pm 0.13$ & $4.28 \pm 0.04$ \\
\hline $80(\mathrm{Gel})$ & $4.44 \pm 0.09$ & $\mathrm{~N} / \mathrm{A}$ \\
\hline 100 & $4.42 \pm 0.04$ & N/A \\
\hline Waveform arrival d & $\begin{array}{r}\text { nd shape change st } \\
\text { coupon }\end{array}$ & 50-cycle of PITT Ren \\
\hline
\end{tabular}


Table 3.4 Pitch/Catch waveform arrival time for 100-hour coupons

\begin{tabular}{|c|c|c|c|c|c|c|}
\hline \multicolumn{7}{|c|}{$\begin{array}{l}\text { ION TESTING - ACOUSTO-ULTRASONIC ASSESSMEN' } \\
\text { PITCH/CATCH WAVEFORM ARRIVAL TIME } \\
\text { - ISOTHERMAL EXPOSURE - }\end{array}$} \\
\hline \multicolumn{7}{|c|}{ Stressed René N5/MCrAIY/APS Coupons } \\
\hline \multirow[b]{2}{*}{ Time, Hrs } & \multicolumn{6}{|c|}{ Temperature, ${ }^{\circ} \mathrm{C}$} \\
\hline & $900(\# 12)$ & waveform & $1000(\# 4)$ & waveform & $1100(\# 3)$ & waveform \\
\hline As-Manufactured & $4.18 \pm 0.04$ & -- & $4.18 \pm 0.08$ & -- & $4.06 \pm 0.05$ & -- \\
\hline 100 & $4.24 \pm 0.02$ & delay & $4.1 \pm 0.00$ & forward & $4.02 \pm 0.04$ & forward \\
\hline \multicolumn{7}{|c|}{ Unstressed René N5/MCrAIY/APS Coupons } \\
\hline \multirow[b]{2}{*}{ Time, Hrs } & \multicolumn{6}{|c|}{$\begin{array}{l}\text { Temperature, }{ }^{\circ} \mathrm{C} \\
\end{array}$} \\
\hline & 900(\#11) & waveform & $1000(\# 5)$ & waveform & $1100(\# 24)$ & waveform \\
\hline As-Manufactured & $4.14 \pm 0.05$ & -- & $3.96 \pm 0.05$ & -- & $4.14 \pm 0.05$ & -- \\
\hline 100 & $4.22 \pm 0.11$ & delay & $3.96 \pm 0.05$ & No change & $4.10 \pm 0.00$ & forward \\
\hline *Forward: $\mathrm{r}$ & $\begin{array}{l}\text { elay: recei } \\
\text { jed wavefor }\end{array}$ & $\begin{array}{l}\text { waveform } \\
\text { s move tov }\end{array}$ & $\begin{array}{l}\text { delayed (wa } \\
\text { rds the trigg }\end{array}$ & $\begin{array}{l}\text { ve speed red } \\
\text { r signal (wa) }\end{array}$ & $\begin{array}{l}\text { ced) } \\
\text { e speed incr }\end{array}$ & ised) \\
\hline
\end{tabular}

Table.3.5 Pitch/Catch waveform arrival time for 300-hour coupons

\begin{tabular}{|c|c|c|c|c|c|c|c|c|c|c|c|c|}
\hline \multicolumn{13}{|c|}{$\begin{array}{c}\text { VALIDATION TESTING - ACOUSTO-ULTRASONIC ASSESSMENT } \\
\text { PITCH/CATCH WAVEFORM ARRIVAL TIME( } \mu \mathrm{s}) \\
\text { - ISOTHERMAL EXPOSURE - }\end{array}$} \\
\hline \multicolumn{13}{|c|}{ Stressed René N5/MCrAIY/APS Coupons } \\
\hline \multirow{2}{*}{\multicolumn{2}{|c|}{ Time, Hrs }} & \multicolumn{11}{|c|}{ Temperature, ${ }^{\circ} \mathrm{C}$} \\
\hline & & \multicolumn{2}{|c|}{ 900(\#9) } & \multicolumn{2}{|c|}{ waveform } & \multicolumn{2}{|c|}{$1000(\# 10)$} & \multicolumn{2}{|c|}{ waveform } & \multicolumn{2}{|c|}{$1100(\# 7)$} & waveform \\
\hline \multicolumn{2}{|c|}{ As-Manufactured } & \multicolumn{2}{|c|}{$4.2 \pm 0.00$} & \multicolumn{2}{|c|}{--} & \multicolumn{2}{|c|}{$4.10 \pm 0.00$} & \multicolumn{2}{|c|}{--} & \multicolumn{2}{|c|}{$4.10 \pm 0.00$} & -- \\
\hline \multicolumn{2}{|c|}{$\mathbf{3 0 0}$} & \multicolumn{2}{|c|}{$3.84 \pm 0.05$} & \multicolumn{2}{|c|}{ forward } & \multicolumn{2}{|c|}{$3.84 \pm 0.05$} & \multicolumn{2}{|c|}{ forward } & \multicolumn{2}{|c|}{$3.88 \pm 0.08$} & forward \\
\hline \multicolumn{13}{|c|}{ Unstressed René N5/MCrAIY/APS Coupons } \\
\hline \multirow[b]{2}{*}{ Time, Hrs } & \multicolumn{12}{|c|}{ Temperature, ${ }^{\circ} \mathrm{C}$} \\
\hline & \multicolumn{2}{|c|}{$900(\# 14)$} & & $\begin{array}{l}\text { avefor } \\
\mathrm{m}\end{array}$ & \multicolumn{2}{|c|}{$1000(\# 6)$} & \multicolumn{2}{|c|}{ waveform } & \multicolumn{2}{|c|}{$1100(\# 16)$} & \multicolumn{2}{|c|}{ waveform } \\
\hline $\begin{array}{c}\text { As- } \\
\text { Manufactured }\end{array}$ & \multicolumn{2}{|c|}{$3.96 \pm 0.05$} & \multicolumn{2}{|c|}{--} & \multicolumn{2}{|c|}{$4.12 \pm 0.05$} & \multicolumn{2}{|c|}{--} & \multicolumn{2}{|c|}{$4.2 \pm 0.05$} & \multicolumn{2}{|r|}{--} \\
\hline 300 & \multicolumn{2}{|c|}{$3.56 \pm 0.05$} & & rward & 3.7 & $4 \pm 0.05$ & for & ward & 3.92 & \pm 0.04 & & orward \\
\hline
\end{tabular}




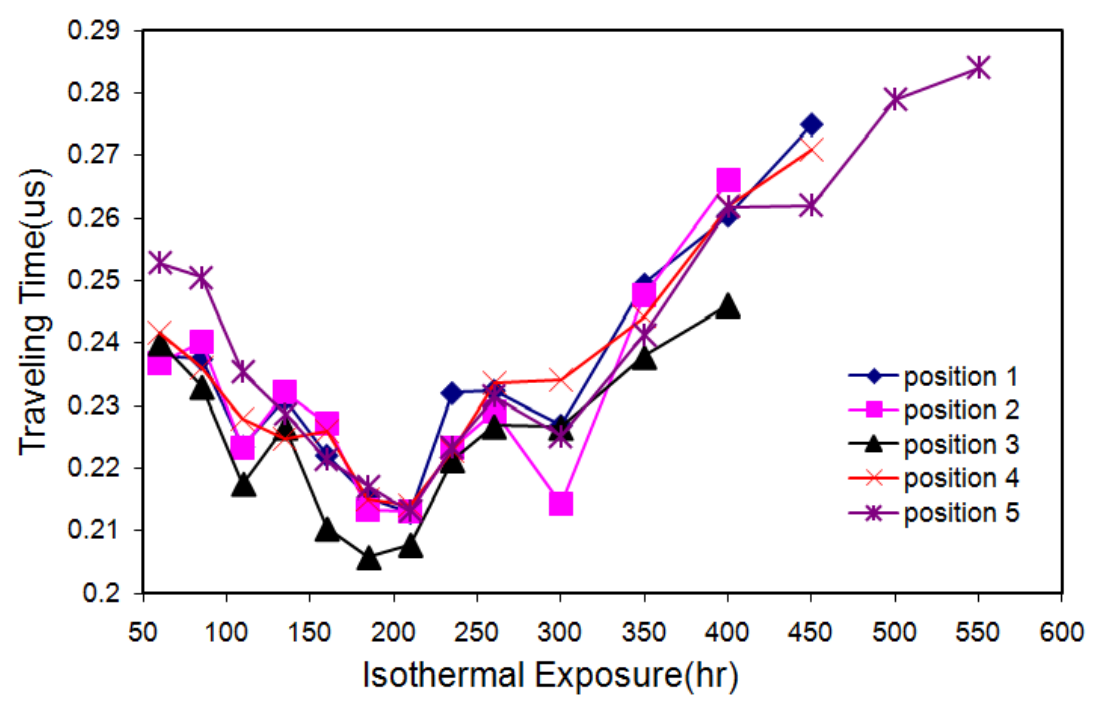

(a) Round trip traveling time in the top coat of the first isothermal René N5 coupon

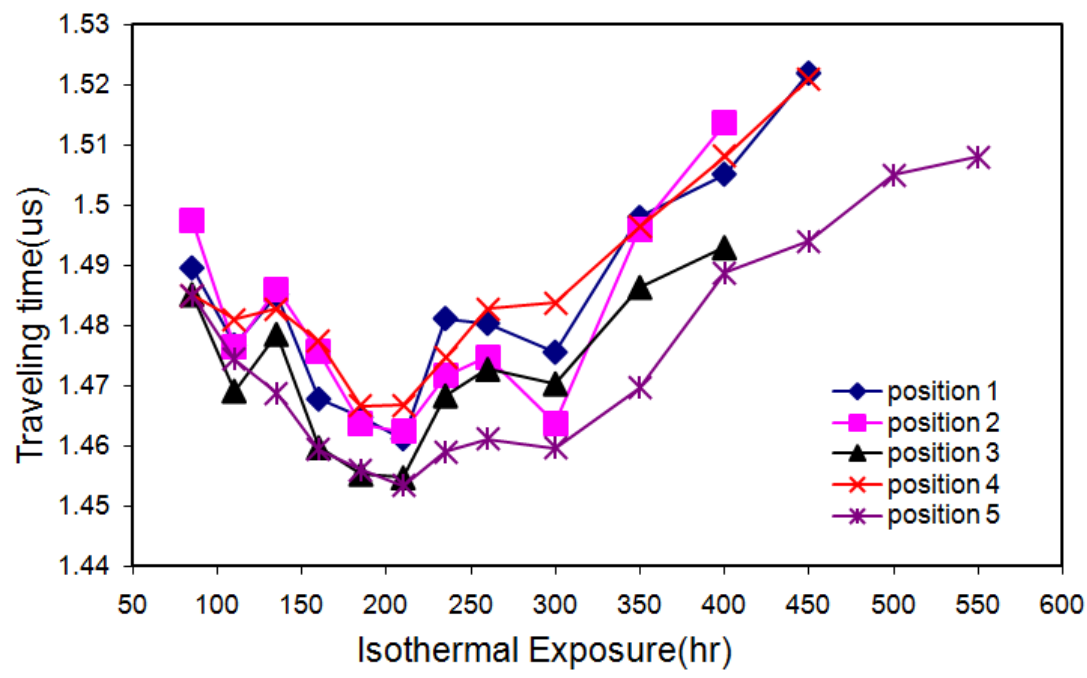

(b) Total traveling time in the first isothermal René N5 coupon

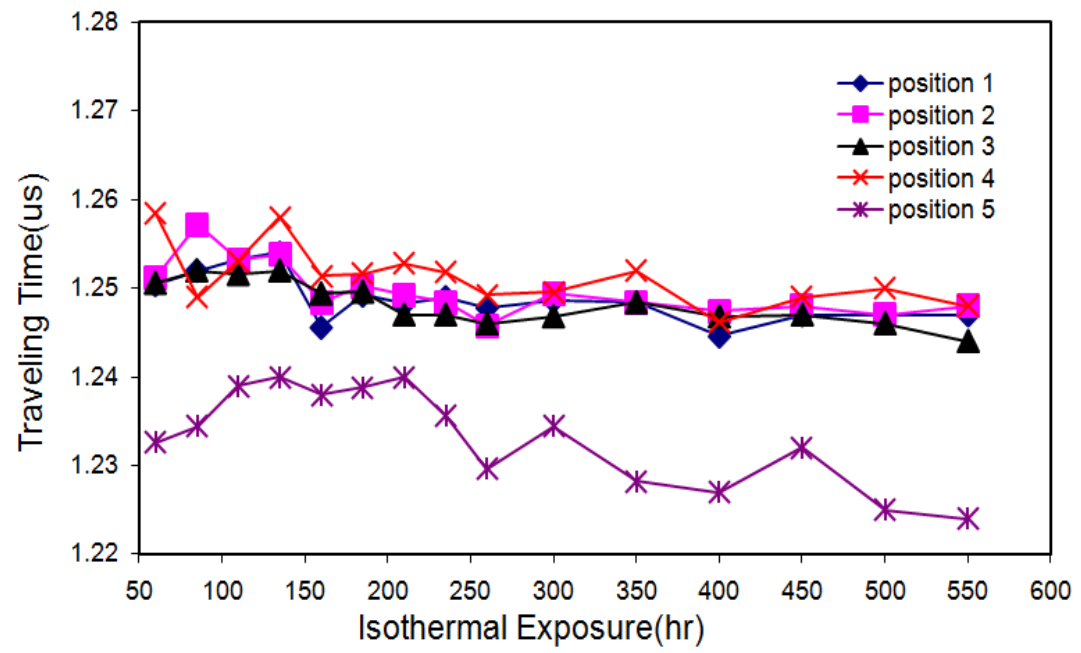

(c) Traveling time in the substrate and bon coat of first isothermal René N5 coupon

Figure 3.28 Round trip traveling time in the first WVU isothermal René N5 coupon 


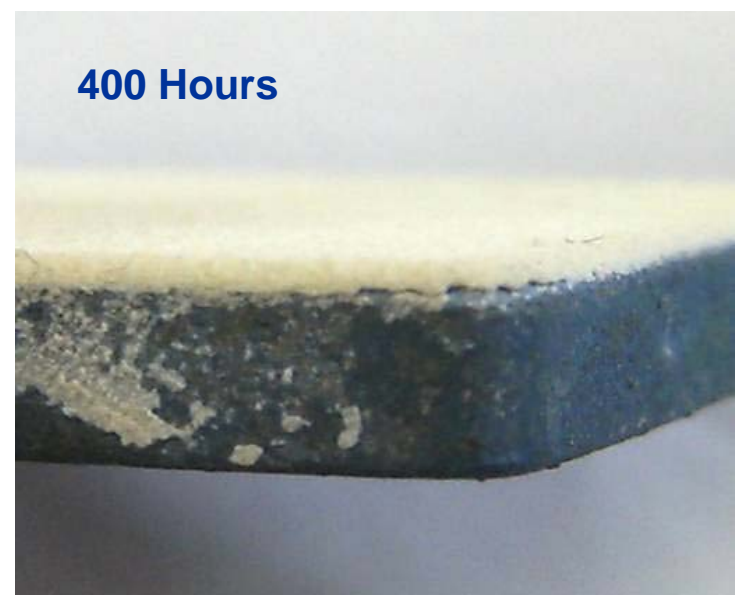

Picture 3.1 Spallation at one corner of WVU isothermal René N5 coupon after 400 hours of exposure

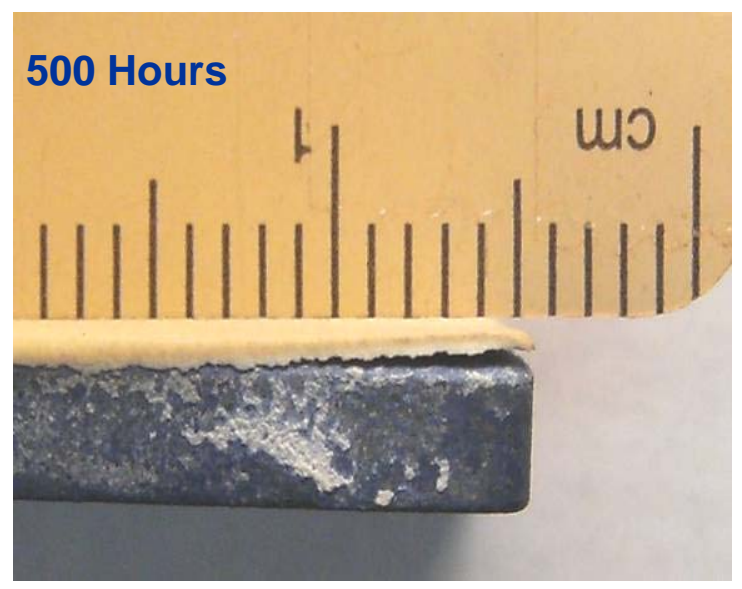

Picture 3.3 Spallation at one corner of WVU isothermal René N5 coupon after 500 hours of exposure

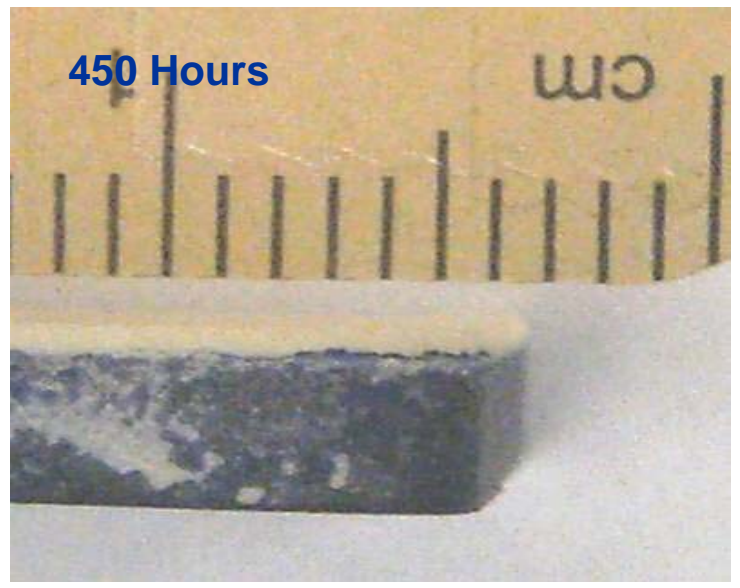

Picture 3.2 Spallation at one corner of WVU isothermal René N5 coupon after 450 hours of exposure

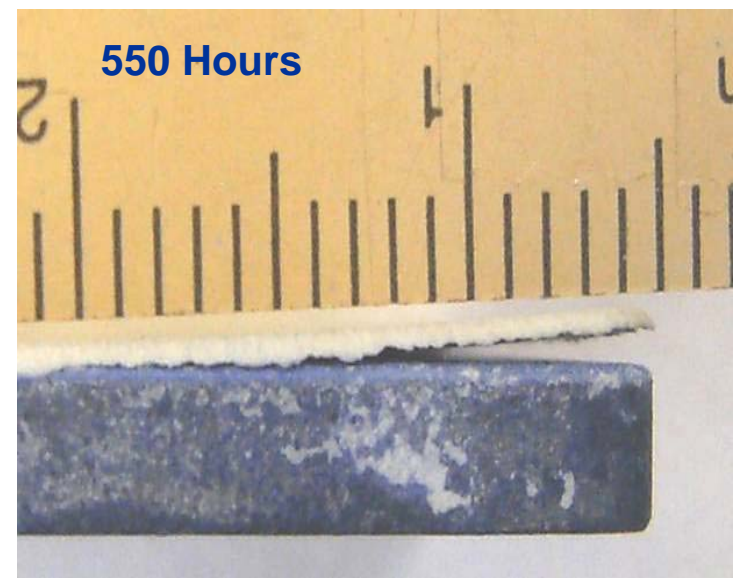

Picture 3.4 Spallation at one corner of WVU isothermal René N5 coupon after 550 hours of exposure 


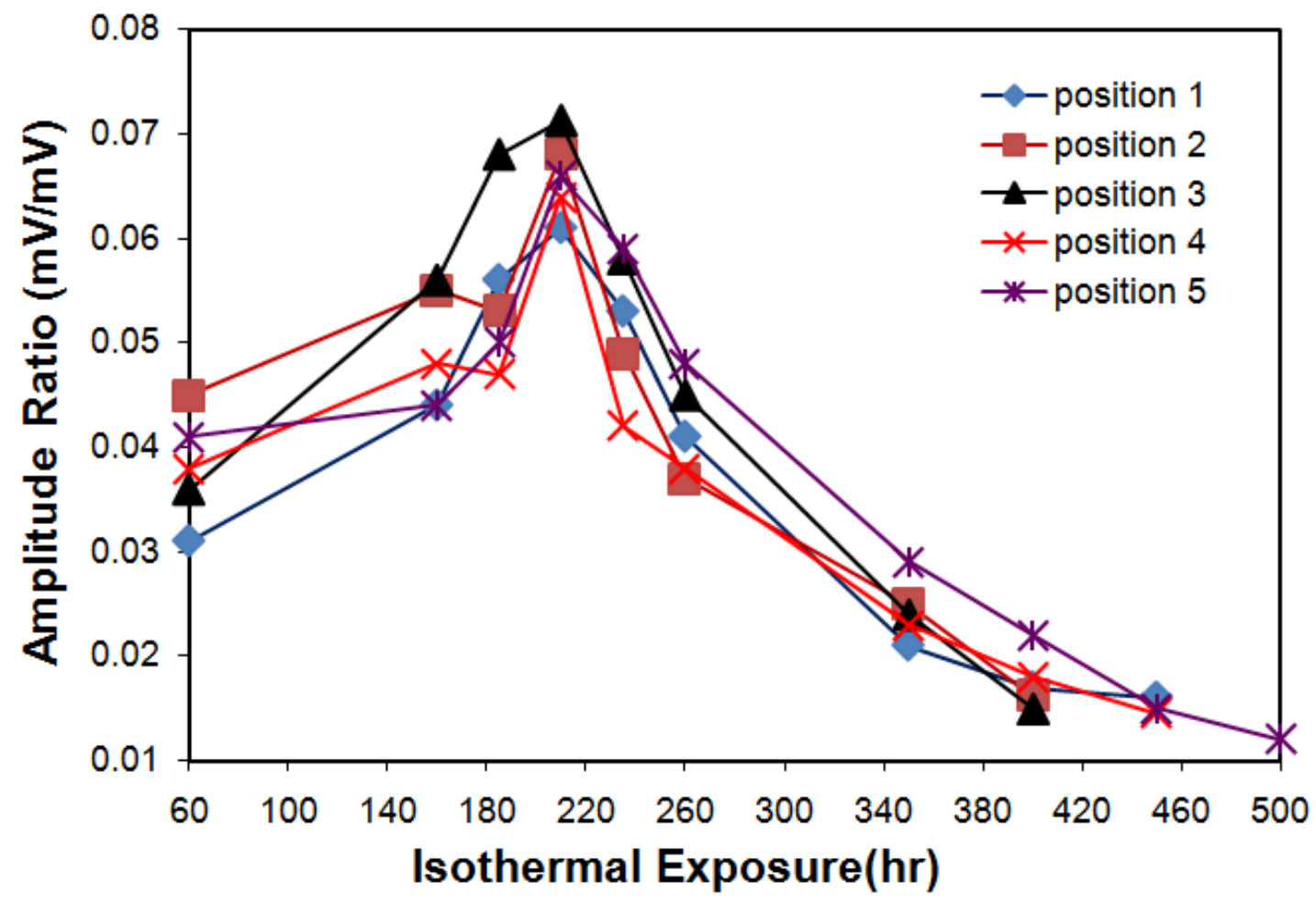

Figure 3.29 Amplitude ratio (A2/A1) vs. exposure hour pulsing on the metal side for the first isothermal René N5 coupon

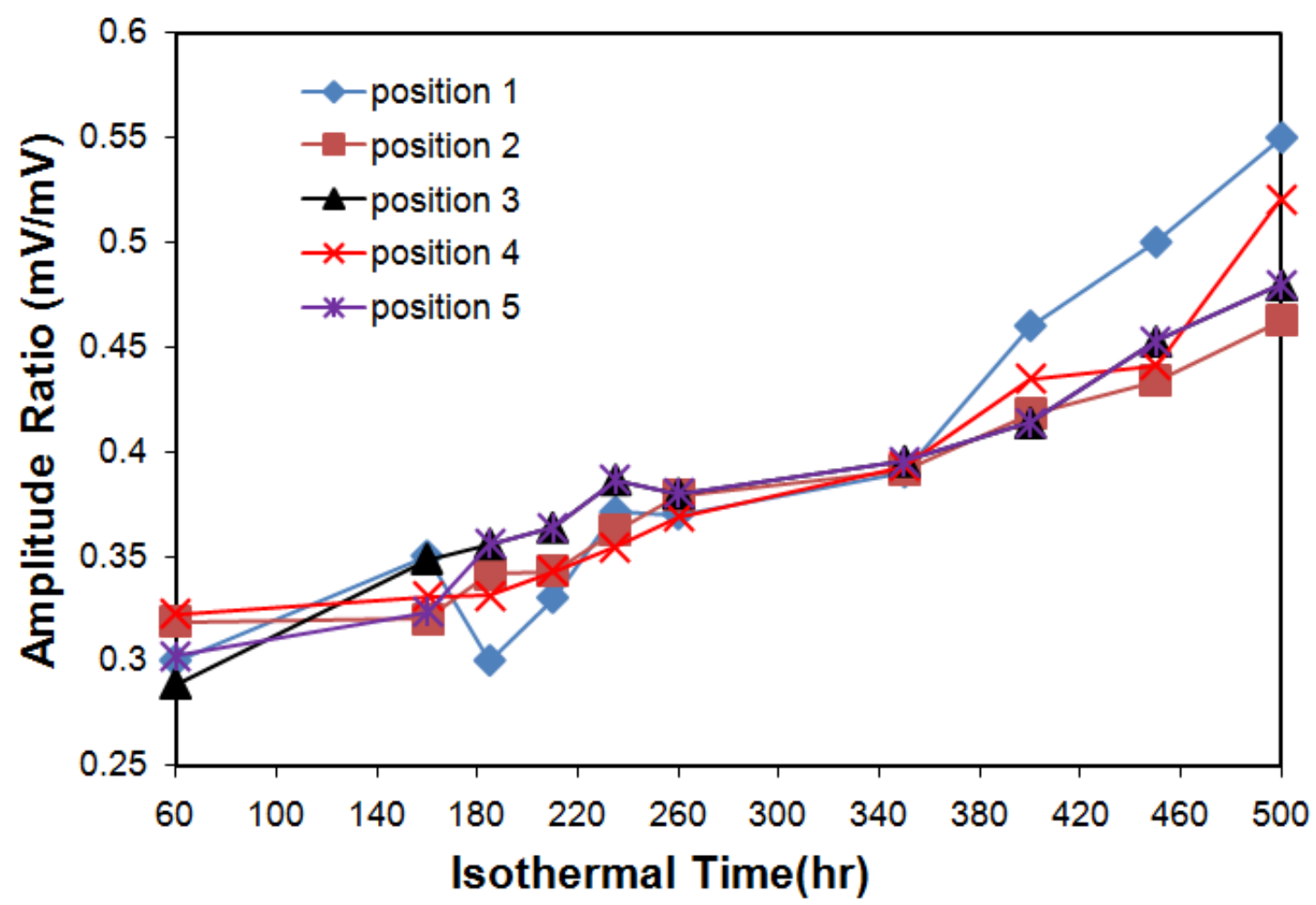

Figure 3.30 Amplitude ratio (A2/Delay line) vs. exposure hour pulsing on the top coat side for the first isothermal René N5 coupon 


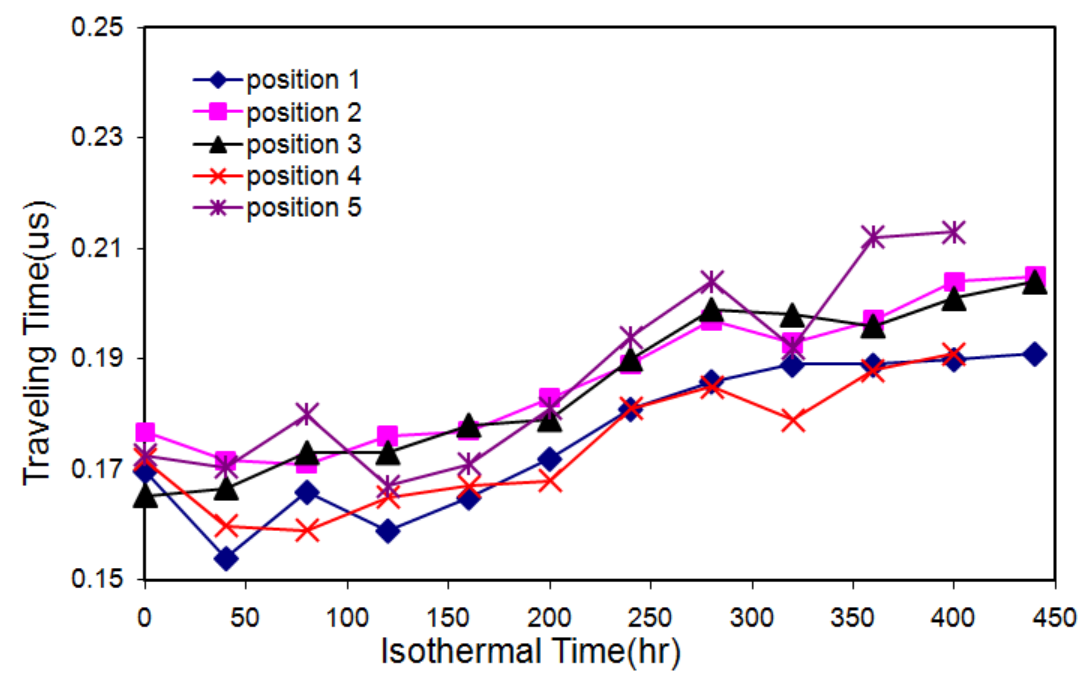

(a) Round trip traveling time in the top coat of the New René N5 Coupon \#1

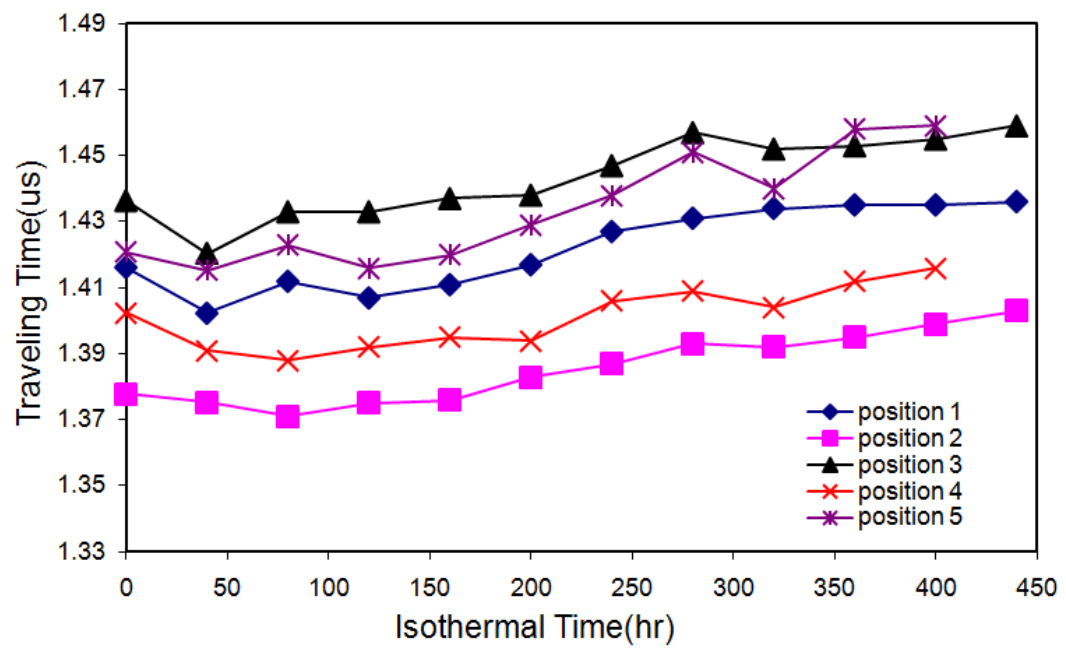

(b) Total traveling time in the New René N5 Coupon \#1

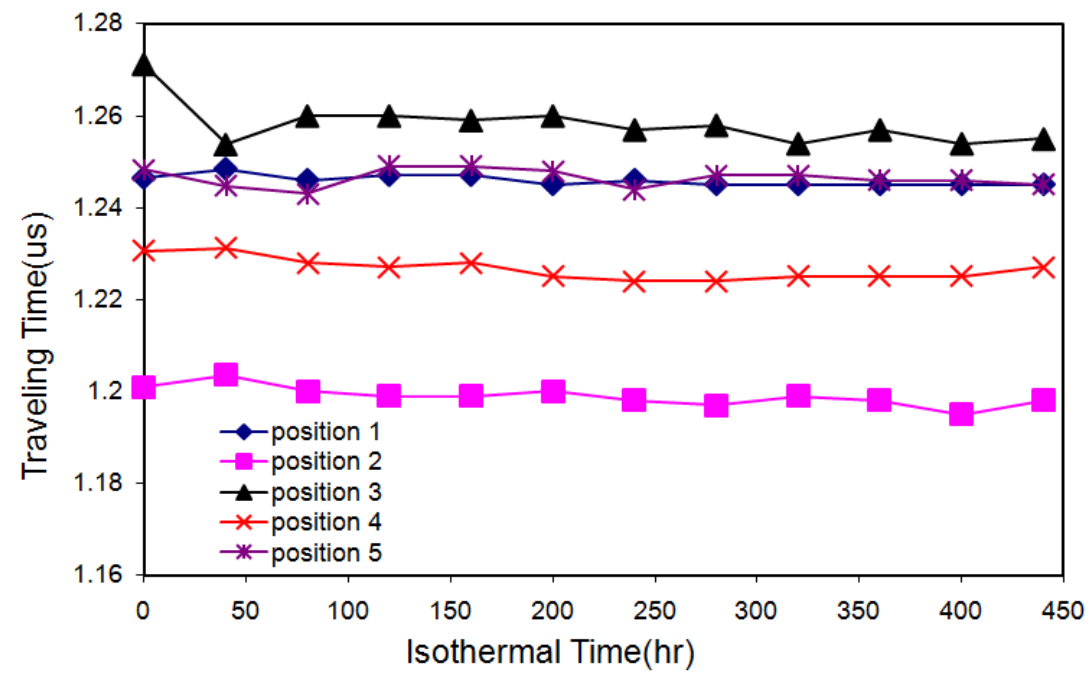

(c) Traveling time in substrate and bond coat of the New René N5 Coupon \#1

Figure 3.31 Pulse-Echo round trip traveling time in the New René N5 Coupon \#1 


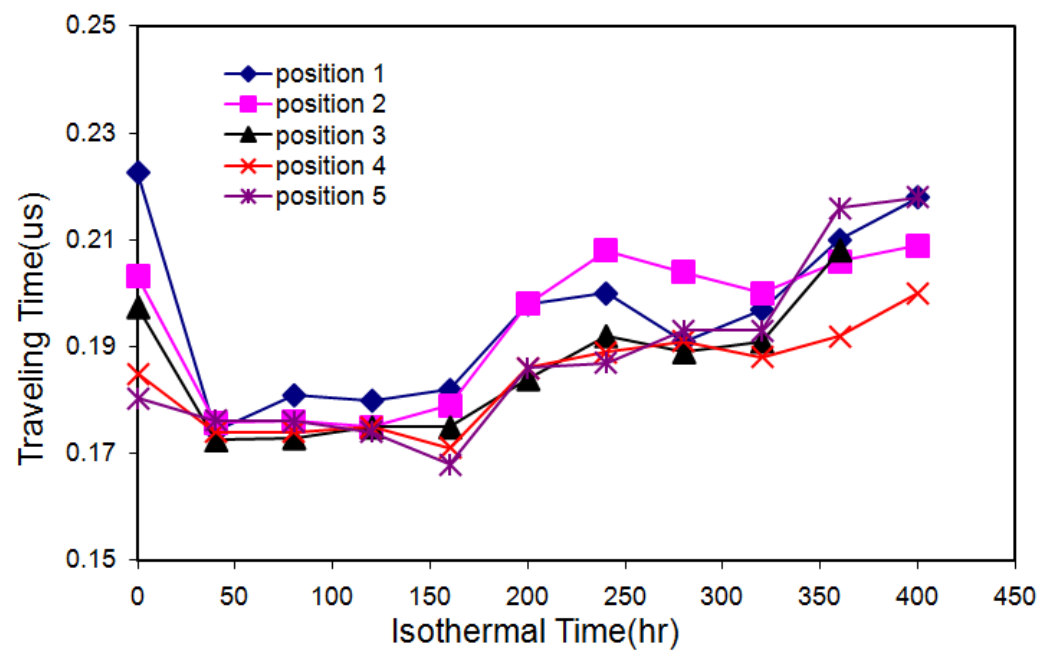

(a) Round trip traveling time in the top coat of the New René N5 Coupon \#2

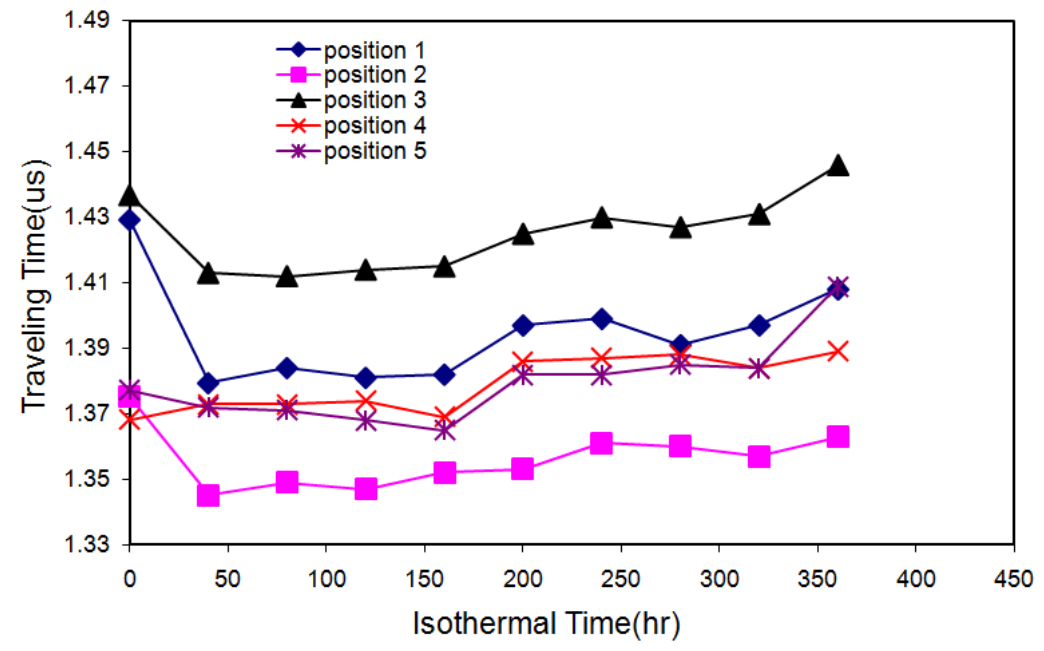

(b) Total traveling time in the New René N5 Coupon \#2

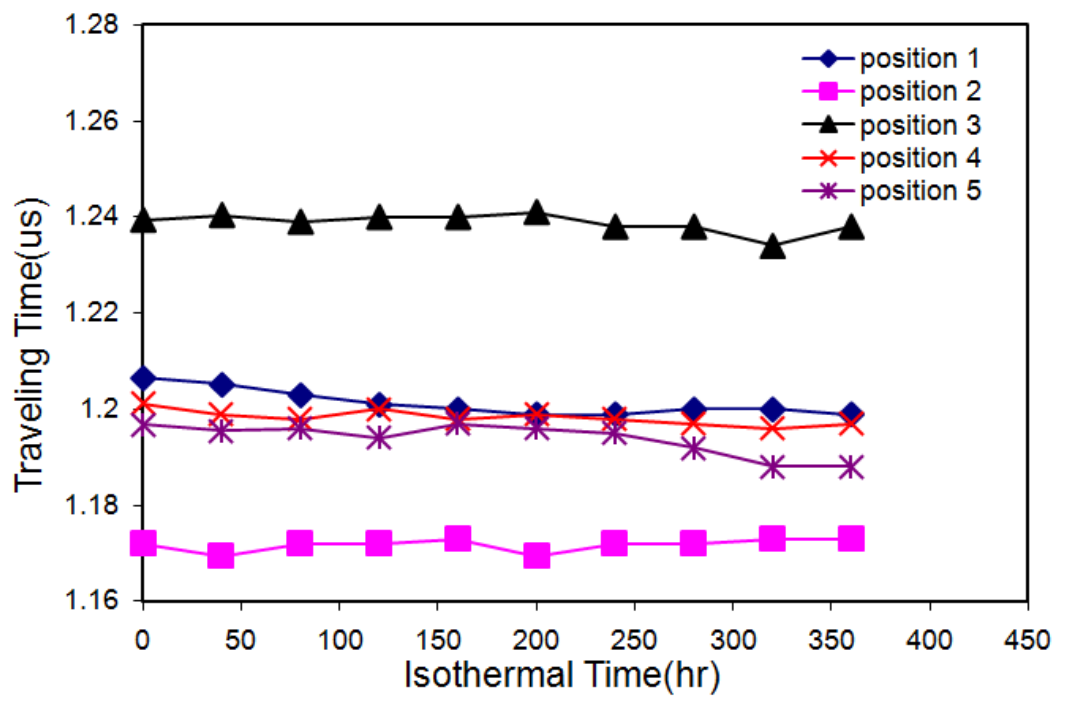

(c) Traveling time in substrate and bond coat of the New René N5 Coupon \#2

Figure 3.32 Pulse-Echo round trip traveling time in the New René N5 Coupon \#2 


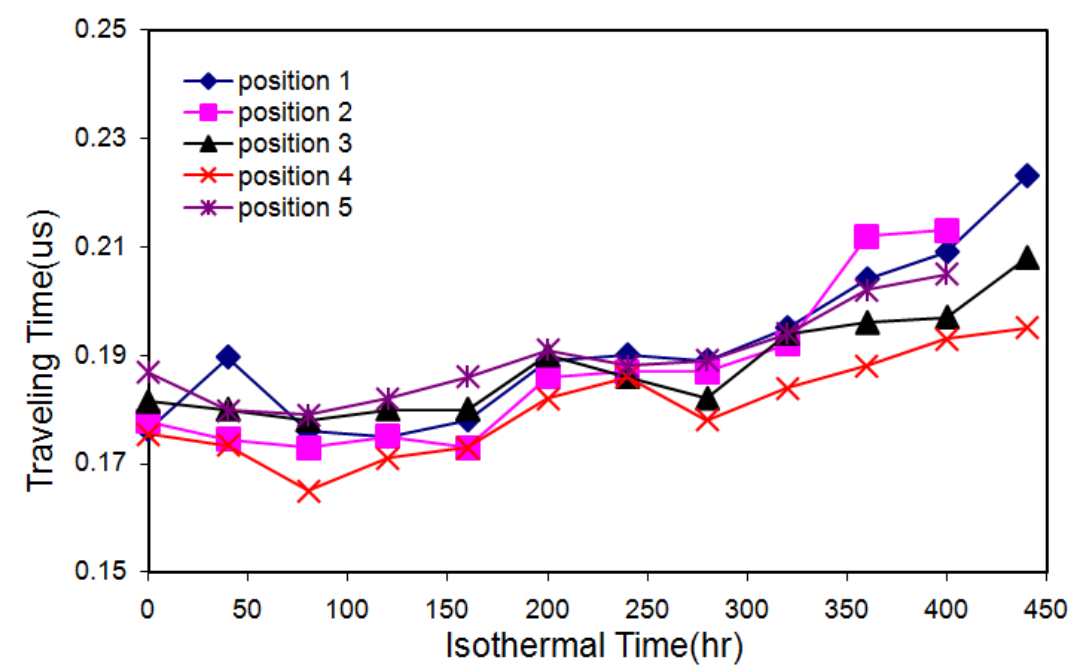

(a) Round trip traveling time in the top coat of the New René N5 Coupon \#3

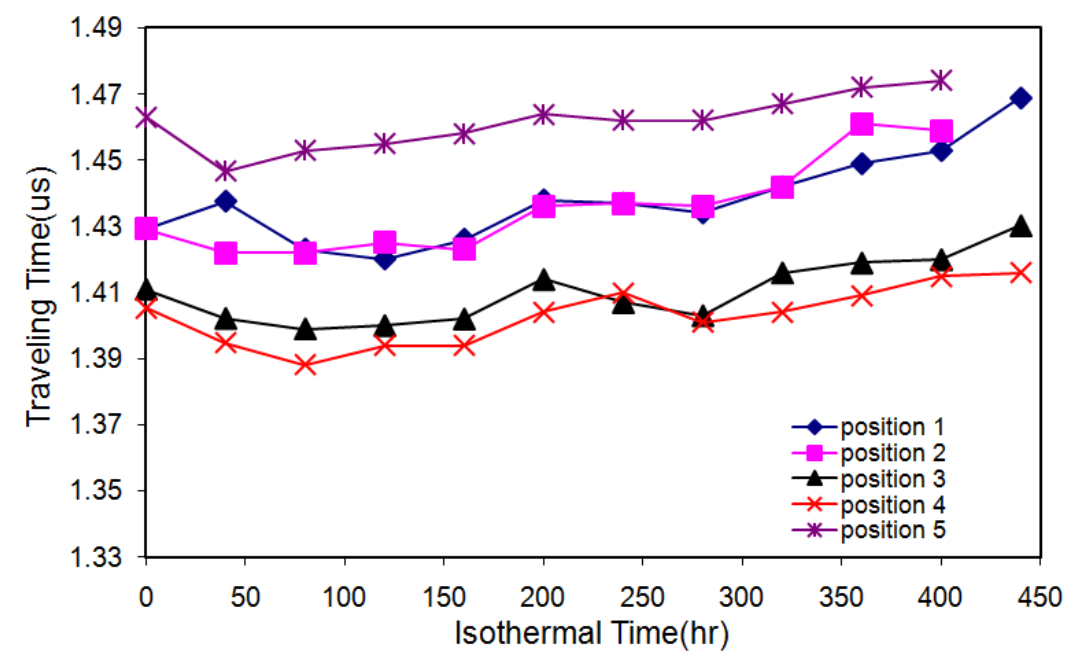

(b) Total traveling time in the New René N5 Coupon \#3

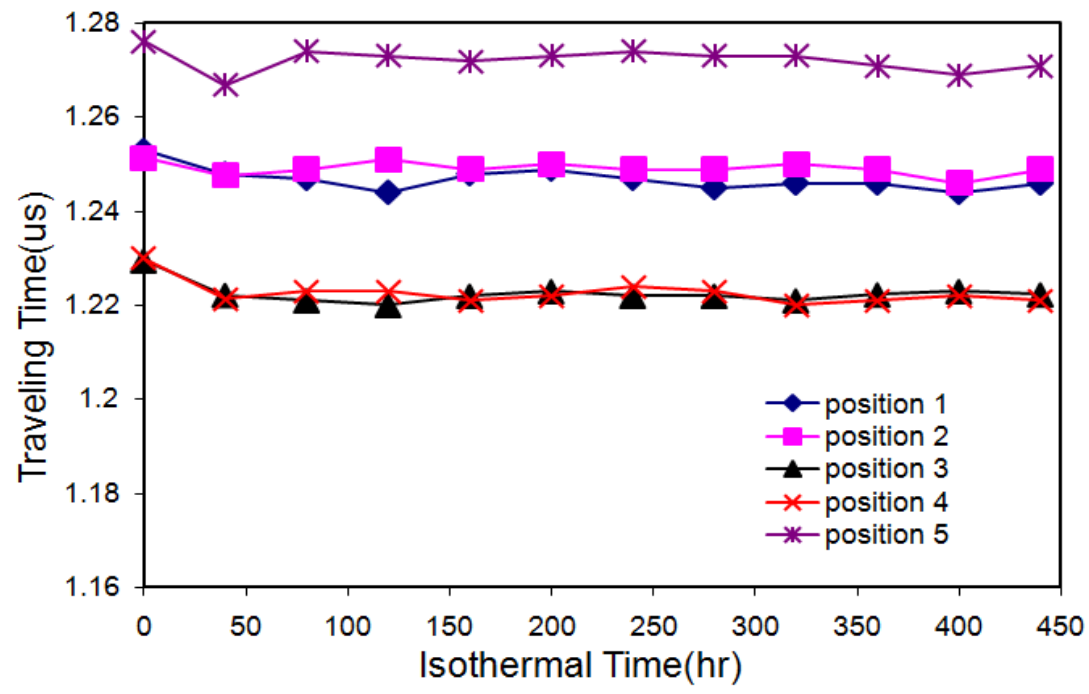

(c)Traveling time in substrate and bond coat of the New René N5 Coupon \#3

Figure 3.33 Pulse-Echo round trip traveling time in the New René N5 Coupon \#3 


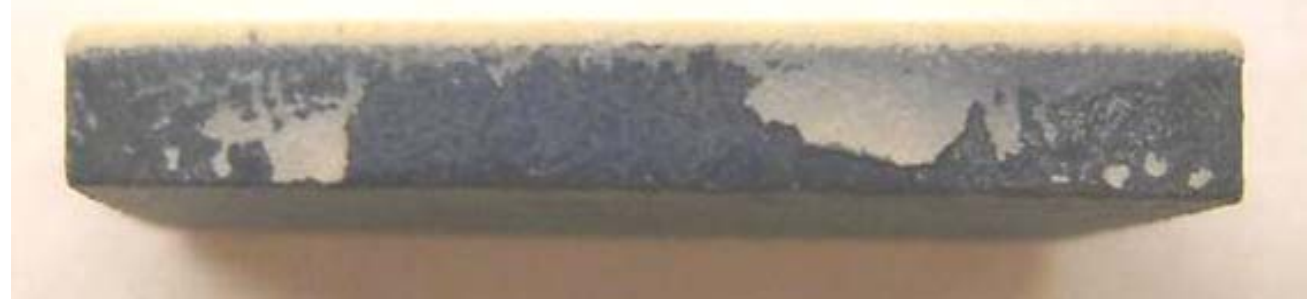

(a) One edge of New René N5 coupon \#1 at 440 hours

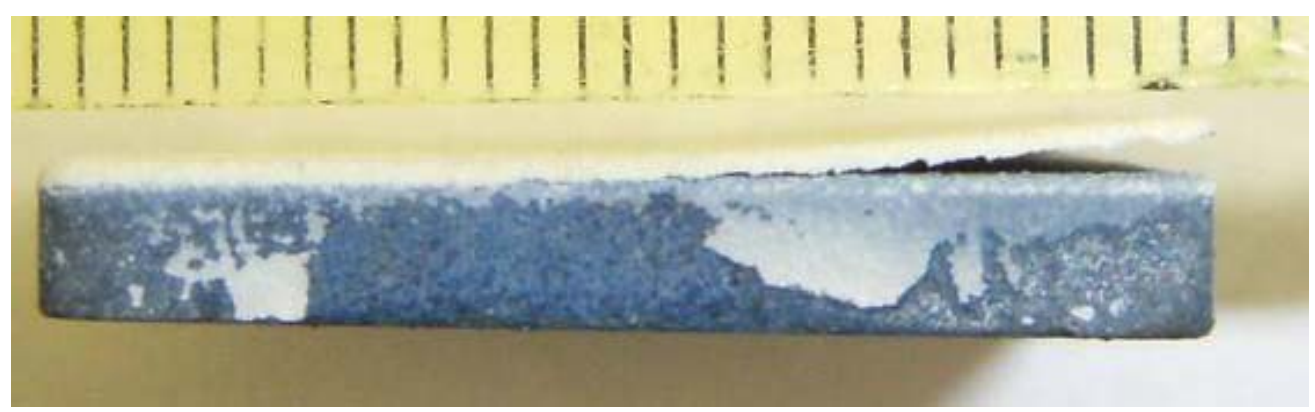

(b) One edge of New René N5 coupon \#1 at 480 hours

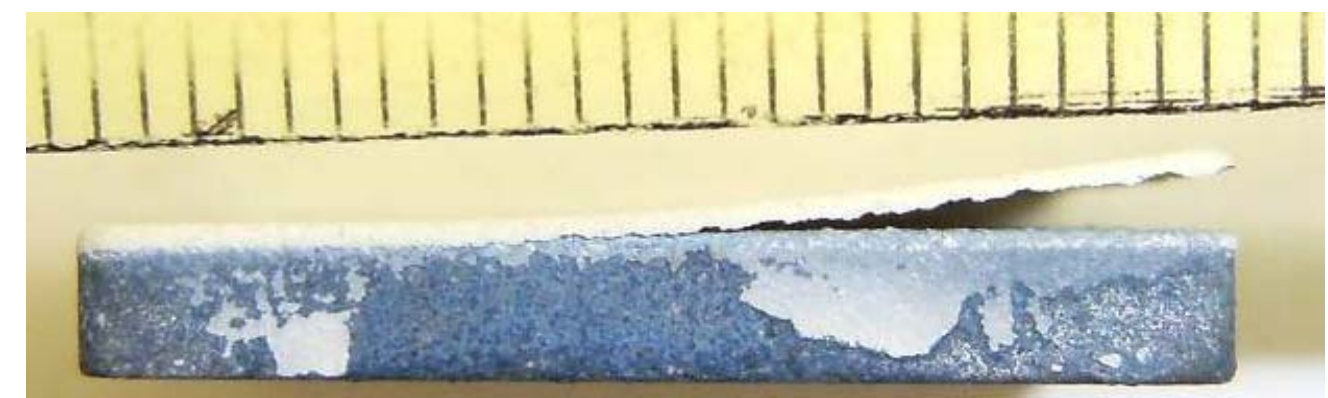

(c) One edge of New René N5 coupon \#1 two days after 480 hours

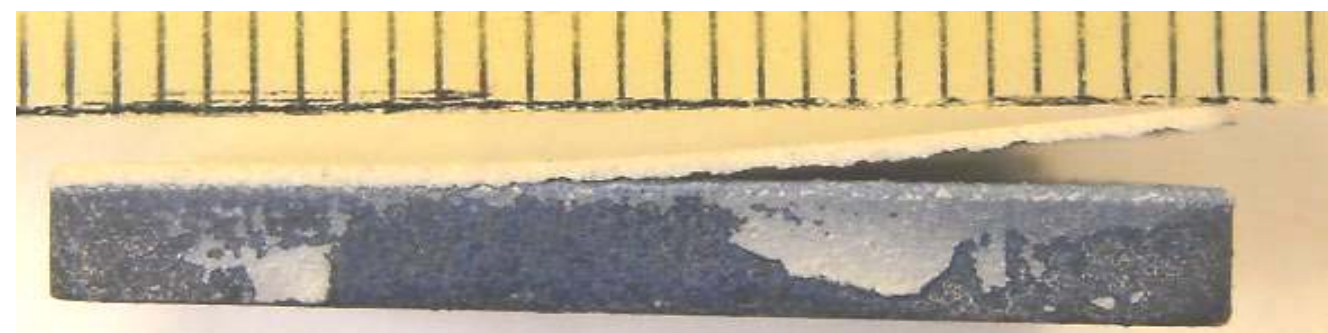

(d) One edge of New René N5 coupon \#1 one week after 480 hours

Picture 3.5 Failure Process along one edge of New René N5 coupon \#1 


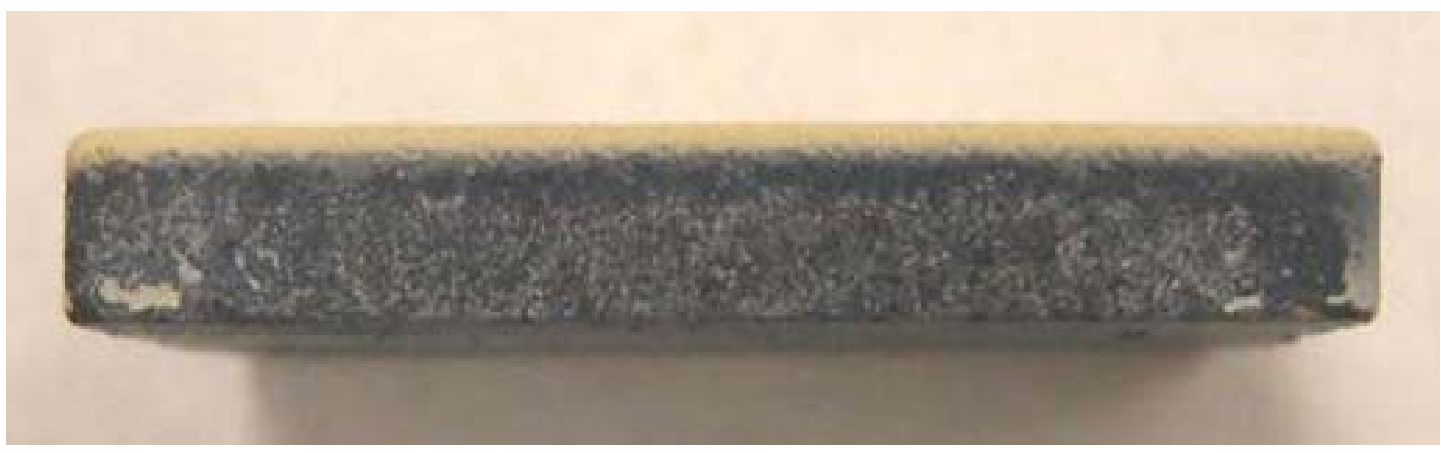

(a) Edge One of New René N5 coupon \#2 at 400 hours

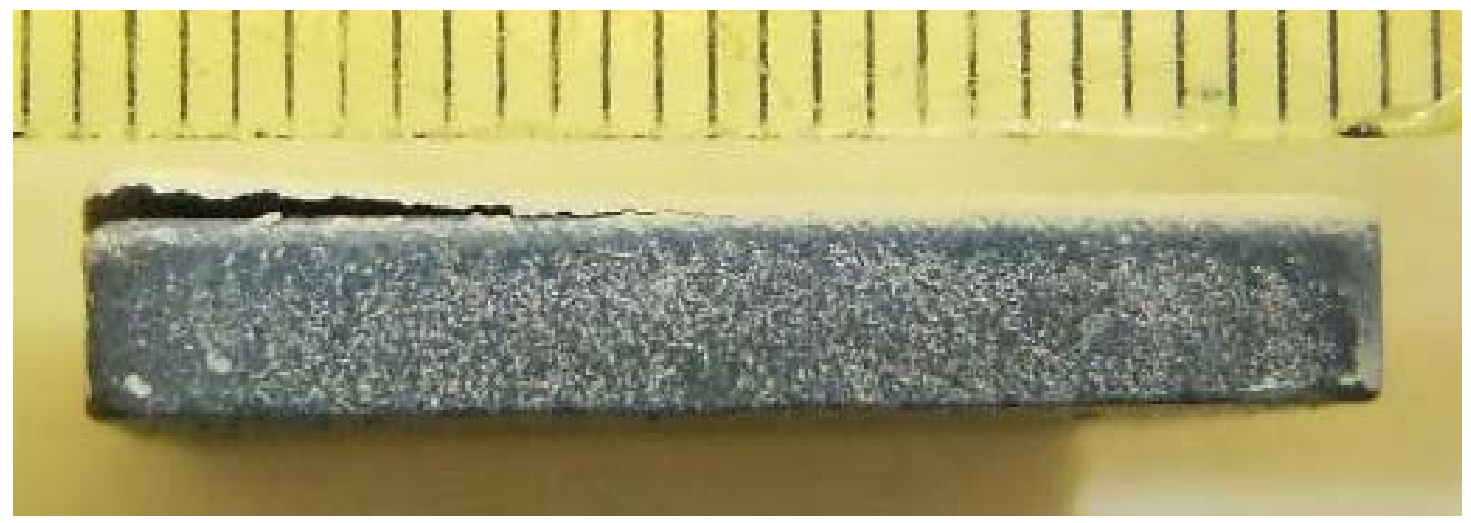

(b) Edge One of New René N5 coupon \#2 at 440 hours

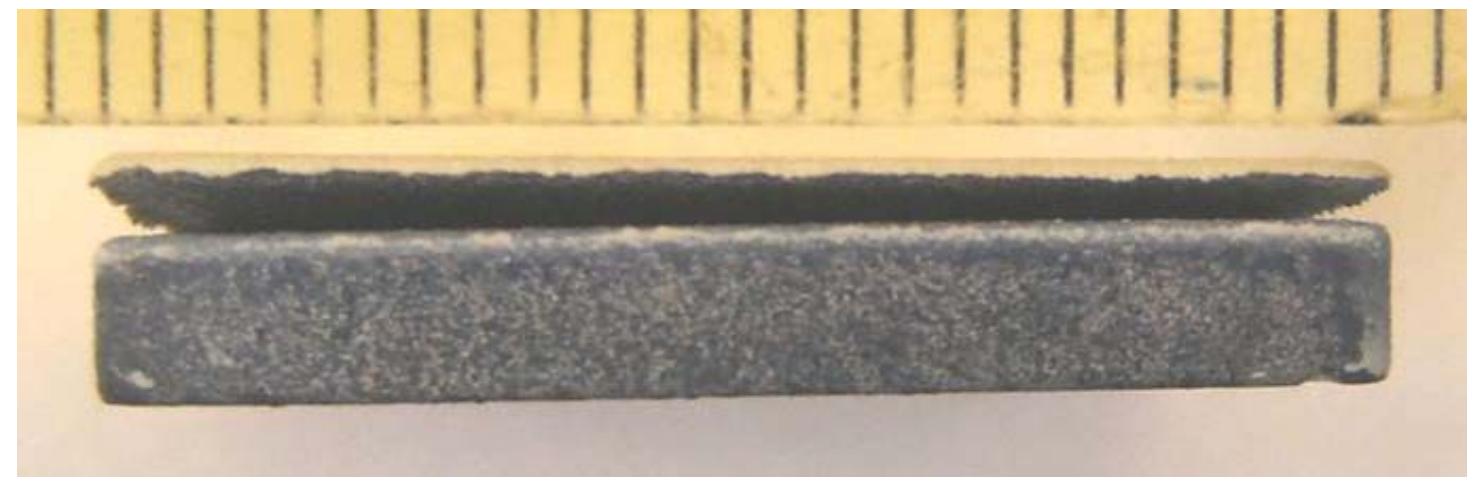

(c) Edge One of New René N5 coupon \#2 two days after 440 hours

Picture 3.6 Failure Process along Edge One of New René N5 coupon \#2 


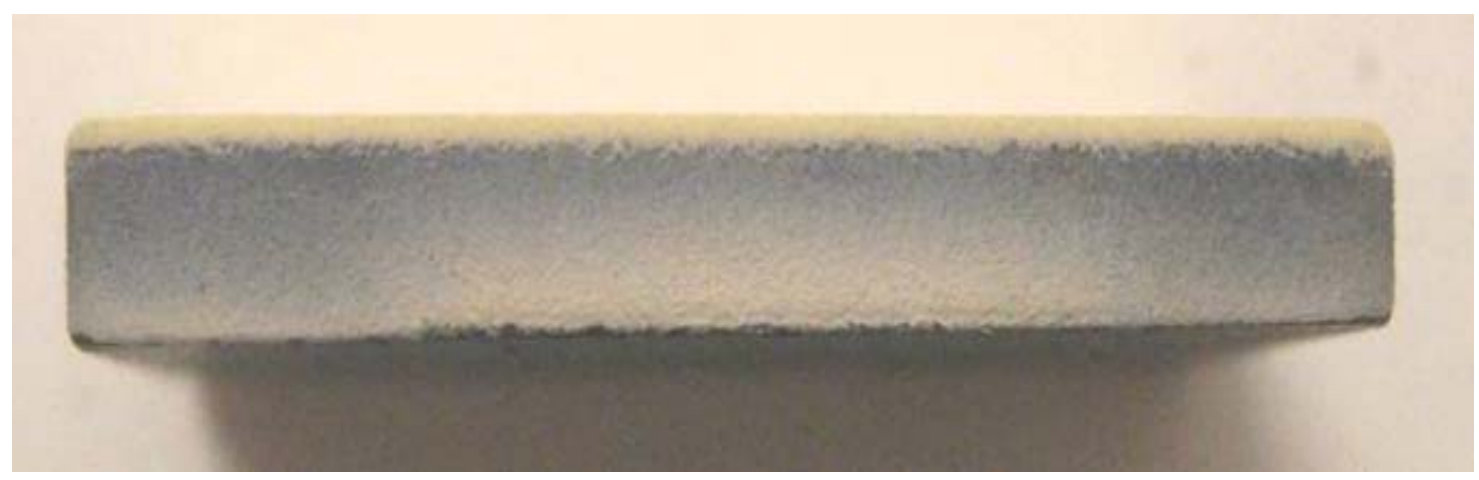

(a) Edge Two of New René N5 coupon \#2 at 400 hours

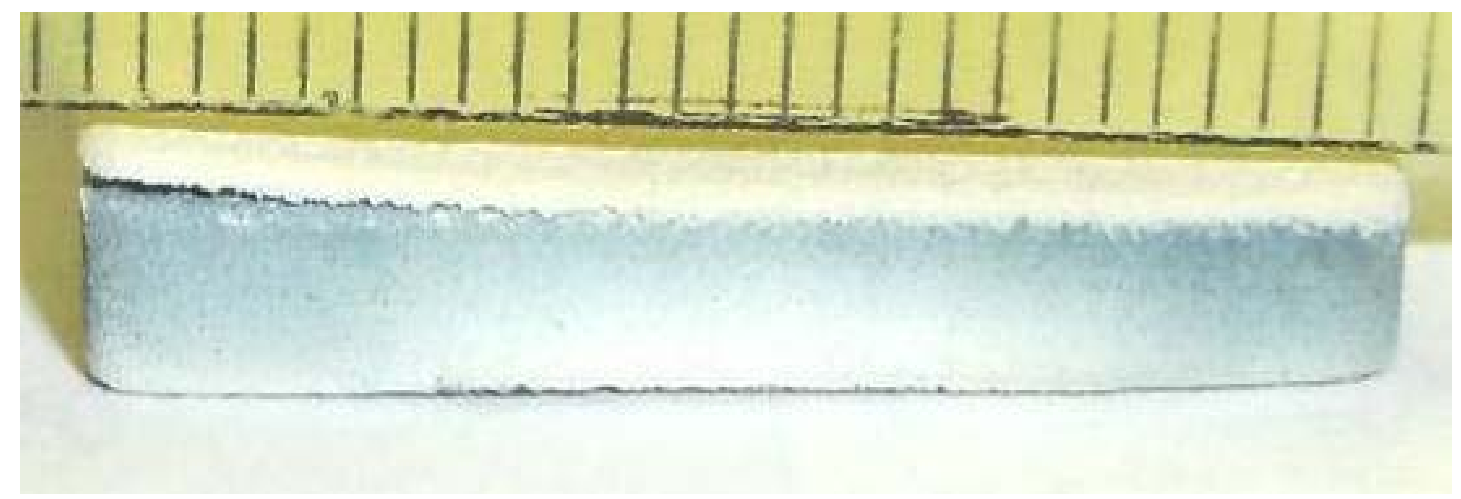

(b) Edge Two of New René N5 coupon \#2 at 440 hours

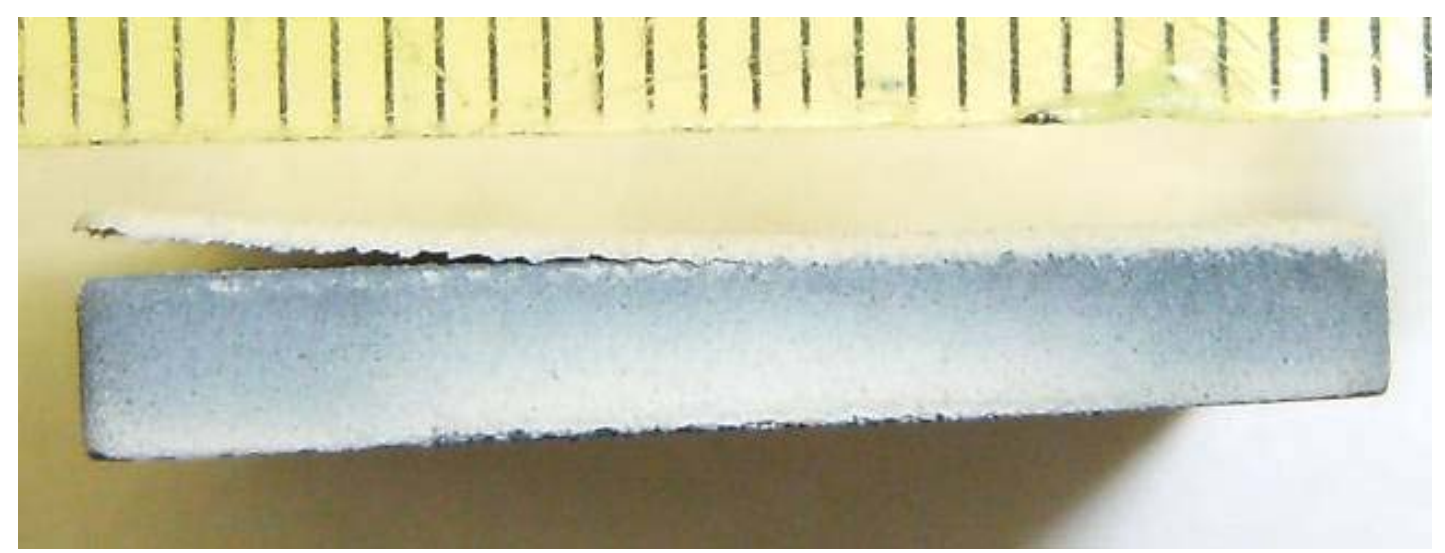

(c) Edge Two of New René N5 coupon \#2 two days after 440 hours

Picture 3.7 Failure Process along Edge Two of New René N5 coupon \#2 


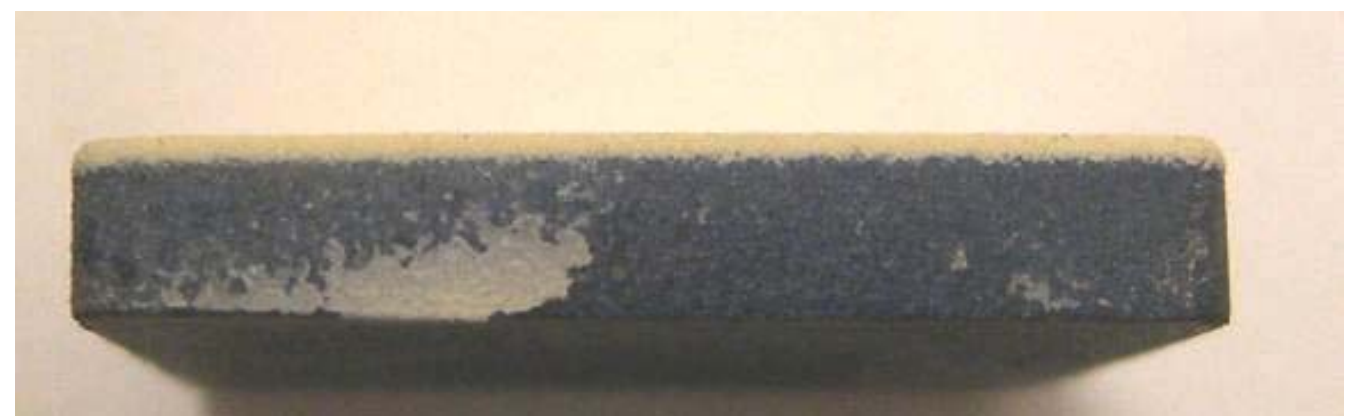

(a) One edge of New René N5 coupon \#3 at 440 hours

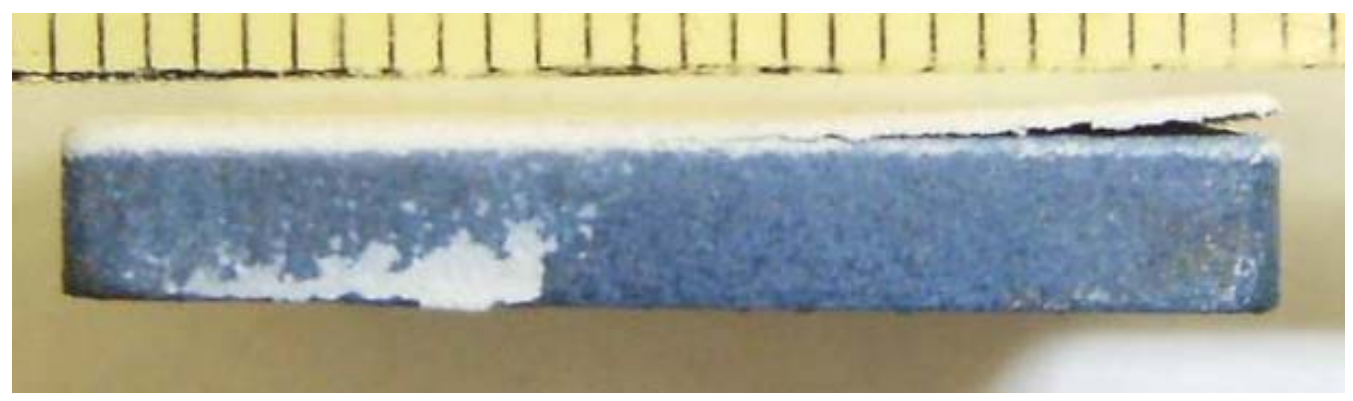

(b) One edge of New René N5 coupon \#3 at 480 hours

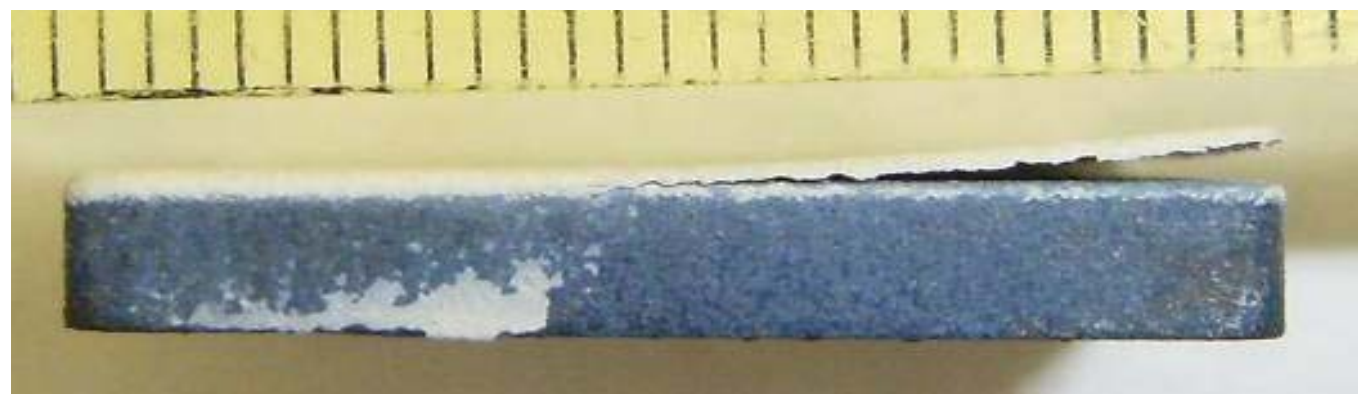

(c) One edge of New René N5 coupon \#3 two days after 480 hours

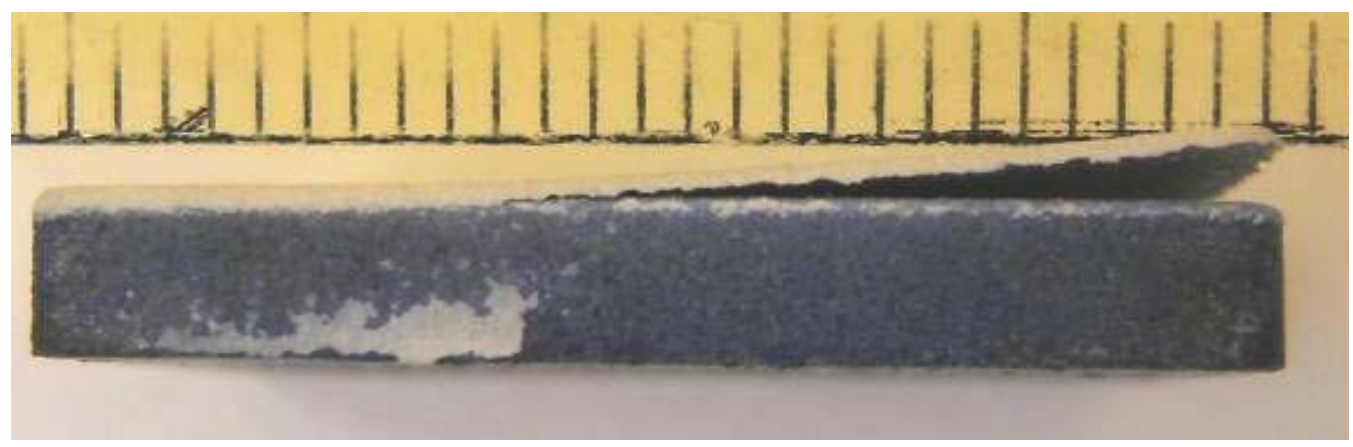

(d) One edge of New René N5 coupon \#3 one week after 480 hours

Picture 3.8 Failure Process along one Edge of New René N5 coupon \#3 


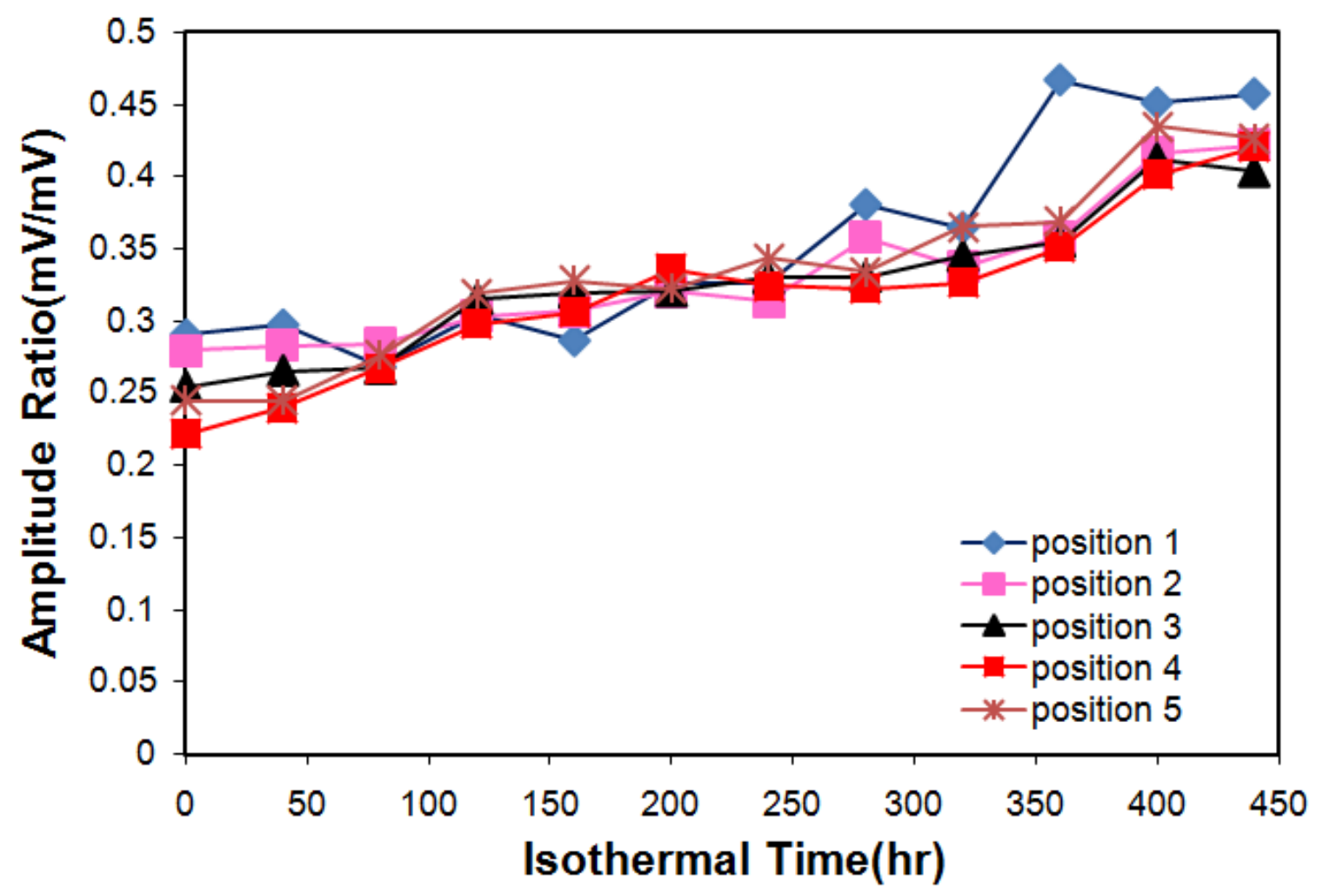

Figure 3.34 A2/A1 amplitude ratio of New René N5 Coupon \#1

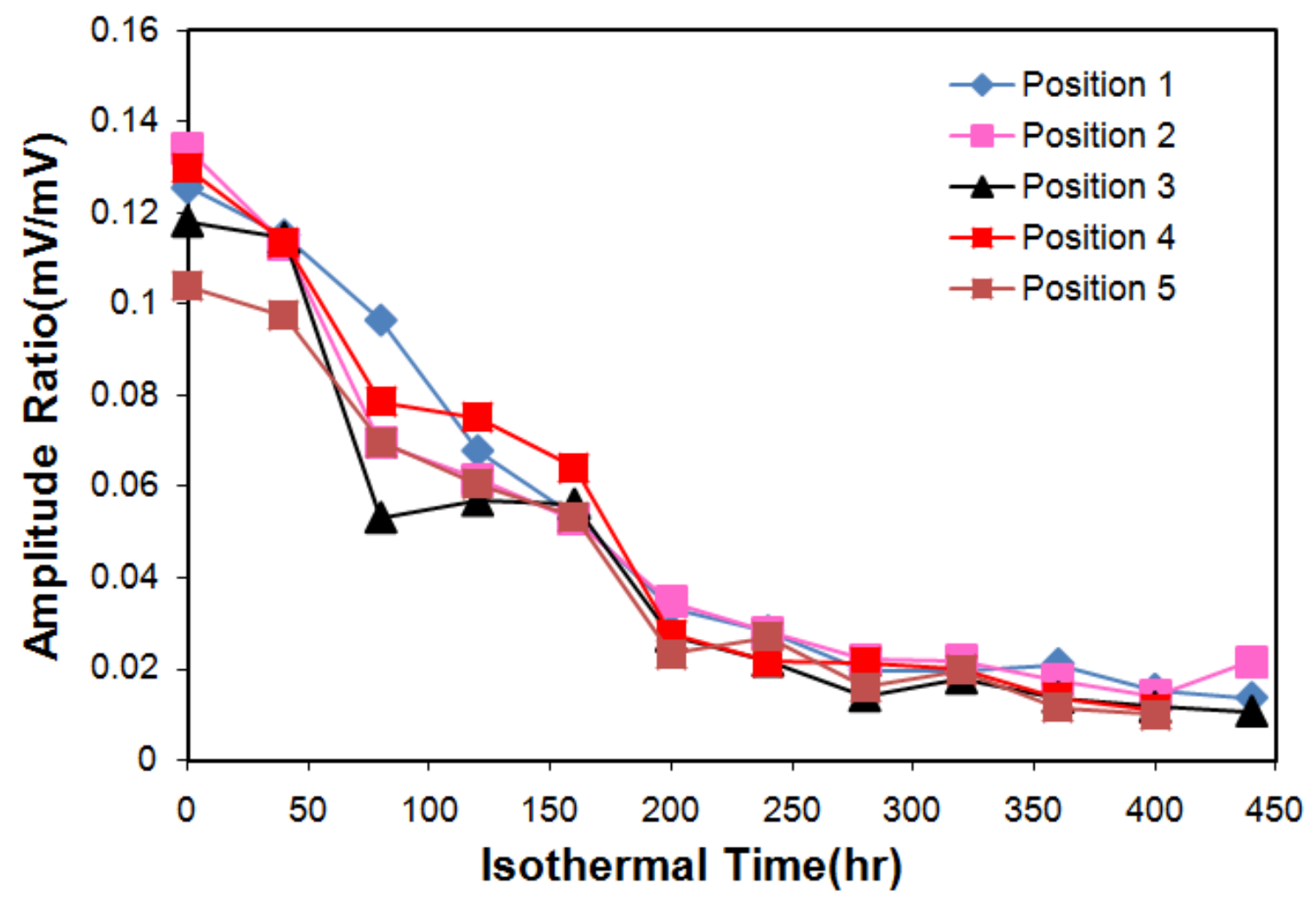

Figure 3.35 A3/Delay line amplitude ratio of New René N5 Coupon \#1 


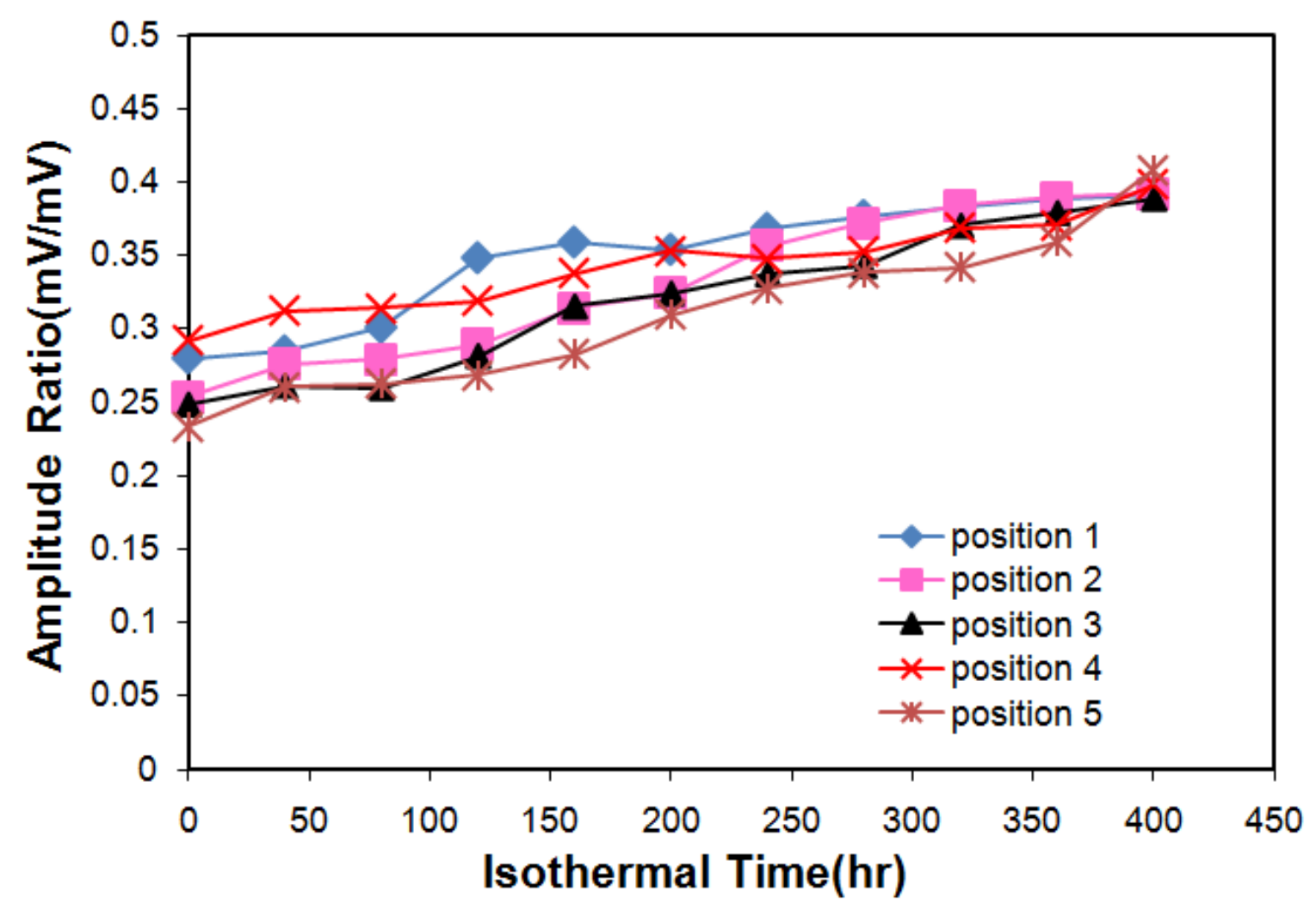

Figure 3.36 A2/A1 amplitude ratio of New René N5 Coupon \#2

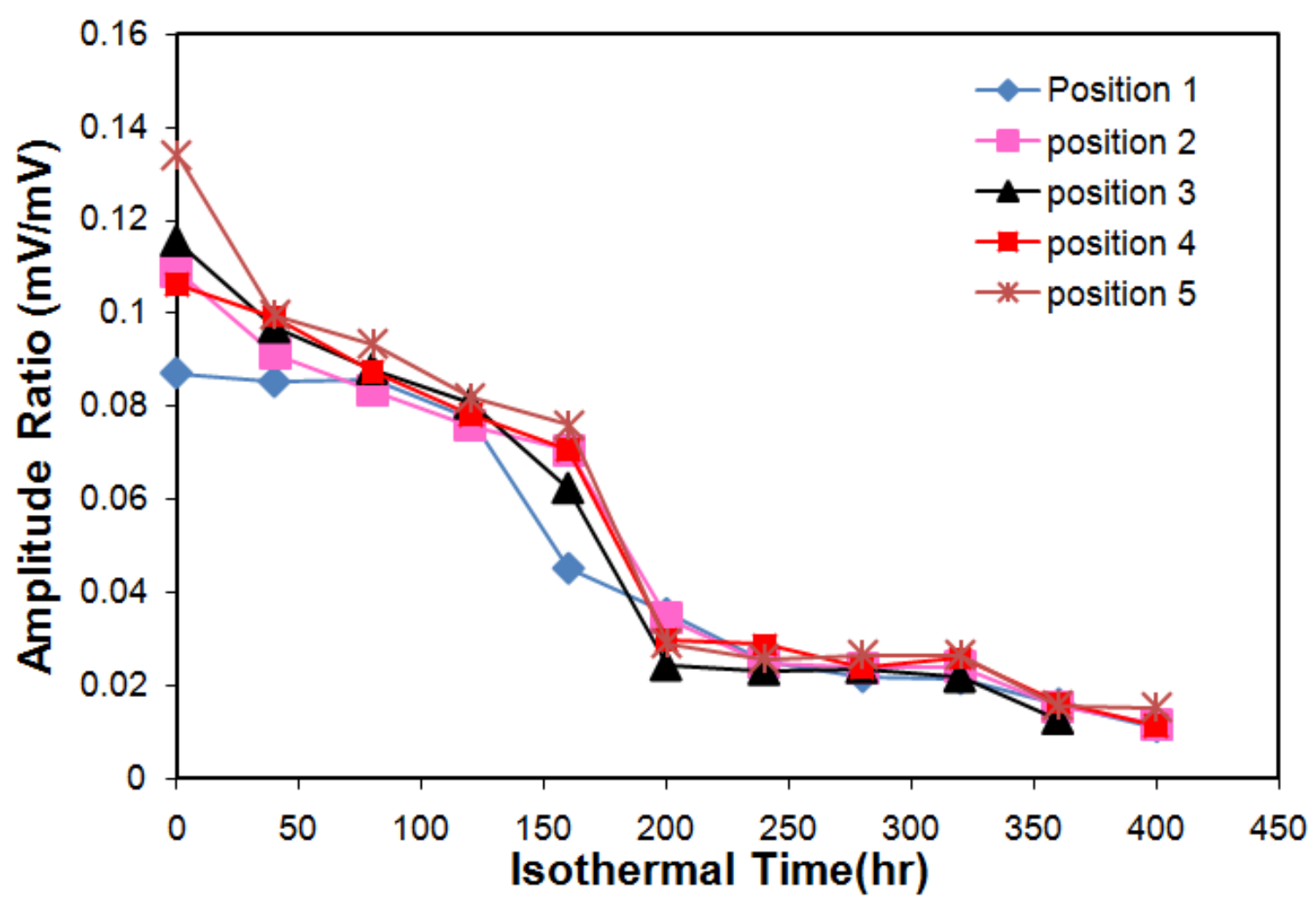

Figure 3.37 A3/Delay line amplitude ratio of New René N5 Coupon \#2 


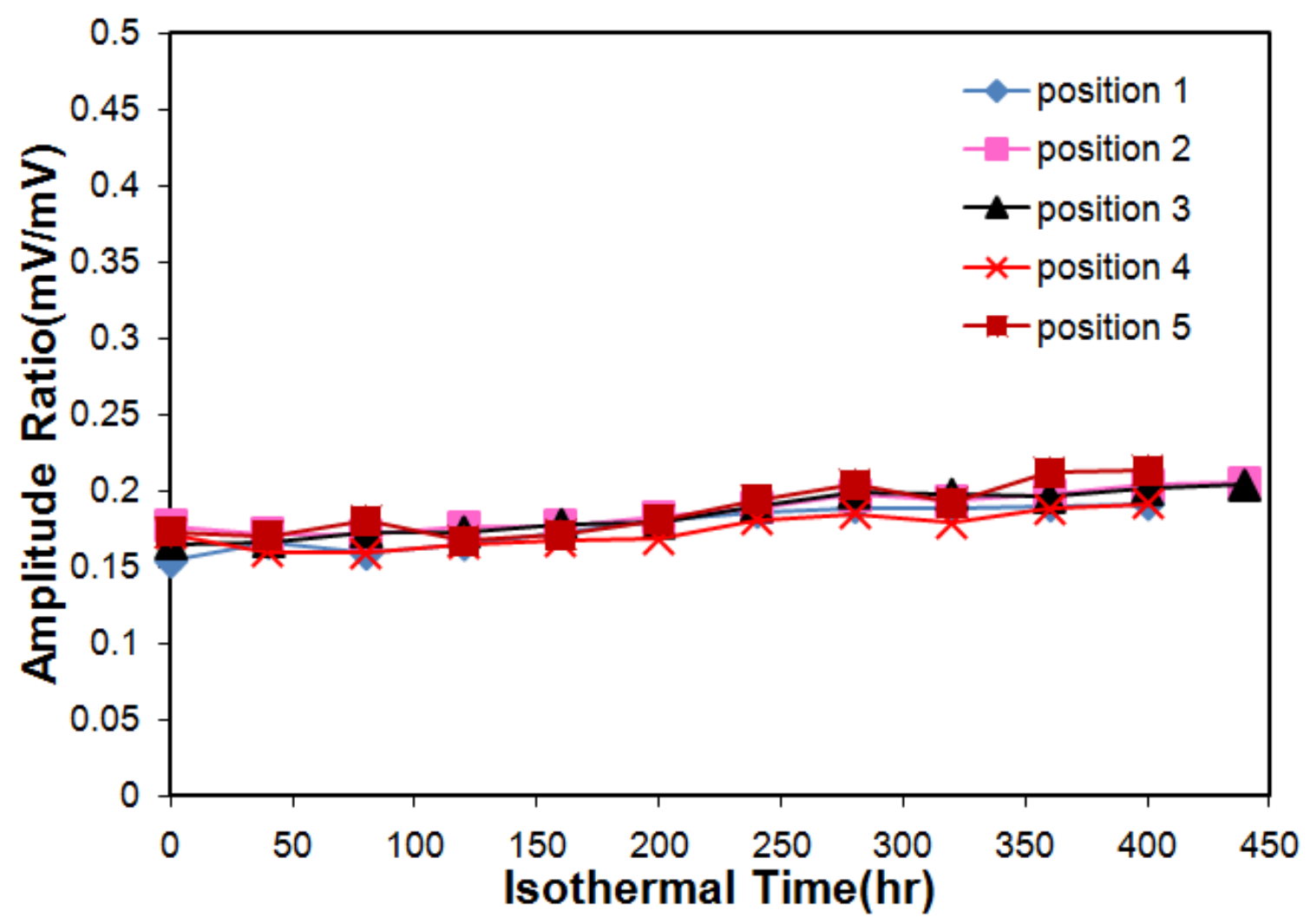

Figure 3.38 A2/A1 amplitude ratio of New René N5 Coupon \#3

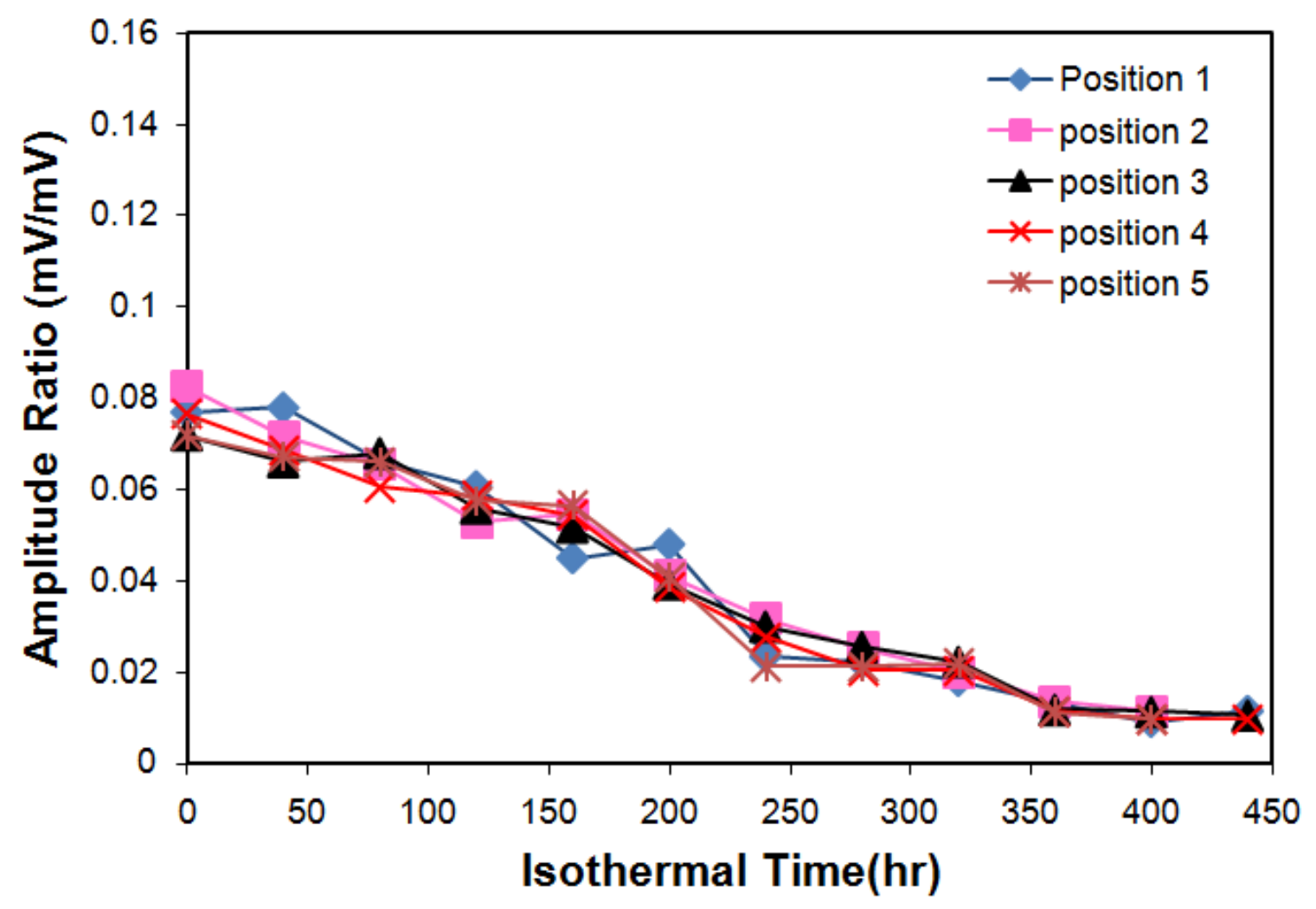

Figure 3.39 A3/Delay line amplitude ratio of New René N5 Coupon \#3 
Table 3.6 Round trip traveling time for two 100 hours René N5 Coupons

\begin{tabular}{|c|c|c|}
\hline \multicolumn{3}{|c|}{$\begin{array}{c}\text { TABLE 3.6 } \\
\text { ACOUSTO-ULTRASONIC ASSESSMEN } \\
\text { PULSE-ECHO ROUND TRIP TRAVEL TIM } \\
-\quad \text { ISOTHERMAL OXIDATION - } \\
\text { 100-Hrs } \\
\text { TEMPERATURE } \\
1100^{\circ} \mathrm{C}\end{array}$} \\
\hline \multicolumn{3}{|c|}{ René N5/MCrA1Y/APS Coupons } \\
\hline \multirow{2}{*}{ Pulse-Echo Round Trip Traveling Time } & \multicolumn{2}{|c|}{ Coupon \#, Stress Condition } \\
\hline & $\# 3$, stressed & $\# 24$, unstressed \\
\hline Total Time & $1.455 \pm 0.005$ & $1.520 \pm 0.008$ \\
\hline Time in Bond coat and Substrate & $1.215 \pm 0.004$ & $1.250 \pm 0.006$ \\
\hline Time in Top Coat & 0.240 & 0.270 \\
\hline
\end{tabular}

Table 3.7 Pulse-Echo travel time in top coat for stressed 300 hours René N5 Coupon

\begin{tabular}{|c|c|c|c|}
\hline \multicolumn{4}{|c|}{$\begin{array}{c}\text { TABLE } 3.7 \\
\text { ACOUSTO-ULTRASONIC ASSESSMENT } \\
\text { PULSE-ECHO ROUND TRIP TRAVEL TIME IN TOP COAT( } \mu \mathrm{s}) \\
-\quad \text { ISOTHERMAL OXIDATION - } \\
\text { 300-Hrs }\end{array}$} \\
\hline \multicolumn{4}{|c|}{ Stressed René N5/MCrA1Y/APS Coupons } \\
\hline \multirow{2}{*}{ Position } & \multicolumn{3}{|c|}{ Temperature, ${ }^{\circ} \mathrm{C}($ Coupon \#) } \\
\hline & $900(\# 9)$ & $1000(\# 10)$ & $1100(\# 16)$ \\
\hline 1 & $0.305 \pm 0.003$ & $0.228 \pm 0.002$ & $0.257 \pm 0.007$ \\
\hline 2 & $0.303 \pm 0.004$ & $0.217 \pm 0.001$ & $0.229 \pm 0.005$ \\
\hline 3 & $0.303 \pm 0.006$ & $0.245 \pm 0.006$ & $0.247 \pm 0.004$ \\
\hline 4 & $0.269 \pm 0.009$ & $0.221 \pm 0.008$ & $0.242 \pm 0.005$ \\
\hline
\end{tabular}


Table 3.8 Pulse-Echo travel time in top coat for unstressed 300 hours René N5 Coupons

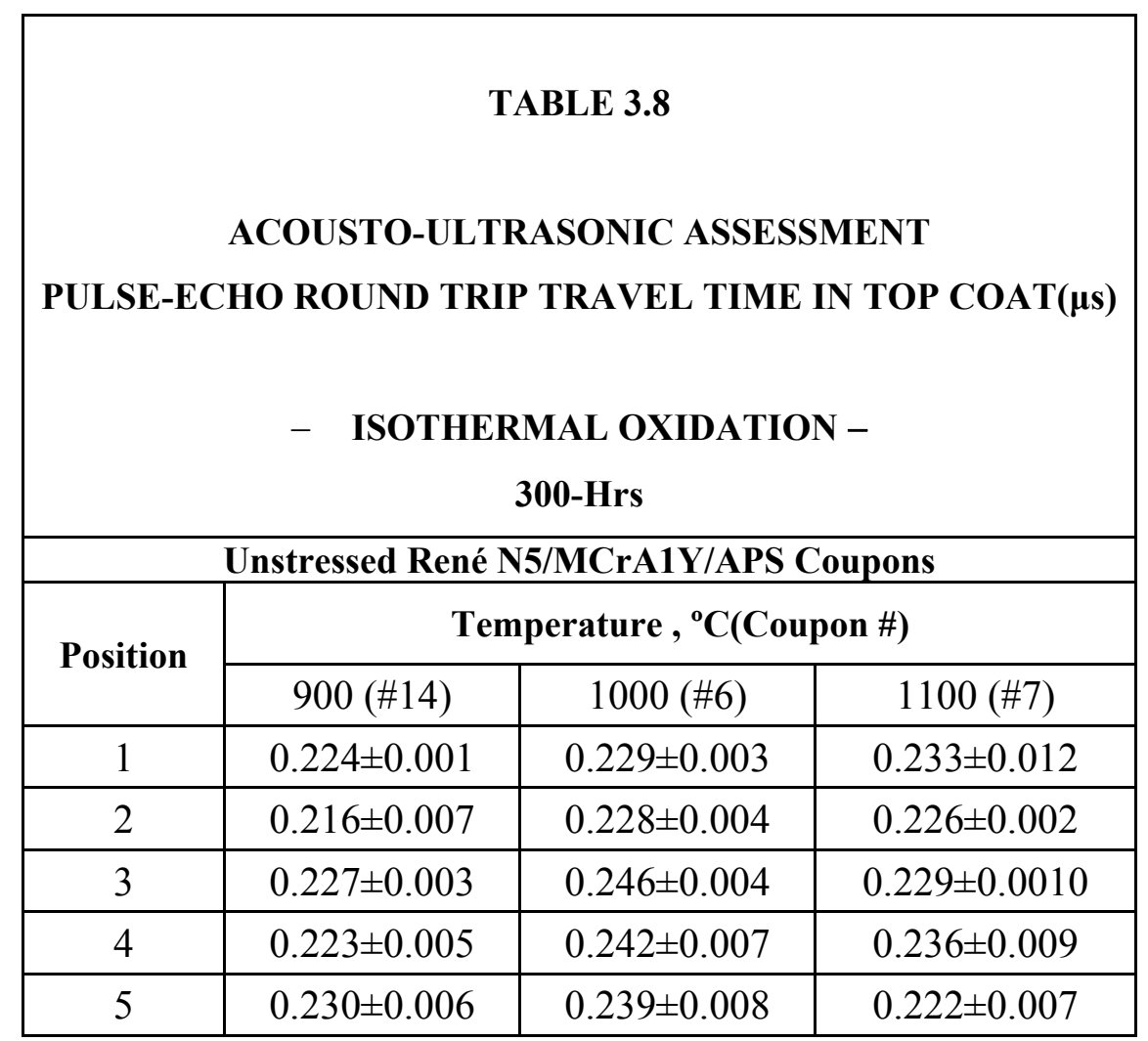

Table 3.9 Pulse-Echo travel time in top coat for 1000 hours René N5 Coupon \#28 under $1000^{\circ} \mathrm{C}$

\begin{tabular}{|c|c|c|}
\hline \multicolumn{3}{|c|}{$\begin{array}{c}\text { ACOUSTO-ULTRASONIC ASSESSMENT } \\
\text { PULSE-ECHO ROUND TRIP TRAVEL TIME IN TOP COAT }(\mu \mathrm{s})\end{array}$} \\
\hline \multicolumn{3}{|c|}{$\begin{array}{c}- \text { ISOTHERMAL OXIDATION - } \\
\text { 1000-Hrs } \\
\text { TEMPERATURE } \\
\mathbf{1 0 0 0}^{\circ} \mathrm{C}\end{array}$} \\
\hline \multicolumn{3}{|c|}{ Stressed René N5/MCrA1Y/APS Coupons \#28 } \\
\hline Position & As-manufactured & 1000-hrs \\
\hline 1 & $0.239 \pm 0.003$ & $0.265 \pm 0.006$ \\
\hline 2 & $0.253 \pm 0.001$ & $0.256 \pm 0.005$ \\
\hline 3 & $0.238 \pm 0.002$ & $0.241 \pm 0.006$ \\
\hline 4 & $0.225 \pm 0.003$ & $0.239 \pm 0.006$ \\
\hline 5 & $0.251 \pm 0.009$ & $0.255 \pm 0.004$ \\
\hline
\end{tabular}


Table 3.10 Pulse-Echo travel time in top coat for 1000 hours René N5 Coupons \#29 under $1000^{\circ} \mathrm{C}$

\begin{tabular}{|c|c|c|}
\hline \multicolumn{3}{|c|}{$\begin{array}{l}\text { ACOUSTO-ULTRASONIC ASSESSMENT } \\
\text { PULSE-ECHO ROUND TRIP TRAVEL TIME IN TOP COAT( } \mu \mathrm{s})\end{array}$} \\
\hline \multicolumn{3}{|c|}{$\begin{array}{c}- \text { ISOTHERMAL OXIDATION - } \\
\text { 1000-Hrs } \\
\text { TEMPERATURE } \\
1^{1000^{\circ} \mathrm{C}}\end{array}$} \\
\hline \multicolumn{3}{|c|}{ Unstressed René N5/MCrA1Y/APS Coupons \#29 } \\
\hline Position & As-manufactured & 1000-hrs \\
\hline 1 & $0.236 \pm 0.004$ & $0.248 \pm 0.006$ \\
\hline 2 & $0.224 \pm 0.006$ & $0.233 \pm 0.002$ \\
\hline 3 & $0.228 \pm 0.004$ & $0.251 \pm 0.006$ \\
\hline 4 & $0.228 \pm 0.008$ & $0.243 \pm 0.002$ \\
\hline 5 & $0.224 \pm 0.003$ & $0.259 \pm 0.009$ \\
\hline
\end{tabular}

Table.3.11 Pulse-Echo travel time in top coat for 1000 hours René N5 Coupons \#13 under $900^{\circ} \mathrm{C}$

TABLE 3.11

ACOUSTO-ULTRASONIC ASSESSMENT PULSE-ECHO ROUND TRIP TRAVEL TIME IN TOP COAT $(\mu \mathrm{s})$

- ISOTHERMAL OXIDATION 1000-Hrs TEMPERATURE $900^{\circ} \mathrm{C}$

\begin{tabular}{|c|c|c|}
\hline \multicolumn{3}{|c|}{ Stressed René N5/MCrA1Y/APS Coupons \#13 } \\
\hline Position & As-manufactured & $\mathbf{1 0 0 0 - h r s ~}$ \\
\hline 1 & $0.230 \pm 0.002$ & $0.267 \pm 0.004$ \\
\hline 2 & $0.225 \pm 0.0011$ & $0.231 \pm 0.006$ \\
\hline 3 & $0.190 \pm 0.009$ & $0.273 \pm 0.008$ \\
\hline 4 & $0.235 \pm 0.007$ & $0.270 \pm 0.002$ \\
\hline 5 & $0.223 \pm 0.008$ & $0.267 \pm 0.001$ \\
\hline
\end{tabular}


Table 3.12 Pulse-Echo travel time in top coat for 1000 hours René N5 Coupons \#20 under $900^{\circ} \mathrm{C}$

\begin{tabular}{|c|c|c|}
\hline \multicolumn{3}{|c|}{$\begin{array}{c}\text { ACOUSTO-ULTRASONIC ASSESSMENT } \\
\text { PULSE-ECHO ROUND TRIP TRAVEL TIME IN TOP COAT }(\mu \mathrm{s})\end{array}$} \\
\hline \multicolumn{3}{|c|}{$\begin{array}{c}-\quad \text { ISOTHERMAL OXIDATION - } \\
\text { 1000-Hrs } \\
\text { TEMPERATURE } \\
900^{\circ} \mathrm{C}\end{array}$} \\
\hline \multicolumn{3}{|c|}{ Nonstressed René N5/MCrA1Y/APS Coupons \#20 } \\
\hline Position & As-manufactured & 1000-hrs \\
\hline 1 & $0.210 \pm 0.005$ & $0.254 \pm 0.005$ \\
\hline 2 & $0.236 \pm 0.005$ & $0.245 \pm 0.005$ \\
\hline 3 & $0.204 \pm 0.005$ & $0.237 \pm 0.005$ \\
\hline 4 & $0.227 \pm 0.005$ & $0.249 \pm 0.005$ \\
\hline 5 & $0.258 \pm 0.005$ & $0.266 \pm 0.005$ \\
\hline
\end{tabular}

Table 3.13 Pulse-Echo travel time in top coat for 3000 hours René N5 Coupons \#18 under $900^{\circ} \mathrm{C}$

\begin{tabular}{|c|c|c|}
\hline \multicolumn{3}{|c|}{$\begin{array}{c}\text { ACOUSTO-ULTRASONIC ASSESSMENT } \\
\text { PULSE-ECHO ROUND TRIP TRAVEL TIME IN TOP COAT }(\mu \mathrm{s})\end{array}$} \\
\hline \multicolumn{3}{|c|}{$\begin{array}{c}-\quad \text { ISOTHERMAL OXIDATION - } \\
\text { 3000-Hrs } \\
\text { TEMPERATURE } \\
9^{\circ} \mathrm{C}\end{array}$} \\
\hline \multicolumn{3}{|c|}{ Stressed René N5/MCrA1Y/APS Coupons \#18 } \\
\hline Position & As-manufactured & 3000-hrs \\
\hline 1 & $0.236 \pm 0.002$ & $0.258 \pm 0.003$ \\
\hline 2 & $0.247 \pm 0.002$ & $0.268 \pm 0.005$ \\
\hline 3 & $0.239 \pm 0.007$ & $0.225 \pm 0.006$ \\
\hline 4 & $0.233 \pm 0.005$ & $0.237 \pm 0.005$ \\
\hline 5 & $0.255 \pm 0.008$ & $0.264 \pm 0.003$ \\
\hline
\end{tabular}


Table 3.14: Pulse-Echo travel time in top coat for 3000 hours René N5 Coupons \#19 under $900^{\circ} \mathrm{C}$

\begin{tabular}{|c|c|c|}
\hline \multicolumn{3}{|c|}{$\begin{array}{c}\text { ACOUSTO-ULTRASONIC ASSESSMENT } \\
\text { PULSE-ECHO ROUND TRIP TRAVEL TIME IN TOP COAT }(\mu \mathrm{s})\end{array}$} \\
\hline \multicolumn{3}{|c|}{$\begin{array}{c}-\quad \text { ISOTHERMAL OXIDATION - } \\
\text { 3000-Hrs } \\
\text { TEMPERATURE } \\
900^{\circ} \mathrm{C}\end{array}$} \\
\hline \multicolumn{3}{|c|}{ Unstressed René N5/MCrA1Y/APS Coupons \#19 } \\
\hline Position & As-manufactured & 3000-hrs \\
\hline 1 & $0.241 \pm 0.001$ & $0.257 \pm 0.007$ \\
\hline 2 & $0.262 \pm 0.006$ & $0.244 \pm 0.004$ \\
\hline 3 & $0.249 \pm 0.005$ & $0.252 \pm 0.007$ \\
\hline 4 & $0.223 \pm 0.003$ & $0.246 \pm 0.003$ \\
\hline 5 & $0.244 \pm 0.004$ & $0.262 \pm 0.009$ \\
\hline
\end{tabular}

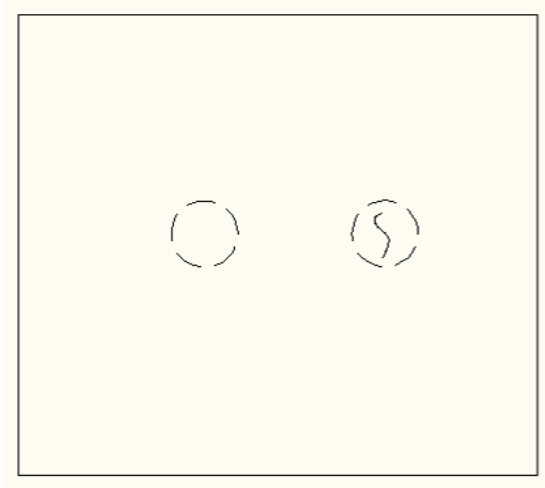

Figure 3.40 Location of the initial crack

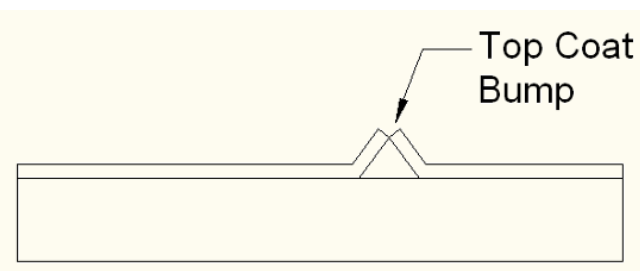

Figure 3.42 Cross section view of initial failure

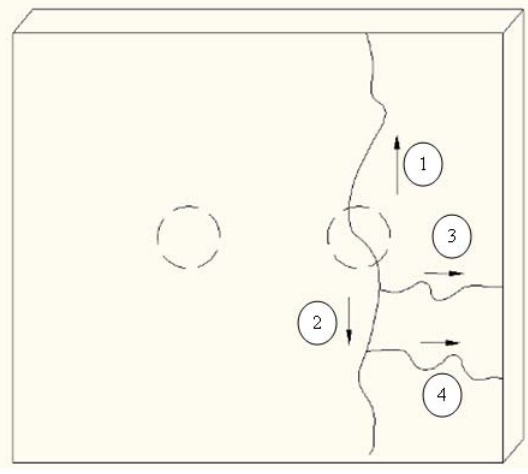

Figure 3.4110 minutes after initial crack

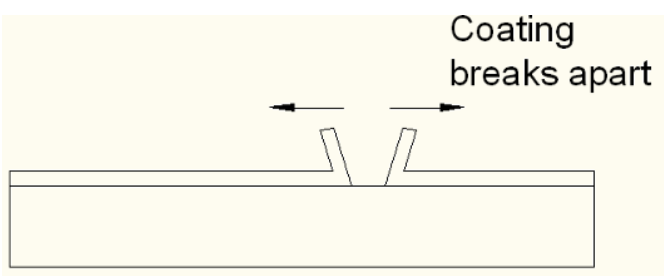

Figure 3.43 Top coat failure 


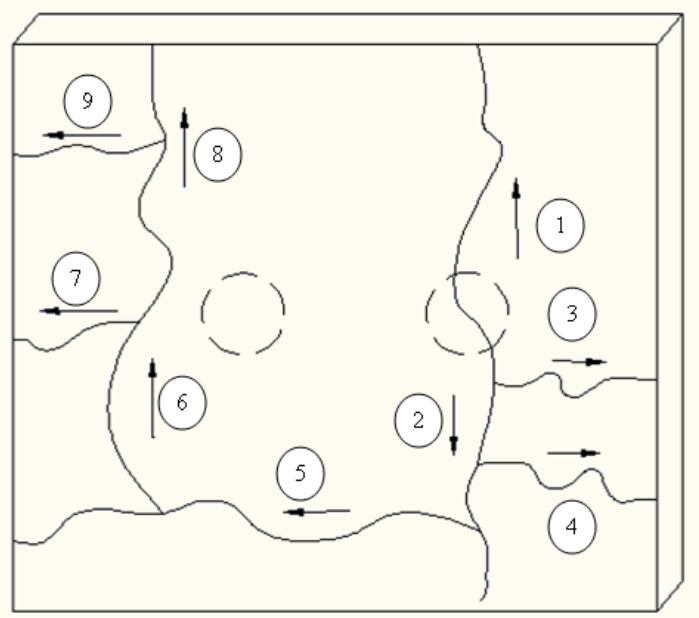

I

Figure 3.44 Crack propagation pattern

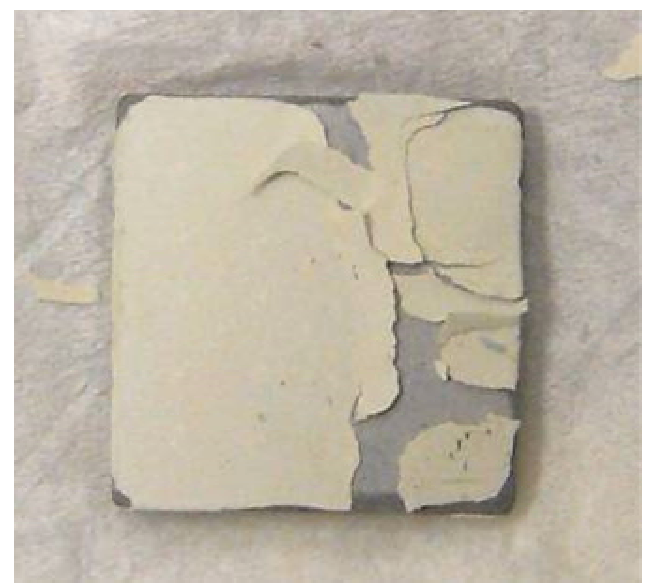

Picture 3.9 Crack pattern at about 10 minutes after the first crack initiated

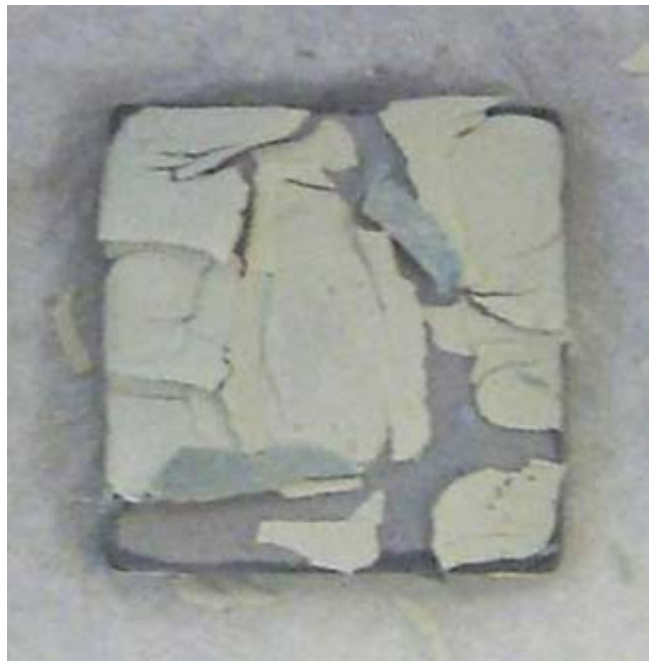

Picture 3.10 Crack pattern at about 42 minutes after the first crack initiated 


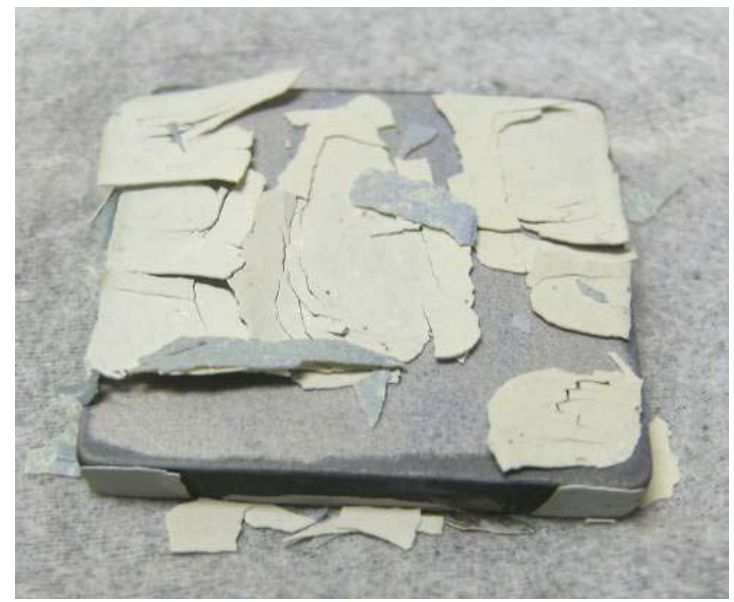

Picture 3.11 Final failure of Haynes 230 coupon (View One)

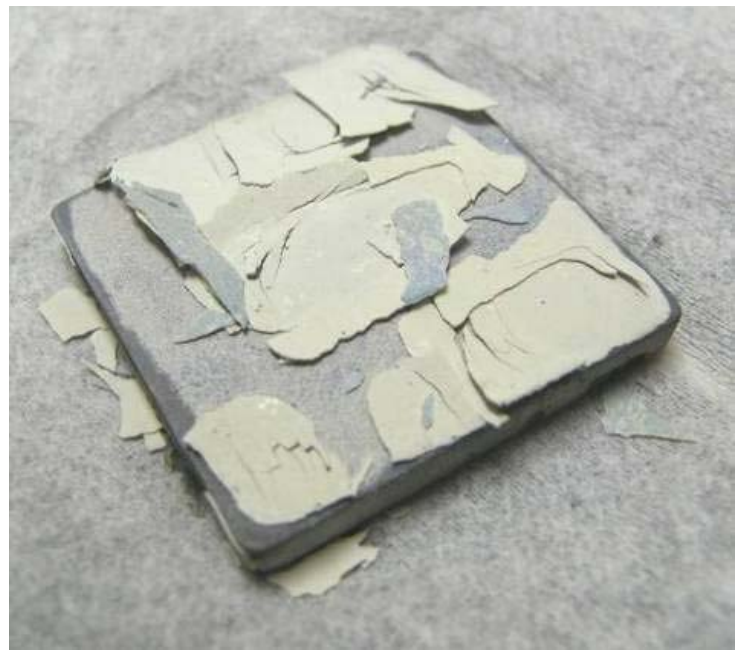

Picture 3.12 Final failure of Haynes 230 coupon (View Two)

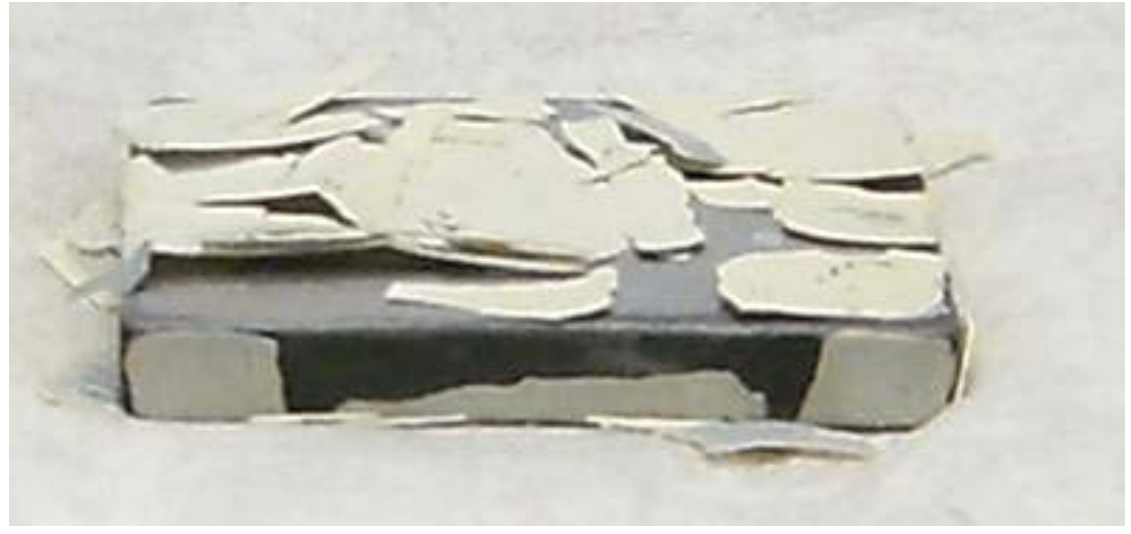

Picture 3.13 Final failure of Haynes 230 coupon (cross section) 


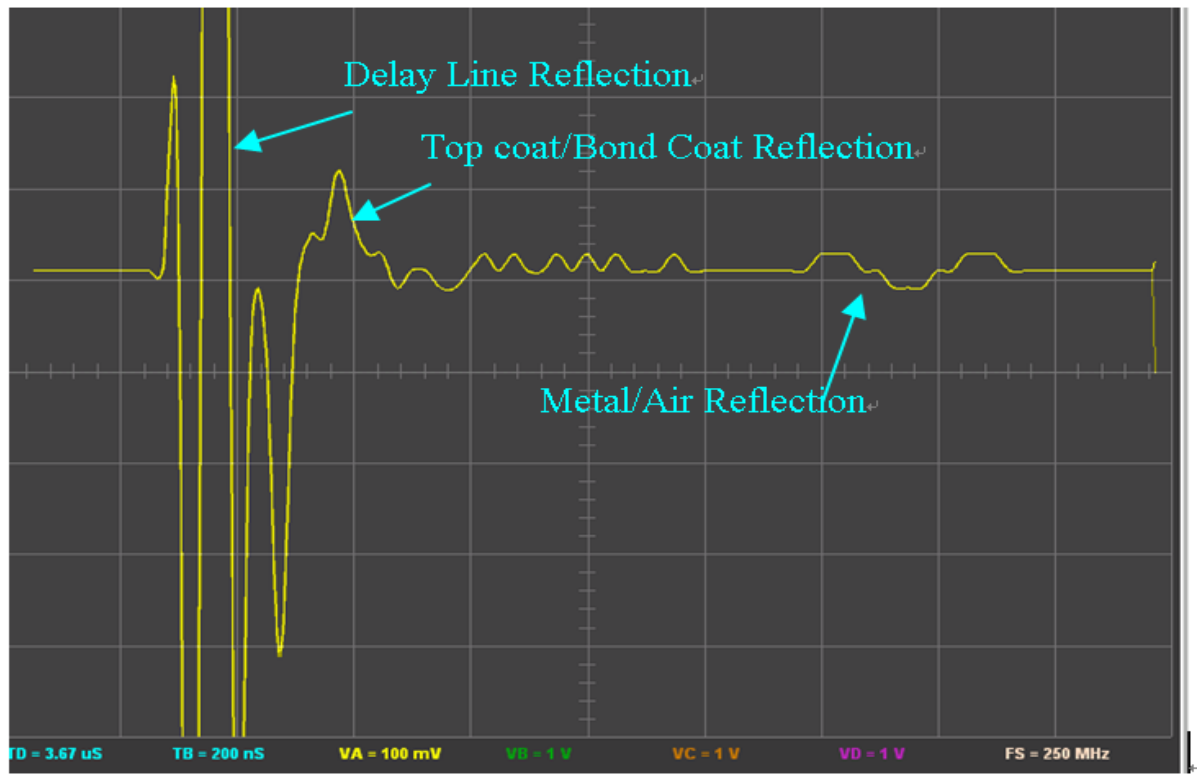

Figure 3.45 Pulse-Echo waveform of the model turbine blade

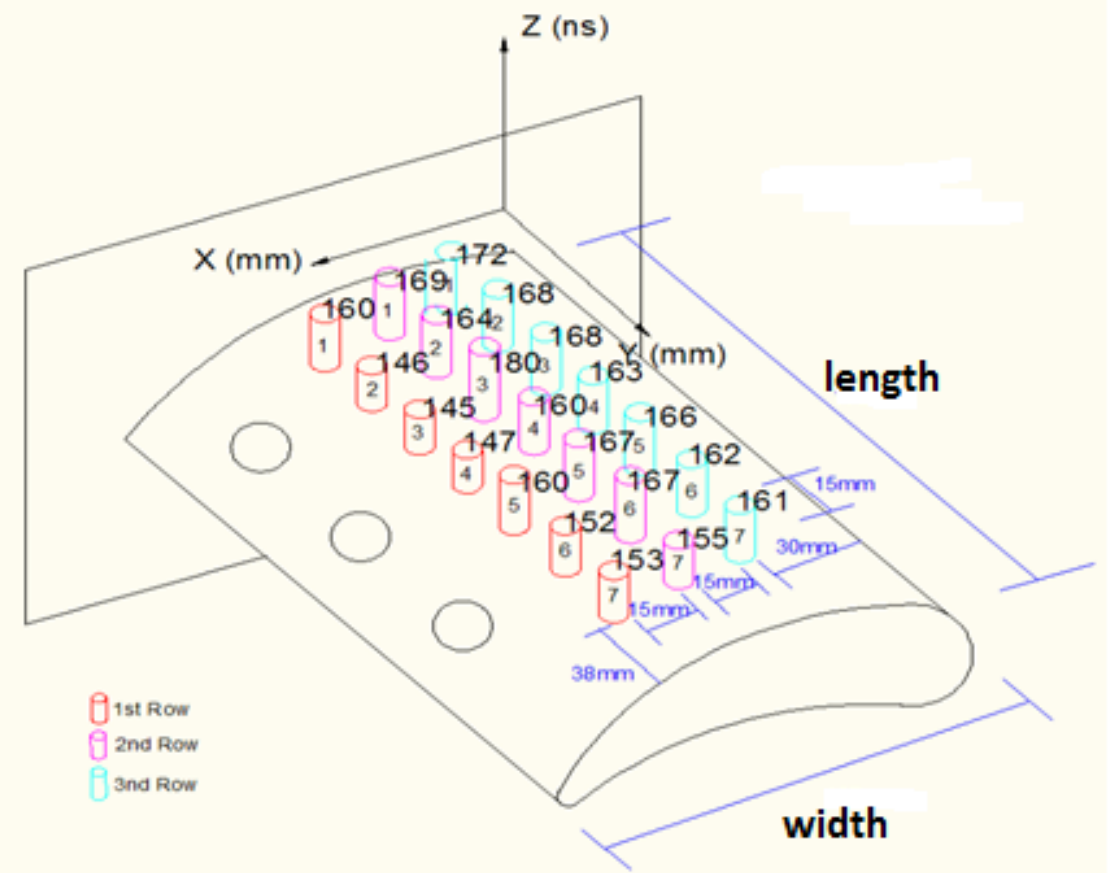

Figure 3.46 Pulse-Echo traveling time in the top coat of the model turbine blade on the convex side 


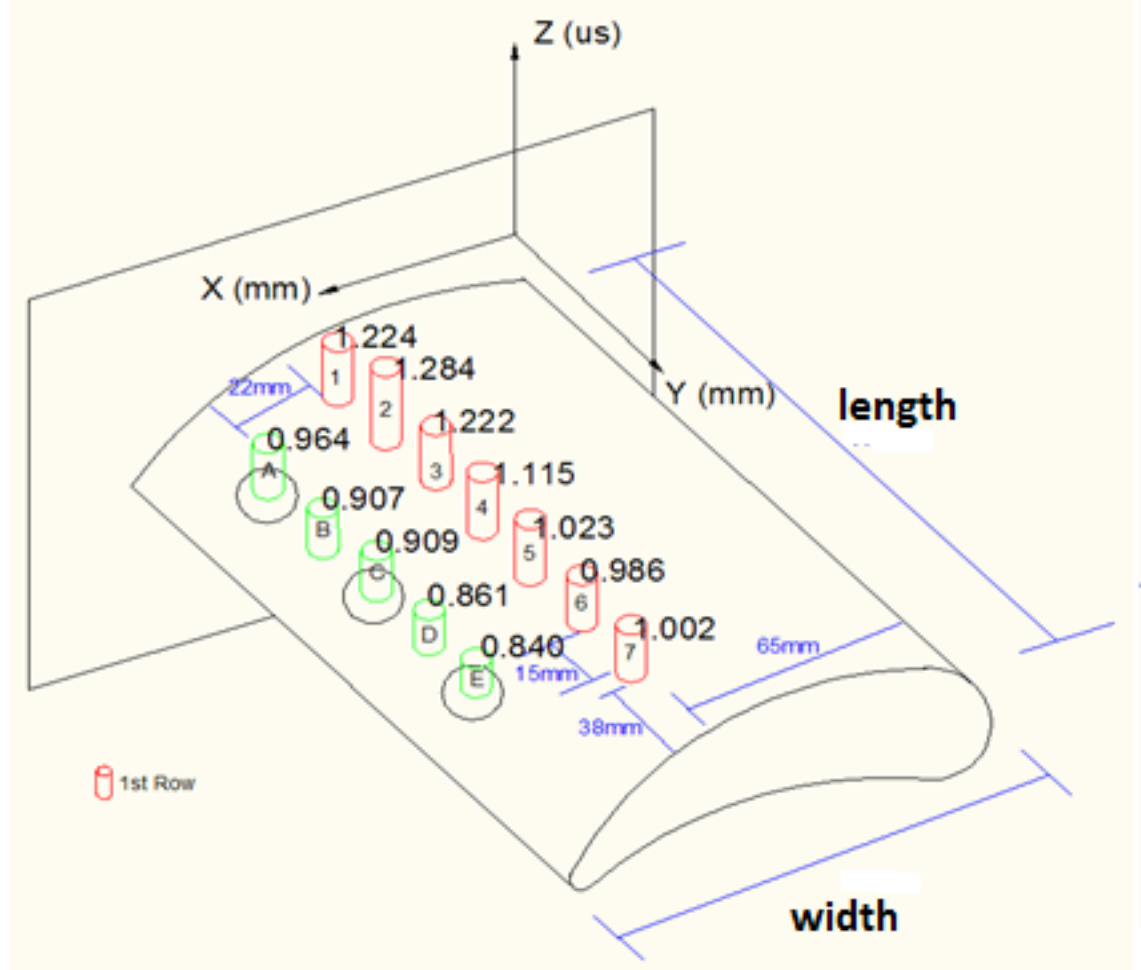

Figure 3.47 Pulse-Echo traveling time in the substrate of the model turbine blade on the convex side

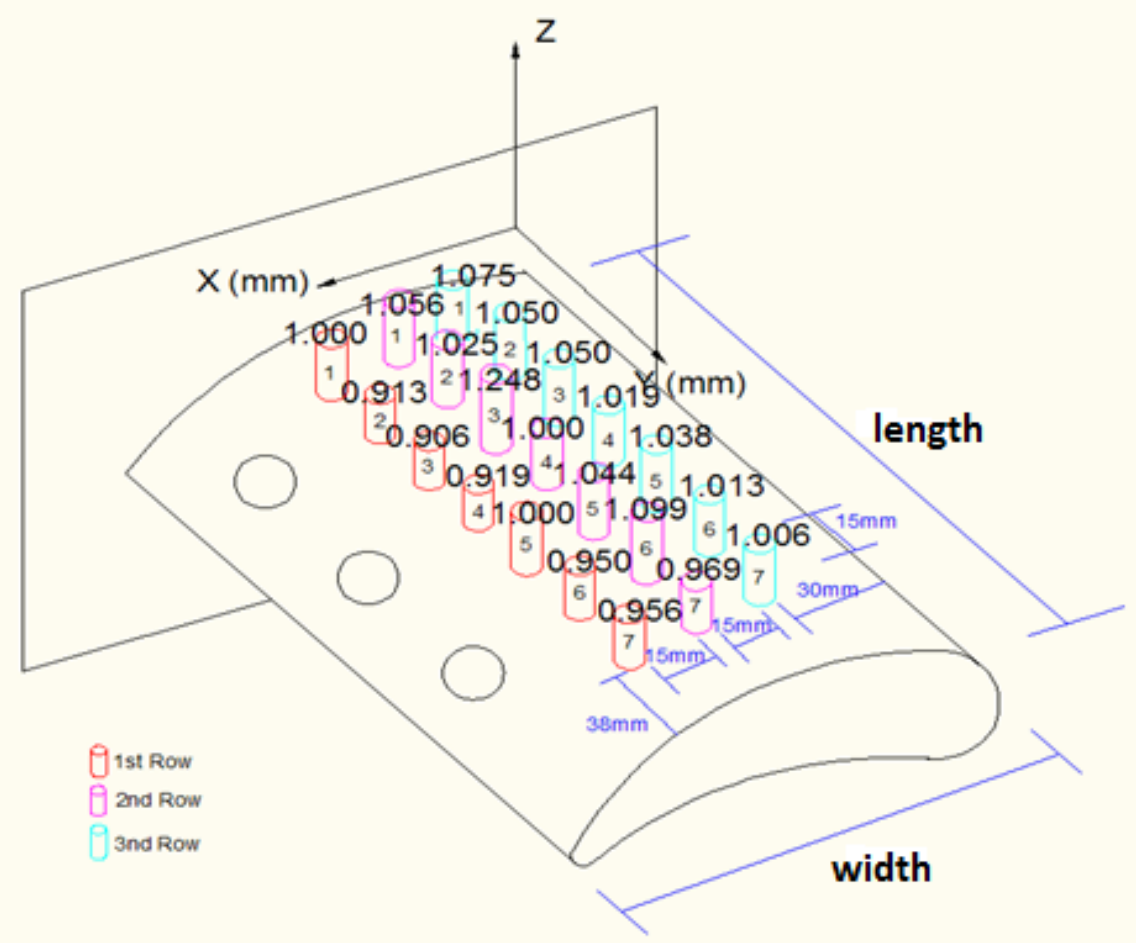

Figure 3.48 Normalized top coat thickness distribution of the model turbine blade (convex side) 


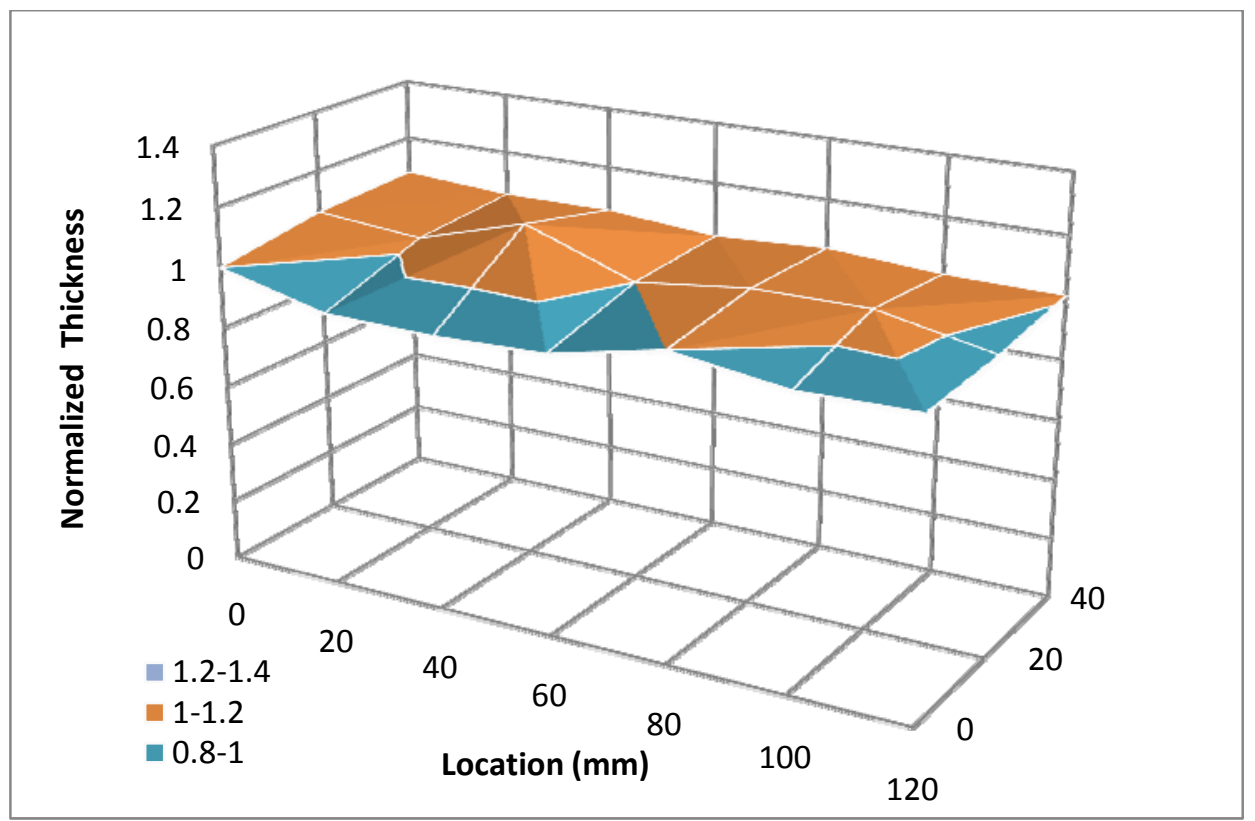

Figure 3.49 Normalized top coat thickness distribution

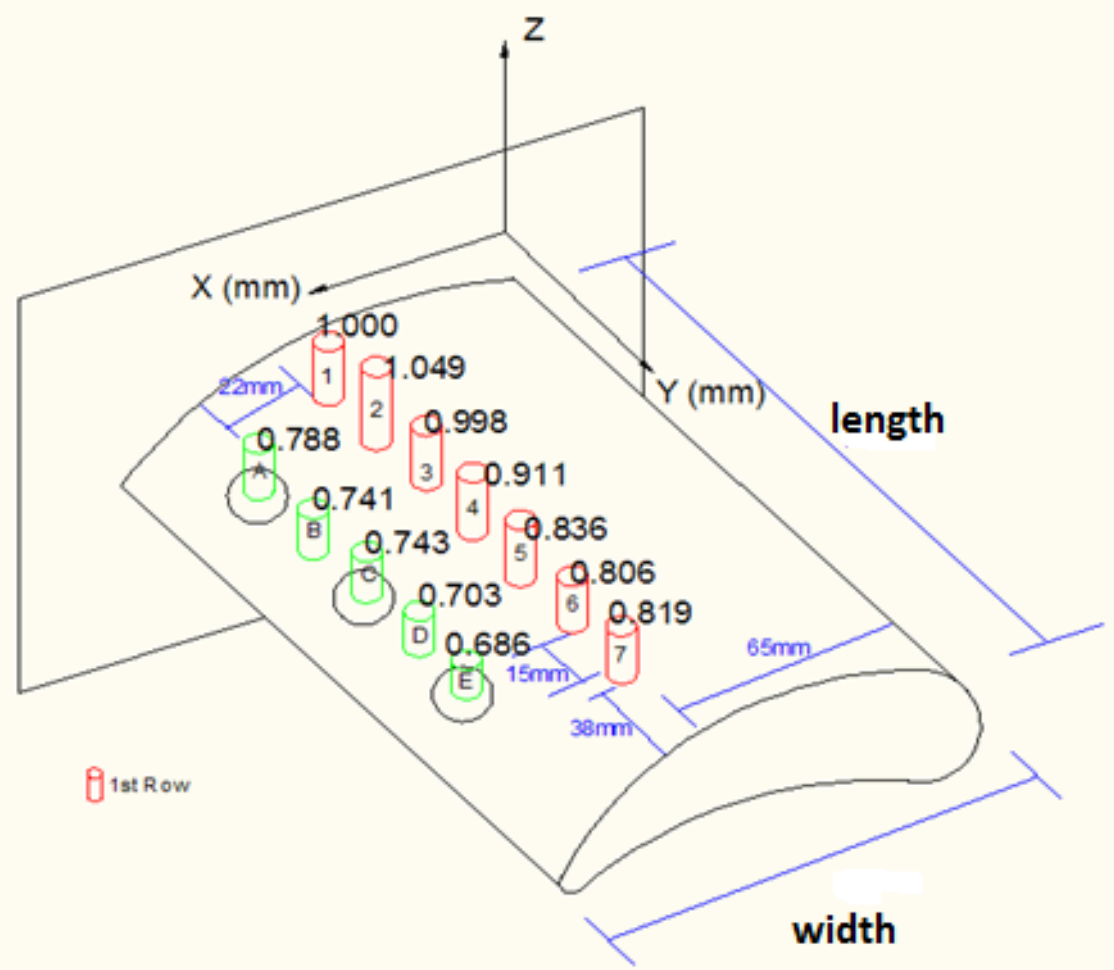

Figure 3.50 Normalized metal plus bond coat thickness distribution of the turbine blade (convex side) 


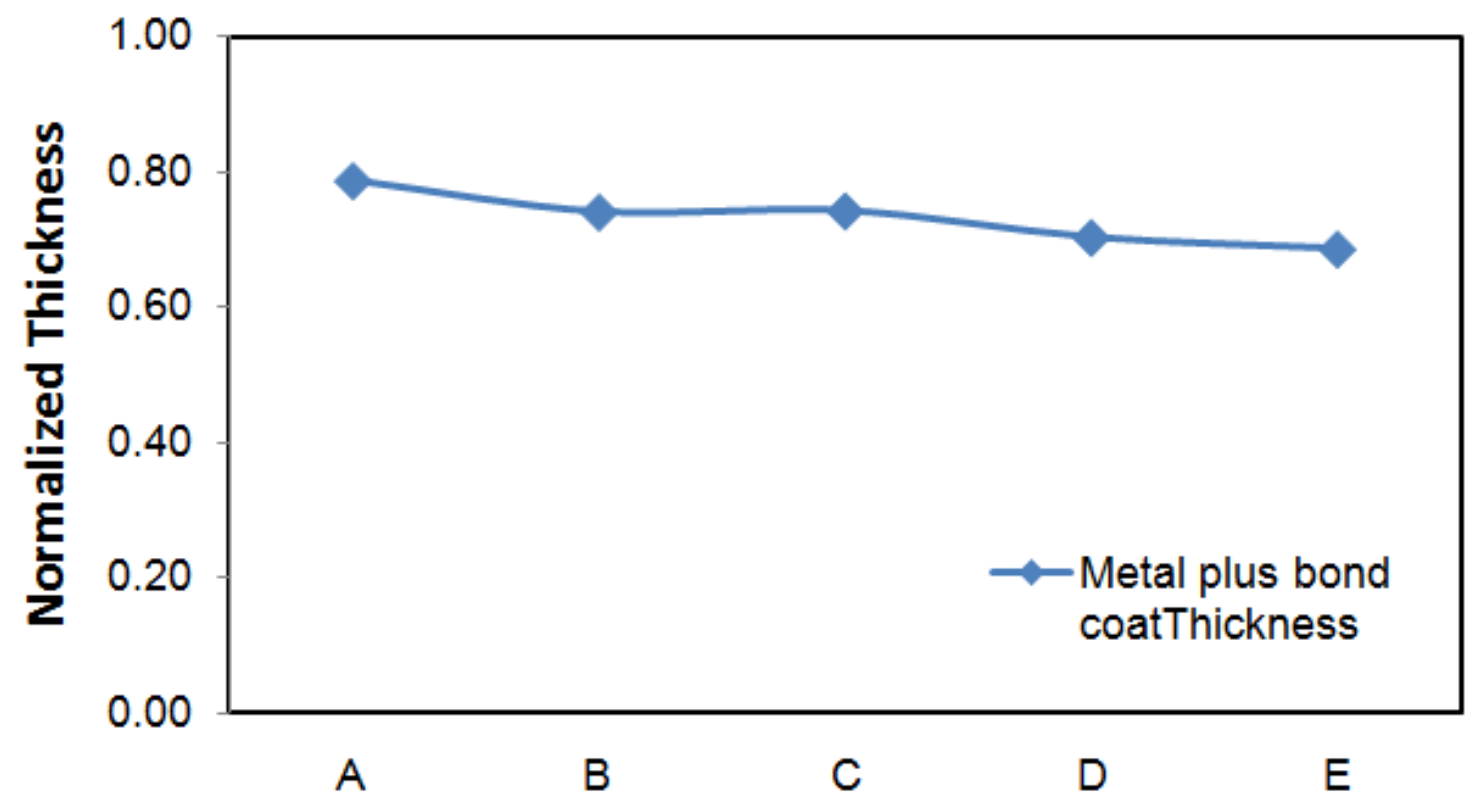

Figure 3.51 Normalized metal plus bond coat thickness distribution from Location 1 to 7 on the $1^{\text {st }}$ Row

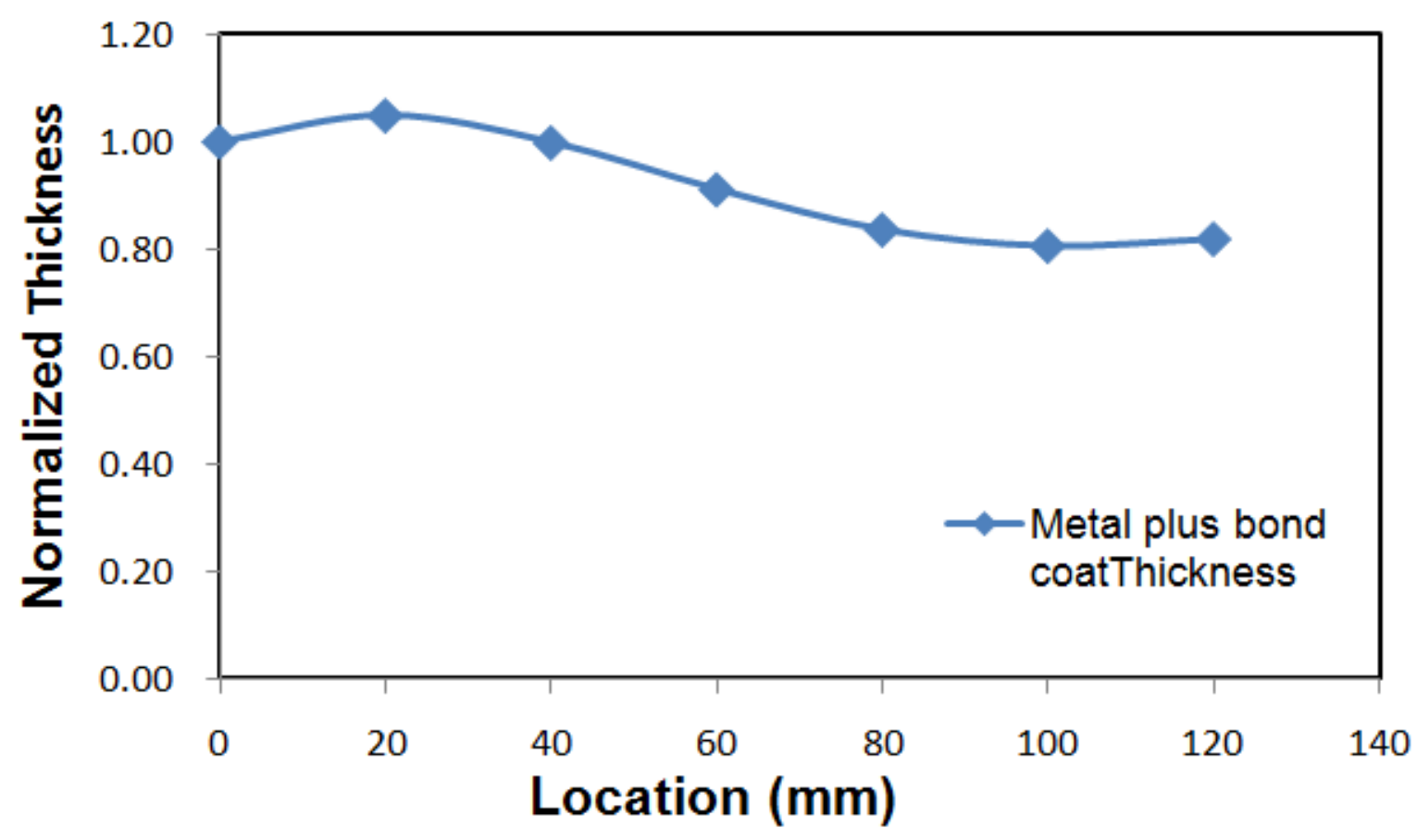

Figure 3.52 Normalized metal plus bond coat thickness distribution from Location A to $\mathrm{E}$ 


\section{CHAPTER IV}

\section{THERMAL BARRIER COATING MATERIAL PROPERTIES ASSESSMENT}

\subsection{INTRODUCTION}

Efforts have been put on the evaluation of the material properties of the ceramic top coats such as mass density and the Young's modulus. The internal stress caused by the difference in the thermal expansion coefficient between ceramic top coat and metallic bond coat/substrate promotes coating damage after repetition of thermal exposure. Therefore, understanding the value of the Young's modulus can estimate the extent of the generated thermal stress which is critical to the TBC material reliability (Ohki et al., 2007). From the ultrasonic viewpoint, the longitudinal wave speed in the top coat obtained from Pulse-Echo method is dependent on both the Young's modulus and mass density. If the mass density could be obtained quantitatively, the Young's modulus of the top coat could be calculated. In this chapter, the mass densities of both the free standing APS YSZ and EBPVD YSZ were measured using Archimedes' principle. To find the influence due to thermal loading, the mass density of the free standing APS YSZ was also measured at different thermal exposure stages. The Young's modulus value of the top coat at different thermal exposure times under different temperatures were calculated using our Pulse-Echo data with the thickness data provided by U PITT. The porosity of the coating is usually reduced after thermal exposure partly due to sintering effect. This leads to a reduction of the strain tolerance in combination with an increase of the Young's modulus (Siebert et al., 1999). The Young's modulus and mass density for APS 7YSZ top coat was searched in the literatures and these values will be tabulated to compare with the results from our findings.

\subsection{EXPERIMENT}

\subsubsection{TOP COAT DENSITY MEASUREMENT}

The mass densities of the EBPVD 7YSZ top coat from isothermal Haynes 230 and free stand APS 7YSZ were measured using Archimedes' principle. The pictures of the two kinds of top coat are shown in Picture 4.1 and Picture 4.2. The equipments used in the measurement includes: a scale with a resolution of about $\pm 0.1 \mathrm{mg}$ (shown in Picture 
4.3), a pipette with a resolution of about $\pm 10 \mu \mathrm{L}$ used to draw up the water from the tube (shown in Picture 4.4), a furnace in which the coating released from the pipe were placed to dry out the moisture (shown in Picture 4.5), and a tube with an inner diameter of about $6 \mathrm{~mm}$, where the coating were put inside to measure the volume change from the increase of water level (shown in Picture 4.6).

The procedure for the measurement was summarized as follows: The coating was broken into pieces in order to fit into a small inlet of the tube and the weight was measured using the scale with high precision. After the weight was obtained, the coating was put into the tube which was filled with water up to a marked line. The water level inside the tube increased because of the volume change. A pipette was used to draw out the water until the water level returned to the marked line. The water from the pipette was weighed and volume was obtained because the mass density of the water is known. Then, the coating was dried out in a furnace for repeating the experiment.

The experiments were repeated 10 times for the EBPVD 7YSZ top coat. The averaged result for the 10 measurements for the top coat of WVU Haynes 230 coupon turns out to be $5571.5 \pm 198.3 \mathrm{~kg} / \mathrm{m}^{3}$. While the APS YSZ top coat were measured at different exposure hours, the mass density value for as-manufactured APS 7YSZ was measured to be $5305 \pm 99.2 \mathrm{~kg} / \mathrm{m}^{3}$, an average of five measurements. After 50 hours of isothermal exposure under $1100^{\circ} \mathrm{C}$, the average mass density averaged from five experimental results was $5570 \pm 184 \mathrm{~kg} / \mathrm{m}^{3}$. This value is higher than that measured when it was new (as-manufacture). A possible reason for this is the oxide from the base metal, on which the top coat was laid upon during the thermal exposure, has attached onto the top coat (with an indication of gray color) which might cause the increase in the weight. After 130 hours of exposure, the oxide from the base metal was cleaned off from the top coat to ensure the accuracy of the results, and the mass density was measured to be $5313.5 \mathrm{~kg} / \mathrm{m}^{3} \pm 122.4$. The result shows that the density does not exhibit much change after 130 hours of exposure compared to the value from the as-manufacture state. The measured values for two types of top coat were found to be quite close to those from the literatures as shown in Table 4.1. 


\subsubsection{TOP COAT YOUNG'S MODULUS CALCULATION}

The Young's modulus of the APS and EBPVD YSZ top coat was evaluated using the Pulse-Echo data from WVU and the thickness data from U. PITT. The Young's modulus of APS YSZ top coat was also evaluated at different exposure hours under different temperatures. The speeds of the longitudinal wave propagating in the thickness direction of these two coupons were calculated using the Pulse-Echo traveling time and top coat thickness data. Thus, using the equation of the longitudinal wave speed, the Young's modulus can be calculated:

$$
C_{L}=\sqrt{\frac{\lambda+2 \mu}{\rho}}
$$

Where, $C_{L}$ is the longitudinal wave speed, $\lambda$ and $\mu$ are the Lame' constants and $\rho$ is the mass density. Also, $\lambda$ and $\mu$ can be written in terms of Young's modulus, $E$ and Poisson's ratio, $v$ as

$$
E=C_{L}^{2} \cdot \rho \frac{(1+v)(1-2 v)}{(1-v)}
$$

Using these relations, the Young's moduli of two coupons (\#3 stressed, \#24 nonstressed) after 100 -hour exposure under $1100^{\circ} \mathrm{C}$ were calculated. From the PulseEcho results, the traveling time in the ceramic top coating was obtained by subtraction between the total time and the time of substrate plus bond coat $(0.12 \mu$ s for Coupon \#3 and $0.135 \mu$ s for Coupon \#24). With the thickness data provided by U PITT ( $334.15 \mu \mathrm{m}$ for Coupon \#3 and $346.04 \mu \mathrm{m}$ for Coupon \#24), the wave speed in the ceramic top coat can be calculated as $2784.6 \mathrm{~m} / \mathrm{s}$ for Coupon \#3 and $2563.3 \mathrm{~m} / \mathrm{s}$ for Coupon \#24. The density of the ceramic top coat after thermal exposure can also be calculated, with the known initial density and porosity both initial and after the thermal exposure. The following equation can be utilized to calculate the density.

$$
\mathrm{p}=1-\rho / \rho_{\mathrm{o}}
$$

Where, $p$ is the porosity and $\rho_{o}$ is the grain density under pore-free APS YSZ, which is found to be $6070 \mathrm{~kg} / \mathrm{m}^{3}$ (Jadhav, 2006). The porosity after 100-hour exposure was provided by U PITT as $11.68 \%$ for Coupon \#3 and $11.62 \%$ Coupon for \#24. Then the top coat density after 100-hour exposure can be calculated as $5361 \mathrm{~kg} / \mathrm{m}^{3}$ for Coupon $\# 3$ and $5364 \mathrm{~kg} / \mathrm{m}^{3}$ for Coupon \#24. Assuming the Poisson's ration of the top coat to be 0.20 and with known mass density and longitudinal wave speed, the Young's modulus 
values of the top coat of these two coupons can be calculated as $37.4 \mathrm{GPa}$ for Coupon \#3 and $37.1 \mathrm{GPa}$ for Coupon \#24. The same method was used to calculate the top coat Young's moduli of 300-hour René N5 coupons, which were exposed at different temperatures and under different stress conditions. The results are shown in Table 4.2. The Young's modulus values for APS YSZ top coat were found in the literatures and are summarized in Table 4.3.

The Young's modulus of the EBPVD top coat of the failed H230 coupon after 60hour was calculated using the mass density found in the literature and the assumed thickness, and a comparison was made with the value found in the literature. The WVU H230 coupon was tested using Pulse-Echo on the remaining top coat surface and the bond coat surface (where the top coat has spalled). The Pulse-Echo time acquired on the top coat surface is $1.1746 \mu$ s for round-trip and the time obtained on the bond coat surface is $1.1250 \mu \mathrm{s}$. The subtraction between those time results in the round-trip traveling time on the top coat as $49.6 \mathrm{~ns}$. The mass density of YSZ deposited by EBPVD method was found to be about $5570 \mathrm{~kg} / \mathrm{m}^{3}$. The thickness of the YSZ top coat was assumed to be $100 \mu \mathrm{m}$, and then the measured longitudinal wave speed can be calculated as $4032 \mathrm{~m} / \mathrm{s}$. With a Poisson's ratio value of 0.25 for EBPVD YSZ reported in the literature (Zhao and Xiao, 2006) and using the equation of the longitudinal wave speed, the Young's modulus of the WVU H230 EBPVD YSZ can be calculated to be about 75.5 GPa. It is noted that the top coat thickness of the coupon was an assumed values. If the thickness is known, then the wave speed is certain. The uncertainty in thickness influence the Young's Modulus prediction; namely, a 10\% variation of thickness $(90$ $110 \mu \mathrm{m}$ ) would mean the wave speed are $3629 \sim 4435 \mathrm{~m} / \mathrm{s}$ and Young's modulus values in the range of $61.2 \sim 91.3 \mathrm{GPa}$. 


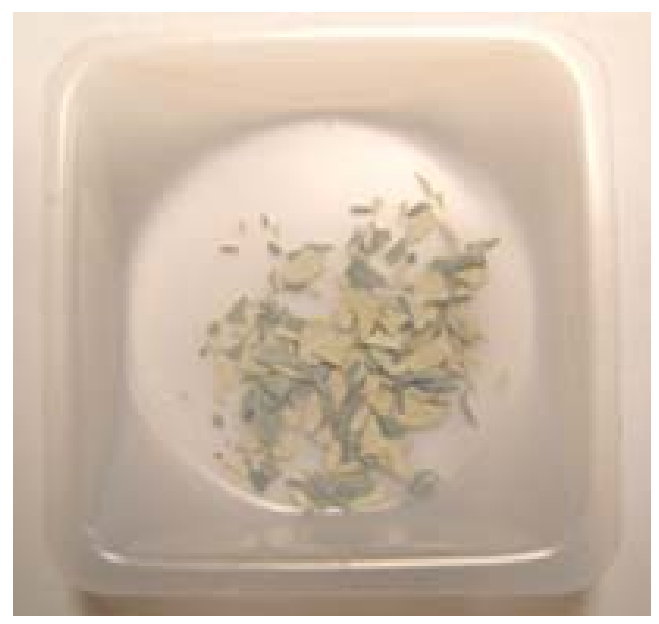

Picture 4.1 EBPVD YSZ top coat

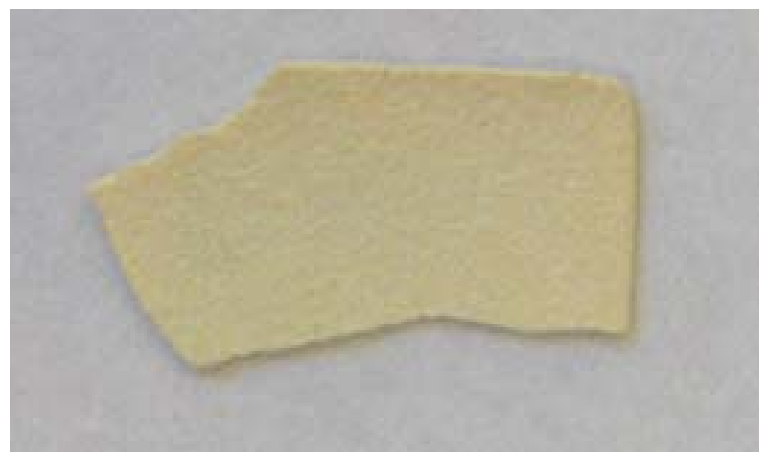

Picture 4.2 Free standing APS YSZ top coat

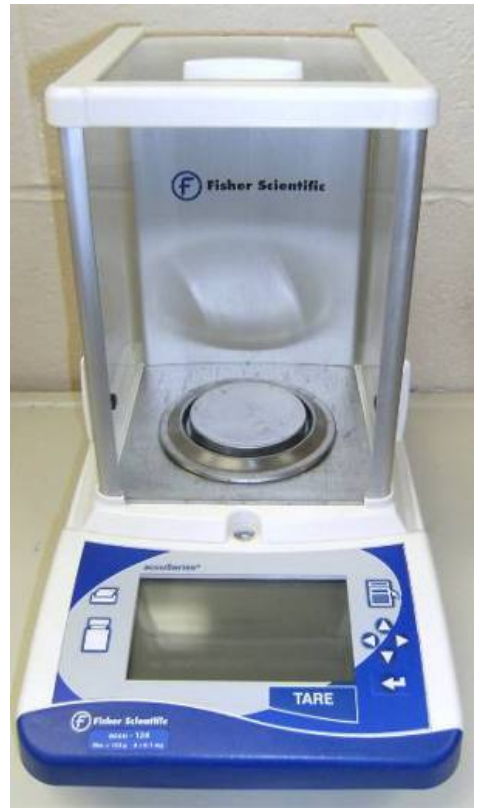

Picture 4.3 Scale

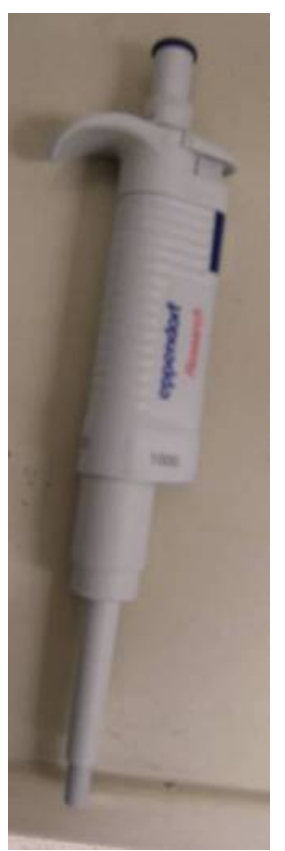

Picture 4.4 Pipette 


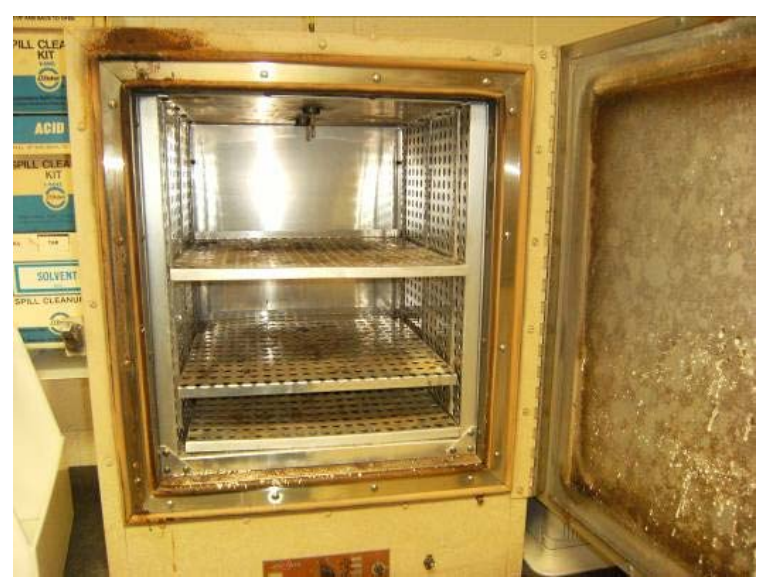

Picture 4.5 Furnace

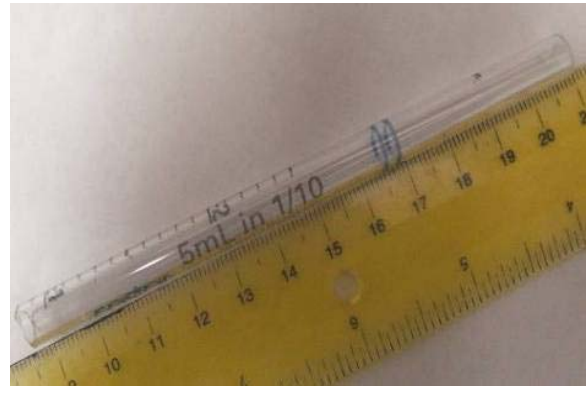

Picture 4.6 Plastic pipe

Table 4.1 Mass density of YSZ top coat from literatures

\begin{tabular}{|c|c|}
\hline $\begin{array}{c}\text { Top coat type } \\
\text { Mass density } \\
\left(\mathrm{kg} / \mathrm{m}^{3}\right)\end{array}$ \\
\hline $\begin{array}{c}\text { APS YSZ (7 wt\%) } \\
\text { (Jadhav, 2006) }\end{array}$ & 5160 \\
\hline APS YSZ & 5760 \\
(Tryon, 2005) & \\
\hline $\begin{array}{c}\text { APS YSZ (7 wt \%) } \\
\text { (UTSR final report, 2007) }\end{array}$ & 5160 \\
\hline EBPVD YSZ & \\
(Crowell, 2008) & 5900 \\
\hline
\end{tabular}


Table 4.2 Young's moduli calculation for 300 hours René N5 coupons

\begin{tabular}{|c|c|c|c|c|c|c|}
\hline \multirow{2}{*}{ Items } & \multicolumn{2}{|c|}{$900^{\circ} \mathrm{C}$} & \multicolumn{2}{c|}{$1000^{\circ} \mathrm{C}$} & \multicolumn{2}{c|}{$1100^{\circ} \mathrm{C}$} \\
\cline { 2 - 7 } & Stressed & $\begin{array}{c}\text { Non- } \\
\text { stressed }\end{array}$ & Stressed & $\begin{array}{c}\text { Non- } \\
\text { stressed }\end{array}$ & Stressed & $\begin{array}{c}\text { Non- } \\
\text { stressed }\end{array}$ \\
\hline Coupon No. & $\# 9$ & $\# 14$ & $\# 10$ & $\# 6$ & $\# 16$ & $\# 7$ \\
\hline $\begin{array}{c}\text { Porosity (\%) } \\
(\text { Slaughter, Karaivanov, } \\
\text { 2008) }\end{array}$ & 0.1844 & 0.2125 & 0.1458 & 0.179 & 0.1645 & 0.1583 \\
\hline $\begin{array}{c}\text { Density after 300- } \\
\text { hr(kg/m })^{3}\end{array}$ & 4950.7 & 4780.1 & 5185.0 & 4953.5 & 5071.5 & 5106.1 \\
\hline $\begin{array}{c}\text { Travel time in top coat } \\
(\mu \mathrm{s})\end{array}$ & 0.152 & 0.112 & 0.114 & 0.115 & 0.128 & 0.117 \\
\hline $\begin{array}{c}\text { Top coat thickness }(\mu \mathrm{m}) \\
(\text { Slaughter and } \\
\text { Karaivanov, 2008) }\end{array}$ & 349.89 & 316.81 & 328.41 & 307.31 & 326.63 & 325.03 \\
\hline $\begin{array}{c}\text { Longitudinal wave } \\
\text { speed (m/s) }\end{array}$ & 2301.9 & 2828.7 & 2880.8 & 2672.3 & 2551.8 & 2778.0 \\
\hline $\begin{array}{c}\text { Calculated top coat } \\
\text { Young's modulus (GPa) }\end{array}$ & 23.6 & 34.4 & 38.7 & 32.0 & 29.7 & 35.5 \\
\hline
\end{tabular}

Table 4.3 Young's modulus of YSZ top coat from literatures

\begin{tabular}{|c|c|c|c|}
\hline Top coat type & $\begin{array}{c}\text { Young's } \\
\text { modulus } \\
\text { As-sprayed } \\
(\mathrm{GPa})\end{array}$ & $\begin{array}{c}\text { Exposed } \\
\text { condition }\end{array}$ & $\begin{array}{c}\text { Young's } \\
\text { modulus } \\
\text { after Exposure } \\
(\mathrm{GPa})\end{array}$ \\
\hline $\begin{array}{c}\text { APS YPSZ (7.6wt\%), } \\
(\text { Pual, 2003) }\end{array}$ & 22 & $1200^{\circ} \mathrm{C}, 20-\mathrm{hr}$ & 38 \\
\cline { 3 - 4 } & $1400^{\circ} \mathrm{C}, 20-\mathrm{hr}$ & 48 \\
\hline $\begin{array}{c}\text { APS YSZ (7 wt\%) } \\
\text { (Jordan and Padture, 2007) }\end{array}$ & $\mathrm{N} / \mathrm{A}$ & $1121^{\circ} \mathrm{C}, 40$-cycle & $32 \sim 41$ \\
\hline $\begin{array}{c}\text { APS PSZ (7 wt\%) } \\
\text { (Ohki et al, 2007) }\end{array}$ & 35.1 & $900^{\circ} \mathrm{C}, 1$ year & 46.9 \\
\hline
\end{tabular}




\section{CHAPTER V \\ CONCLUSIONS AND FUTURE WORK}

\subsection{CONCLUSIONS}

An ultrasonic technique has been developed to detect the change of material properties and provide early warning of delamination of TBC systems. Results show that the technique developed can detect the internal delamination and degradation of the top coat at different exposure hours nondestructively. Early warning of delamination was identified before it could be visually observed. The ultrasonic signals (traveling time, amplitude) were found to be very sensitive to the growth of internal delamination.

Surface wave measurement setup was developed for the estimation of top coat thickness and material degradation after thermal exposure. The mass density of the free standing APS and EBPVD YSZ top coats were measured using Archimedes' principle. Finite Element analysis simulation of the wave propagation on a simplified TBC system with nonlinear effects was conducted. The FEA results correlate well with the experimental observation and can clearly show detection of a small embedded void simulating delamination. The FEA can be used to predict the material properties of different components in the TBC system.

The Young's modulus values of APS YSZ top coat of TBC coupons at different exposure hours can be calculated using the measured signals. The proposed technique was successfully demonstrated on a new model turbine blade coated with TBC for thickness and material properties estimation and the results were comparable with those of the TBC coupons.

\subsection{FUTURE WORK}

The cyclic thermal testing of three APS YSZ Rene N5 coupons at $1100^{\circ} \mathrm{C}$ will begin shortly. The mass density measurement of the APS 7YSZ top coat will continue after different exposure hours using Archimedes' Principle. The influence of the thermal exposure on the top coat mass density will be studied. In addition, a new surface wave 
experimental setup having point contact between sensors and the TBC top coat has been developed to decrease the contact area on the top coat, which will enable us to calculate the top coat thickness and simultaneously track top coat material properties change due to thermal exposure. Furthermore, the study of the speed of the Rayleigh surface wave and the longitudinal wave in porous, inhomogeneous material will continue. Further modification of the FEA model will be needed to consider the porous nature and horizontal residual stress effect on the top coat and TGO.

The next phase project will also explore the possibility to quantify the critical size of the delamination that will lead to failure of a TBC system. A verification will be done regarding to the delamination detection. The coupon will be cross-sectioned when the Pulse-Echo test results show the sign of internal. SEM will be performed to check the location of potential delamination. 


\section{REFERENCES}

Achenbach, J. D., "Quantitative Nondestructive Evaluation," International Journal of Solids and Structures, Volume 37, Issues 1-2, pp.3-27, 2000.

Alvin, M. A., Alman, D., Covino, B., Tylczak, J., Pettit, F., Meier, G., Yanar, N., Chyu, M., Mazzotta, D., Slaughter, W., Karaivanov, V., Seetharaman, S., Kang, B., Feng, C., $\mathrm{Chen}, \mathrm{H}$. and $\mathrm{Fu}, \mathrm{T}$., "Materials and Component Development for Advanced Turbine Systems," EPRI 5th International Conference on Advances in Materials Technology for Fossil Power Plants, The Electric Power Research Institute, FL., 2007.

Alvin, M.A., "Materials and Component Development for Advanced Turbine Systems," 22nd Annual Conference on Fossil Energy Materials," Pittsburgh, PA, 2008.

Bose, S., "High Temperature Coatings," Elsevier, 2007.

Busso, E.P., Wright, L., Evans, H.E., McCartney, L.N., Saunders, S.R., Osgerby, S., and Nunn., J., "A Physics-Based Life Prediction Methodology for Thermal Barrier Coating Systems," Acta Materialia, Volume 55, Issue 5, pp.1491-1503, 2007.

Chen, H. L., Zhang, B., and Alvin, M.A., "Nondestructive Detection of Delamination in Thermal Barrier Coatings using Ultrasonic Techniques," Proceedings of ASME Turbo Expo 2009, Orlando, FL., 2009.

Chen, X., Hutchinson, J.W., and Evans, A.G., "Simulation of the High Temperature Impression of Thermal Barrier Coatings with Columnar Microstructure," Acta Materialia, Volume 52, pp.565-571, 2004.

Crowell, M. W., "Dynamics of Kink Band Formation in Columnar Thermal Barrier Oxides," Acta Materialia, Volume 56, Issue 16, pp. 4150-4159, 2008.

Cruse, T. A., Stewart, S. E., and Ortiz, M., "Thermal Barrier Coating Life Prediction Model Development," ASME Journal of Engineering Gas Turbines Power, Volume 110, pp.610-616, 1998.

Crutzen, H.P., Lakestani, F., and Nicholls, J.R., "Ultrasonic Characterization of Thermal Barrier Coatings," IEEE Ultrasonics Symposium, 1996.

Crutzen, H.P., Lakestanit, F., and Nicholls, J.R., "SAW for the Non Destructive Evaluation of Thermal Barrier Coatings," IEEE ultrasonic Symposium, 1997.

DeMasi-Marcin, J.T., Sheffler, K.D., and Bose, S., "Mechanisms of Degradation and Failure in a Plasma-deposited Thermal Barrier Coating," Journal of Engineering for Gas Turbines and Power, Volume 112, Issue 4, 1990.

Desai, V.H., "Nondestructive Evaluation of TBC Electrochemical Impedance Spectroscopy," Advanced Materials Processing \& Analysis Center and Department of Mechanical, Materials \& Aerospace Engineering, University of Central Florida, 1998. 
Eldridge, J I., Spuckler, C.M., and Nesbitt, J.A., "Nondestructive Evaluation of Thermal Barrier Coating by Mid-Infrared Reflectance Imaging," Ceramic Engineering and Science Proceedings, 2005.

Ellingson, E., Visher, R., Lipanovich, R., and Deemer, C., "Optical NDT Techniques for Ceramic Thermal Barrier Coatings," Material Evaluation, Volume 64, pp.45-51, 2006.

Ellingson, W.A., Koehl, R.D., Engel, H.P., Stuckey, J.B., Sun, J.G., and Smith, R. G., "Development of Nondestructive Evaluation Methods for Structural Ceramics," Proceedings of the 11th Annual Conference on Fossil Energy Materials, 1997.

Epstein, A.H., Senturia, S.D., Anathasuresh, G., Ayon, A., Breuer, K., Chen, K-S, Ehrich, F.E., Gauba, G., Ghodssi, R., Groshenry, Jacobson, C., S., Lang, J.H., Lin, C-C., Mehra, A., Mur Miranda, J.O., Nagle, S., Orr, D.J., Piekos, E., Schmidt, M.A., Shirley, G., Spearing, S.M., Tan, C.S., Tzeng, Y-S, and Waitz, I.A., "Power MEMS and Microengines," IEEE Transducers '97 Conference, Chicago, 1997.

Ghosn, L.J., and Raj, S.V., "Residual Stresses in Thermal Barrier Coatings for a Cu-8Cr4Nb Substrate System," NASA, 2002.

Giampaolo, T., "Gas turbine handbook: Principles and Practice, Fourth Edition," Fairmount Press, 2009.

Govindarajan, N., Bhangale, R. K., and Ganesan, N., "Life Prediction of Functionally Graded Thermal Barrier Coatings," TATA consultancy service, 2007.

Grünling, H.W., and Mannsmann, W., "Plasma Sprayed Thermal Barrier Coatings for Industrial Gas Turbines: Morphology, Processing and Properties," Journal de Physique IV, Colloque C7, Supplémejnt au Journal de Physique III, Volume 3, 1993.

Haynes, J.A., Ferber, M.K., Porter, W.D., and Rigney, E.D., "Mechanical Properties and Fracture Behavior of Interfacial Alumina Scales on Plasma-sprayed Thermal Barrier Coatings," Materials at High Temperatures, Volume 16, pp. 49-69, 1999.

Heckman, D. "Finite Element Analysis of Pressure Vessels," University of California, Davis, 1998.

Jadhav, A.D., "Low-thermal-conductivity Plasma-sprayed Thermal Barrier Coatings with Engineered Microstructures," Acta Materialia, Volume 54, Issue 12, pp.3343-3349, 2006.

Koolloos, M.F.J., "Behavior of Low Porosity Microcracked Thermal Barrier Coatings under Thermal Loading," PhD dissertation, Eindhoven university of technology, 2001.

Kuroda, S., and Clyne, T.W., "The Quenching Stress in Thermally Sprayed Coatings," Thin Solid Films, Volume 200, Issue 1, pp.49-66,1991. 
Marijnissen, W.G., and Van Lieshout, A., "The Evolution of Thermal Barrier Coatings Status and Upcoming Solutions for Today's Key Issues," Surface and Coatings Technology, Volume 120-121, pp.61-67, 1999.

Muralidhar, C., Venkata Reddy, M., and Kumaran, K., "Study and Performance Evaluation of Thermal Barrier Coatings (TBCs) Using Infrared Thermography," Proceedings of National Seminar on Non-Destructive Evaluation, Hyderabad, 2006.

Newell, J., Man, K., and Stark, B., "Finite Element Analysis and Applications to MEMS," NASA, 2002.

Nicholls, J.R., Lawson, K.J., Johnstone, A., and Rickerby, D.S., "Methods to Reduce the Thermal Conductivity of EB-PVD TBCs," Surface and Coatings Technology, Volume 151-152, pp.383-391, 2002.

Ohki, M., "Application of Indentation Test to the Evaluation of TBC Young's Modulus," Recent Advancement of Theory and Practice in Hardness Measurement, Hardmeko, 2007.

Padture, N.P., Gell, M., and Jordan, E.H., "Thermal Barrier Coatings for Gas Turbine Engine Applications," Science, Volume 296, pp.280-284, 2002.

Paul, S., "Using of Impulse Excitation Technique to Monitor the Effect of Heat Treatment on the Mechanical Behavior of Plasma Sprayed Coating," University of Cambridge, 2004.

Portinha, A., Teixeira, V., Monteiro, A., Costa, M. F., Lima, N., Martins, J., and Martinez, D., "Surface Analysis of Nanocomposite Ceramic Coatings," Surface and Interface Analysis, Volume 35, Issue 9, pp.723 - 728, 2002.

Rabiel, A., and Evans, A. G., "Failure Mechanisms Associated with the Thermally Grown Oxide in Plasma-Sprayed Thermal Barrier Coatings," Acta Materialia, Volume 48, pp.3963-3976, 2000.

Renusch, D., and Schütze, M., "Measuring and Modeling the TBC Damage Kinetics by Using Acoustic Emission Analysis," Surface \& Coatings Technology, Volume 202, pp.740-744,2007.

Roge', B., Fahr, A., Gigue` re, J.S.R., and McRae, K.I., "Nondestructive Measurement of Porosity in Thermal Barrier Coatings," Journal of Thermal Spray Technology, Volume 12, Issue 4, 2003.

Schlichting, K. W., Padture, N. P., Jordan, E.H., and Gell, M., "Failure Modes in Pasmasprayed Thermal Barrier Coatings," Materials Science and Engineering: A, Volume 342, Issues 1-2, 2001.

Shi, J., Karlsson, A.M., Baufeld, B., and Bartsh, M., "Evolution of Surface Morphology of Thermo-Mechanically Cycled NiCoCrAIY Bond Coats," Materials Science \& Engineering, Volume 434, pp.39-52, 2006. 
Siebert, B., Funke, C., Vaben, R., and Stover, D., "Changes in Porosity and Young's Modulus due to Sintering of Plasma Sprayed Thermal Barrier Coatings," Journal of Materials Processing Technology, Volume 92-93, pp.217-223, 1999.

Slaughter, W.S., and Karaivanov, V., "Personal Communication," University of Pittsburgh, Oct, 2008.

Sun, J.G., "Development of Nondestructive Evaluation Methods for Thermal Barrier Coatings," An Invited Summary for Inclusion in the Proceedings of the 22nd Annual Conference on Fossil Energy Materials, Pittsburgh, 2008.

Swadźba, L., Moskal, G., Mendala, B., and Gancarczyk, T., "Characterization of Air Plasma Sprayed TBC Coating during Isothermal Oxidation at $1100^{\circ} \mathrm{C}$," Journal of Achievements in Materials and Manufacturing Engineering, Volume 21, pp.81-84, 2007.

Teixeira, V., Andritschky, M., Fischer, W., Buchkremer, H.P., and Stfver, D., "Analysis of Residual Stresses in Thermal Barrier Coatings," Journal of Material Processing Technology, Volume 92-93, pp.209-221, 1999.

Trubelja, M.F., Nissley, D.M., Bornstein, N.S. and Marcin, J.T.D., "Pratt and Whitney Thermal Barrier Coating Development," Advanced Turbine Systems Annual Program Review, Conference Proceedings, FETC Publications, 1997.

Tryon, B. S., "Multi-layered Ruthenium-Containing Bond Coats for Thermal Barrier Coatings," PhD dissertation, University of Michigan, 2005.

Jordan, E. H., and Padture, P.N., "Superior Thermal Barrier Coatings for Industrial GasTurbine Engine Using a Novel Solution Plasma Spray Process," UTSR Final report, 2007.

Waki, H., and Kobayashib, A., "Influence of the Mechanical Properties of CoNiCrA1Y Under-Coating on the High Temperature Fatigue Life of YSZ Thermal-barrier-coating system," Vacuum, Volume 83, Issue 1, 2008.

Willemetz, J.C., Nowicki, A., Meister, J.J., De Palma, F., and Pante, G., "Bias and Variance in the Estimate of the Doppler Frequency Induced by a Wall Motion Filter," Ultrasonic Imaging, Volume 11, Issue 3, pp.215-225, 1989.

Wright, P. K., and Evans, A. G., "Mechanisms Governing the Performance of Thermal Barrier Coatings," Current Opinion in Solid State and Materials Science, Volume 4, Issue 3, 1999.

Zhao, X., and Xiao, P., "Residual stresses in Thermal Barrier Coatings Measured by Photoluminescence Piezospectroscopy and Indentation Technique," Surface and Coatings Technology, Volume 201, pp.1124-1131, 2006. 
Zhou, Y.C., Hashida, T., and Jian, C.Y., "Determination of Interface Fracture Toughness in Thermal Barrier Coating System by Blister Tests," Journal of Engineering Materials and Technology, ASME, 2003.

Zhou, Y. C., and Hashida, T., "Coupled Effects of Temperature Gradient and Oxidation on the Thermal Stress in Thermal Barrier Coating System," International Journal of Solids Structure, Volume 38, pp.4235-4264, 2001. 